Open Access

OBM Transplantation

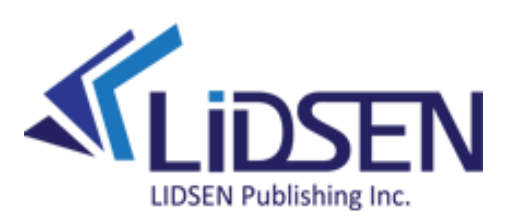

\section{OBM Transplantation 2020}

\section{Volume 4, Issue 4}

Editor-in-Chief

Professor Haval Shirwan

Printed Edition Published in

OBM Transplantation 


\section{Editorial Office}

73 Hongkong Middle Road, Qingdao, China

Tel./Fax: +86-532-8979-9572

E-Mail: transplantation@lidsen.com

http://www.lidsen.com/journals/transplantation

LIDSEN Publishing Inc.

2000 Auburn Drive, One Chagrin Highlands, Suite 200,

Beachwood, OH 44122, USA

Tel.: +1-216-370-7293

Fax: +1-216-378-7505

https://www.lidsen.com

This is a reprint of articles from the Issue 4 published online in the open access journal $O B M$ Transplantation (ISSN 2577-5820) from October 01, 2020 to December 31, 2020. Available at: http://lidsen.com/journals/transplantation/transplantation-04-04

For citation purposes, cite each article independently as indicated on the article page online and as indicated below:

LastName, AA, LastName, BB, LastName, CC. Article Title. Journal Name Year;

Volume(Issue):Article Number; doi. 


\section{Contents}

Shehab Mohamed, Davide Tosi, Sara Pieropan, Andrea Cara, Giovanni Caffarena, Giorgio Alberto Croci, Lorenzo Rosso

The Role of Surveillance Bronchoscopy Following a Lung Transplantation

Reprinted from: OBM Transplantation 2020;4(4):12; doi:10.21926/obm.transplant.2004129 1

Jun Gu, Wei Wang, Guilin Tang, Gokce A. Toruner, Ming Zhao, Steven Sfamenos, Zhenya Tang, Joseph D. Khoury, L. Jeffrey Medeiros

Donor Cell-Derived Acute Myeloid Leukaemia with 3q26.2 Involvement/MECOM Rearrangement - A Case Report and Literature Review

Reprinted from: OBM Transplantation 2020;4(4):11; doi:10.21926/obm.transplant.2004128 12

\section{Naoaki Sakata, Gumpei Yoshimatsu, Shohta Kodama}

The Roles of Collagen in Islet Transplantation

Reprinted from: OBM Transplantation 2020;4(4):17; doi:10.21926/obm.transplant.2004127 23

\section{Kamal Kant Sahu}

Challenges of Organ Transplantation in COVID-19 Era

Reprinted from: OBM Transplantation 2020;4(4):3; doi:10.21926/obm.transplant.2004126 41

\section{Preeti Chhabra, Kenneth L. Brayman}

Current Assessment of Clinical Pancreatic Islet Allotransplantation

Reprinted from: OBM Transplantation 2020;4(4):32; doi:10.21926/obm.transplant.2004125 44

\section{Malcolm Voyce}

Mauss and Organ Transplants: Ideas of Connectivity between Recipients and Donors and the "Spirit of the Gift"

Reprinted from: OBM Transplantation 2020;4(4):9; doi:10.21926/obm.transplant.2004124 77

\section{Marina Moguilevitch, Tracey Straker}

Liver Transplantation as a Cure for Neurologically Advanced Wilson's disease. Learning More from Experience

Reprinted from: OBM Transplantation 2020;4(4):9; doi:10.21926/obm.transplant.2004123 86

\section{Jessica Ferguson, Marisa Holubar, Waldo Concepcion, Dora Ho}

Appropriate Vancomycin Use and Incidence of Vancomycin-Resistant Enterococci in Liver Transplant Recipients

Reprinted from: OBM Transplantation 2020;4(4):7; doi:10.21926/obm.transplant.2004122 95

Courtney Tate, Jason P Butler, Cameron Curley, Siok-Keen Tey, Glen A Kennedy, Ashleigh P Scott "Real World" Australian Experience of Allogeneic Hematopoietic Stem Cell Transplantation (HSCT) in 
Adults with Severe Aplastic Anaemia

Reprinted from: OBM Transplantation 2020;4(4):16; doi:10.21926/obm.transplant.2004121 102

Shalika Katugaha, Oksana Shlobin, Chris King, Steve Nathan, Shambu Aryal, Kareem Ahmad, Whitney Brown

Donor Derived Strongyloidiasis in a Lung Transplant Recipient: From Life Cycle to Hyperinfection Syndrome

Reprinted from: OBM Transplantation 2020;(4):7; doi:10.21926/obm.transplant.2004120...... 118 
Review

\title{
The Role of Surveillance Bronchoscopy Following a Lung Transplantation
}

Shehab Mohamed ${ }^{1,}{ }^{*}$, Davide Tosi ${ }^{1}$, Sara Pieropan ${ }^{1}$, Andrea Cara ${ }^{1}$, Giovanni Caffarena ${ }^{1}$, Giorgio Alberto Croci $^{2}$, Lorenzo Rosso ${ }^{1}$

1. Thoracic Surgery and Lung Transplant Unit Fondazione IRCCS Ca' Granda-Ospedale Maggiore Policlinico, Milan, Italy; E-Mails: shehabmohamedmd@gmail.com; davide.tosi@policlinico.mi.it; sarapieropan90@gmail.com; andrea.cara@unimi.it; giovanni.caffarena@gmail.com; lorenzo.rosso@unimi.it

2. Division of Pathology, Fondazione IRCCS Ca' Granda-Ospedale Maggiore Policlinico, Milan, Italy; E-Mail: giorgio.croci@unimi.it

* Correspondence: Shehab Mohamed; E-Mail: shehabmohamedmd@gmail.com

Academic Editor: Haval Shirwan

OBM Transplantation

2020, volume 4, issue 4

doi:10.21926/obm.transplant.2004129
Received: July 01, 2020

Accepted: November 16, 2020

Published: December 21, 2020

\begin{abstract}
Pulmonary transplantation ( $\mathrm{LuTx}$ ) is established as a treatment option for patients with endstage lung diseases, such as chronic obstructive pulmonary disease, cystic fibrosis, interstitial lung disease, and pulmonary arterial hypertension. Acute rejection and infection are implicated as potential risk factors in developing complications such as bronchiolitis obliterans syndrome (BOS) and chronic rejection, leading to high morbidity and mortality rates after the LuTx. Thus, surveillance procedures after transplantation are crucial to prevent further complications. Clinical monitoring is done through pulmonary function tests and procedural methods such as surveillance bronchoscopy and transbronchial biopsy of lung allografts, which are the most commonly used diagnostic tests. In this review, we aim to analyze the role of bronchoscopy as a surveillance procedure in determining the presence of infection or rejection as well as the management of airway complications after LuTx. We have also discussed the risk and benefit ratio of standard transbronchial biopsy (TBB) and transbronchial cryobiopsy (TCB) as routine performance after LuTx.
\end{abstract}

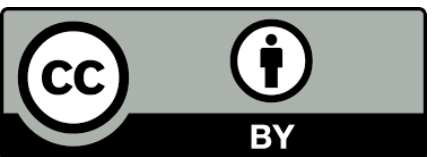

(C) 2020 by the author. This is an open access article distributed under the conditions of the Creative Commons by Attribution License, which permits unrestricted use, distribution, and reproduction in any medium or format, provided the original work is correctly cited. 


\section{Keywords}

Surveillance; bronchoscopy; lung transplantation; rejection; infection

\section{Introduction}

Pulmonary transplantation (LUTX) is established as a treatment option for patients with endstage lung diseases, such as chronic obstructive pulmonary disease, cystic fibrosis, interstitial lung disease, and pulmonary arterial hypertension.

The most recent data from the International Society for Heart and Lung Transplantation (ISHLT) revealed the median survival is 6.7 years for adults who have undergone primary LuTx [1].

The main causes of death after adult LuTx are acute graft failure and non-CMV infection during the first year and chronic rejection in subsequent years [1].

To prevent the occurrence of such complications, clinical monitoring is done through pulmonary function tests and procedural methods such as surveillance bronchoscopy, bronchoalveolar lavage, and transbronchial biopsy of lung allografts, which are the most common diagnostic tests.

All lung transplant centers do not use these surveillance procedures as a scheduled or clinically indicated method because, even though the procedure can identify acute rejection in the early stages, allowing early treatment to improve long-term survival, their role in asymptomatic patients is still controversial. Further, this endoscopic technique allows direct visualization of the airways to determine early complications such as anastomotic dehiscence, ischemia, or stricture.

In this review, we aim to analyze the role of bronchoscopy as a surveillance procedure used in determining the presence of infection or rejection and also managing airway complications after LuTx.

We have also discussed the risk and benefit ratio of standard transbronchial biopsy (TBB) and transbronchial cryobiopsy (TCB) as a routine procedure after LuTx.

\section{Bronchoscopy after Lung Transplantation}

Diagnosis of rejection and infection in asymptomatic patients with lung transplantation could improve the long term survival. Bronchoscopy is a valuable diagnostic tool used as a surveillance procedure. This method uses bronchoalveolar lavage (BAL) to collect the tissue samples for detecting the presence of infection or rejection while assessing airway complications through direct visualization.

\subsection{Infection}

The incidence of developing overall lung allograft infections after LuTx is higher than the other organ transplants. Lung allograft is more susceptible to infections due to immunosuppression, exposure to the environment through inhaled microorganisms, and ischemic complications.

Several organisms, specifically fungi, are associated with the development of airway complications at the anastomotic site, such as hemorrhage, bronchomalacia, and bronchial stenosis [2]. 
Viral, bacterial, and fungal infections are known risk factors associated with the development of BOS [3-8].

Community-acquired respiratory viruses account for about $30 \%$ of all acute respiratory presentations after the LuTx and are also a dominant cause for new respiratory symptoms. Picornavirus, particularly rhinovirus, is the most frequent causative agent for the development of BOS and is recovered in both the upper and lower respiratory specimens, followed by coronavirus and influenza [9].

Among bacterial infections, Pseudomonas aeruginosa is the most common cause for the development of BOS within the first two years of lung transplantation [10].

Similarly, fungal infections are also implicated as a potential risk factor for the development of BOS with high morbidity and mortality rates. The most life-threatening issue is related to invasive aspergillosis [11]. An increased risk of BOS is associated with the colonization of the lung allograft with small conidia Aspergillus species and not the larger ones [8].

One of the latest prospective studies that performed BAL described the most common microbiological findings during the first year of LuTx, where Candida albicans, Pseudomonas aeruginosa, and coagulase-negative Staphylococcus were the most frequent pathogens [12].

Patients with airway infections could be asymptomatic or may present nonspecific symptoms such as cough, secretions, and fever. These clinical indications need to be diagnosed and treated to avoid sequelae.

Infections in asymptomatic patients can be diagnosed using bronchoalveolar lavage (BAL), including microbiological cultures and PCR performed during the surveillance bronchoscopy to guide antibiotic therapy. Contrastingly, for symptomatic patients, computed tomography (CT) scan and bronchoscopy are suggested.

Bronchoscopy is essential not only for BAL or direct visualization of the bronchial anastomosis but also for operative endoscopy procedures, such as debridement of devitalized tissue, dilation of bronchial stenosis, stent placement, laser, cryotherapy, or biopsies.

\subsection{Rejection}

After LuTx, both vasculature and airways of the allograft could be affected by an acute, antibody-mediated, and/or chronic rejection. Acute rejection is characterized by a mononuclear cell infiltration around small vessels and capillaries and/or small airways, which establishes a condition called lymphocytic bronchiolitis. Acute rejection and lymphocytic bronchiolitis are risk factors linked to the development of BOS and chronic airway rejection.

The guidelines of the International Society for Heart and Lung Transplantation (ISHLT) describe pathological grading of acute and chronic cellular rejection. The former is based on the presence of perivascular and interstitial mononuclear infiltrates with chronic rejection, while the latter is based on the presence of fibrous scarring that involves the bronchioles and is sometimes associated with the fibrointimal changes affecting the arteries and veins [13].

Although acute cellular rejection is histologically well defined, there are no standardized diagnostic criteria for antibody-mediated rejection (AMR).

AMR can lead to a range of clinical severity and features, from being asymptomatic with circulatory donor-specific antibody (DSA) through the spectrum to a chronic graft failure. 
To create a uniform definition and consensus document for the diagnosis of AMR, the ISHLT multi-disciplinary society convened a working group in 2016 [14].

This document has identified the following criteria to define an acute pulmonary AMR: allograft dysfunction, DSA positivity, histopathology consistent with AMR, C4d tissue staining, and exclusion of other reasons that cause allograft dysfunction. The degree of confidence in diagnosing AMR is based on the number of criteria present. Clinical AMR is associated with measurable allograft dysfunction, which can be asymptomatic. It may also be sub-clinical, with normal allograft function. Both clinical and sub-clinical AMR were further categorized into three mutually exclusive possibilities (definite, probable, and possible) based on the number of mentioned criteria. "Definite AMR" is identified when all four criteria are met, "Probable AMR" is identified when three criteria are met, or other possible causes have not been excluded, and "Possible AMR" has at least two criteria missing.

Multiple pathological findings of AMR were described in the lung allografts, including capillary inflammation, endothelialitis, and acute lung injury [15-17]. The standard transbronchial biopsy(TBBs) is also essential for the detection and diagnosis of AMR.

Chronic lung allograft dysfunction (CLAD) after the LuTx is described as a clinical manifestation with a range of pathological processes in the airway and parenchyma that lead to a significant and persistent deterioration in the functioning of the lung and occurs for more than three months. This chronic condition is considered a major cause of morbidity and mortality after the LuTx.

CLAD may be presented as a predominantly obstructive ventilatory pattern, a restrictive pattern, or a mixed obstructive and restrictive pattern. The most common manifestations of CLAD are bronchiolitis obliterans syndrome (BOS) and restrictive allograft syndrome, defined by a decrease in the value of FEV1 (amount of air forced from the lungs in $1 \mathrm{~s}$ ), where FEV1> 20\% [18].

Body plethysmography is recommended to measure Total Lung Capacity (TLC) in the patients at three and six months after the transplant and annually thereafter, and also if FEV1 changes to > 10\% from the previous values [18].

Bronchoscopy with transbronchial biopsy (TBB) and bronchoalveolar lavage (BAL) play a major role in the detection of treatable causes of acute rejection and CLAD, such as acute cellular rejection. However, some controversy is involved in using it as a surveillance procedure in asymptomatic patients.

Histological samples obtained during the surveillance bronchoscopy may detect an area of bronchiolitis obliterans, which is uncommon, as the process is patchy and sampling is limited to a specific site.

\subsection{Primary Disease Recurrence}

The recurrence of a primary disease has been reported after lung transplantation, and one such primary disease is sarcoidosis, which is the most common, followed by lymphangioleiomyomatosis (LAM), Langerhans cell histiocytosis (LCH), diffuse granulomatous, diffuse panbronchiolitis, and pulmonary alveolar proteinosis.

The clinically indicated cases are usually diagnosed by high-resolution CT of the lungs, followed by the TBB.

Surveillance TBBs can detect the recurrences as incidental findings.

Recurrence of sarcoidosis after LuTx are described in the literature [19, 20]. 
Several authors have reported that ACR may be more frequent and severe among patients with sarcoid recurrence due to a common immunopathological mechanism [20].

On the other hand, Banga et al. did not observe an increased frequency or severity of ACR with sarcoidosis recurrence and instead found a protective effect. The frequency of ACR episodes among the patients without recurrence of sarcoidosis was similar to those of the ACR rates among patients with different indications on surveillance FB among patients with different indications.

The typical non-necrotizing granulomas seen on TBB specimens in the absence of any other etiology for granulomatous inflammation were pathologically diagnosed.

LAM is a rare disease with even rarer recurrence post-lung transplantation, with only a few studies reporting about it $[21,22]$.

A histopathological examination of the transbronchial biopsy that reveals spindle-shaped LAM cells with no evidence of infection and acute or chronic rejection is suggestive of LAM recurrence.

Clinically indicated TBB after the LuTx is a valid method to detect the recurrence of primary disease during the surveillance. The TBBs are crucial when the primary disease is still asymptomatic.

\section{Surveillance Versus Clinically Indicated Bronchoscopy}

Unfortunately, nowadays, there is no consensus on either performing surveillance bronchoscopy or its frequency in patients with LuTx. This controversy is derived from the possible complications related to the endoscopic procedure. For this reason, there are some variabilities in monitoring practices after the LuTx between different centers.

There is a general agreement on clinical monitoring after the LuTx with spirometry, which is widely used as a non-invasive, cheap, and reproducible method. A drop in the FEV1, greater than $10 \%$ from baseline, is used to trigger investigations to find any treatable cause [23]. Reduction in the lung function tests, radiological changes, dyspnea, cough, or other similar symptoms are some conditions that require clinically indicated bronchoscopy with BAL and TBB.

In contrast, surveillance bronchoscopy with TBB is performed as a part of a routine protocol in asymptomatic patients after the LuTx.

The protocols of TBB as a scheduled procedure are applied at different frequencies in different centers.

Some centers perform TBB/BAL as a surveillance procedure at 3-6-9-12 weeks after the LuTx. After the first three months, only clinically indicated bronchoscopy is performed. If the first 3 and 6-week surveillance bronchoscopies are found to be normal with negative rejection results, the 9week bronchoscopy could be omitted $[24,25]$.

However, not all the evidence supports the need for routine surveillance bronchoscopy in LuTx cases. In 2002, Valentine et al., through an observational single-institution study, concluded that clinically indicated TBB/BAL without routine surveillance sampling of the lung allograft does not decrease the survival of the patient with lung transplantation. The same authors in 2008 estimated that over $50 \%$ of the centers in the United States performed surveillance bronchoscopies, and despite their small study group, the procedure represented a risk to the lung transplant recipient due to no obvious advantage [26, 27].

On the other hand, McWilliams et al. in the same year demonstrated for the first time that bronchoscopy with TBB was a safe procedure in patients with LuTx till the first year. This study 
analyzed 353 TBBs from 124 patients and confirmed a high diagnostic yield for clinically silent acute rejection and infection [28].

In 2014, similar results were reported in a retrospective study by Inoue et al., conducted on 206 TBBs from 28 patients who underwent cadaveric lung transplantation. This study reported $49 \%$ positive results for surveillance, which showed rejection, infection, or colonization, and $47 \%$ for clinically indicated procedures [29].

More recently, Takizawa et al. assessed 1252 bronchoscopies in 247 patients in a single-center retrospective analysis of LuTx recipients who survived the first year. In this study, surveillance bronchoscopy was sufficient to modify the management, mainly in the 2 and 6-week surveillance bronchoscopies, post-LuTx. Also, they concluded that this effect seems to dilute after the second month, making its applicability questionable [30] (Table 1).

Table 1

\begin{tabular}{lll}
\hline & Scheduled TBB & Clinically indicated TBB \\
\hline Tosi et al & 223 & 28 \\
Valentine et al & 156 & 84 \\
McWilliams et al & 232 & 121 \\
Inoue et al & 189 & 17 \\
Takizawa et al & 1252 & 0 \\
\hline
\end{tabular}

In our center, the surveillance procedures are performed to monitor lung allografts at 3, 6, and 12 months after the transplant. These scheduled procedures consist of flexible bronchoscopy performed with local anesthesia and intravenous sedation along with bronchoalveolar lavage (BAL) and transbronchial biopsies (TBBs). Samples are usually taken from the $2 / 3$ segments of the right lower lobe (RLL) with a minimum and maximum of 6 and 8 biopsies, respectively, with a single-use $1.8 \mathrm{~mm}$ transbronchial biopsy forceps. We preferred RLL because it is possible to place a balloonbased endobronchial blocker in the bronchus intermedius in case of severe and uncontrollable bleeding, allowing ventilation to not only the left lung but also to the right upper lobe. In the case of bilateral lung transplantation, we performed biopsies only in one lung due to the risk of bilateral pneumothorax.

Our experience confirmed the importance of surveillance protocol performed using TBBs or CrioTBBs in patients with LuTx. Of patients involved in the protocol, $8 \%$ were diagnosed with AR without any clinical signs, and upon receiving specific medical treatments, the rejection grades were downgraded at the next check-up [25].

There is still no scientific evidence that demonstrates the need to perform surveillance transbronchial biopsies for the diagnosis of acute rejection in a lung transplanted patient due to the lack of randomized trials.

\section{TBB versus TCB}

Transbronchial biopsy (TBB) using forceps is considered the gold standard for the diagnosis of acute rejection after the LuTx. However, tissue samples obtained using this technique could be inadequate to assign a pathological grade according to the revision of the 1996 working 
formulation for the standardization of nomenclature in the diagnosis of lung rejection [13]. In a large percentage of cases, diagnostic inadequacy is due to the crushing artifacts, atelectasis, and hemorrhage within the alveoli [31].

Transbronchial cryobiospsy (TCB) allows us to obtain larger samples with fewer artifacts compared to TBBs. This technique is largely used for the diagnosis of interstitial lung disease. Despite obtaining larger biopsies with preserved histology, which is free of artifacts and a higher number of alveoli and small airways, only a few studies have reported the use of TCB in lung allografts [31].

Several studies have compared the two methods in terms of diagnostic adequacy and complications. In 2013, Fruchter et al. assessed the safety and quality of TCB compared to TBB in 80 cases with 40 patients in each group. The mean diameter of the TCB specimens was $10 \mathrm{~mm}$ compared to $2 \mathrm{~mm}$ of the TBB specimens. The increased specimen diameter resulted in providing adequate tissue in $100 \%$ of the cases, whereas in TBB specimens, three nondiagnostic cases were found. No major complications occurred in the TCB group, whereas a single pneumothorax $(2.5 \%)$ case was observed after TBB. $15 \%$ of bleeding events occurred in the TCB group compared to $2.5 \%$ events in the TBB group [32].

In the same year, Yarmus et al. presented the safety profile and biopsy results from 21 procedures, out of which ten were performed using a rigid bronchoscope whereas 11 were performed with a flexible one. Similar to the previous study, the mean specimen size in the TCB specimen was significantly larger and higher in terms of the percentage of sampled tissue containing open alveoli compared to the TBB; these results were also confirmed by other studies later [31]. TBB samples had significant amounts of crushing artifacts, whereas TCB samples demonstrated no evidence of any artifact, including freezing artifact. Only a single case of pneumothorax was described, which also recovered without treatment, and in almost all the cases, there was bleeding that was not severe enough to require surgical intervention or other invasive treatments [33].

Since 2015, similar complication rates were described in different studies [34-36]. The incidence of mild bleeding in TCB groups ranged between $7.5 \%$ and $22.5 \%$, except for Gershmann et al., who reported the incidence as $2.5 \%$.

The incidence of pneumothorax in TCB groups ranged between $4.5 \%$ and $12.5 \%$, except for Loor et al. who did not report any case. On the other hand, mild bleeding was observed in the TBB groups, ranging between $2 \%$ and $14.6 \%$, while pneumothorax was observed up to $4 \%$ (see Table 2 3 for detailed results).

Table 2 Procedures.

\begin{tabular}{lll}
\hline & TCB & TBB \\
\hline Fruchter et al. & 40 & 40 \\
Yarmus et al. & 21 & 21 \\
Roden et al. & 27 & 27 \\
Montero et al. & 40 & 41 \\
Gershman et al. & 201 & 201 \\
Loor et al. & 321 & 0 \\
Mohamed et al.; Tosi et al. & 75 & 223 \\
\hline
\end{tabular}


Table 3 Complications.

\begin{tabular}{lllll}
\hline & \multicolumn{2}{l}{ Moderate bleeding (\%) } & \multicolumn{2}{l}{ Pneumothorax (\%) } \\
\hline & TCB & TBB & TCB & TBB \\
Fruchter et al. & 15 & 2,5 & 0 & 2,5 \\
Yarmus et al. & 4,8 & 0 & 4,8 & 4,8 \\
Roden et al. & 0 & 3,7 & 0 & 3,7 \\
Montero et al. & 22,5 & 14,6 & 12,5 & 0 \\
Gershman et al. & 2,5 & 2 & 4,5 & 4 \\
Loor et al. & 7,5 & 0 & 7,7 & 0 \\
Mohamed et al.; Tosi et al. & 8 & 1,3 & 1,3 & 3,1 \\
\hline
\end{tabular}

Another complication that followed TBBs in patients with LuTx, described in the literature, is the development of new and transient pulmonary nodules (PNs) at the site of biopsies. Mehta et al. hypothesized that these nodules are related to local hematoma and impaired lymphatic drainage. In this retrospective study, PNs were detected in $13 \%$ of the procedures within 50 days and needed up to 86 days to resolve spontaneously [37]. These new PNs could be radiologically interpreted as malignancies, opportunistic infection, or post-transplant lymphoproliferative disorder. Based on these results, we suggest that all physicians need to be aware of this iatrogenic etiology to avoid unnecessary workup and radiation exposure. In these cases, close observation is a reasonable management approach.

Recently, we have reported 75 cases of cryobiopsies in 54 lung allograft recipients for surveillance purposes, where only up to 2 samples were retrieved using cryoprobe. Diagnostic rates and complications were described and compared to the TBB data from our previous study. The diagnostic rate of acute rejection using TCB was $100 \%$ compared to conventional TBB, where the rate was $83 \%$. Complications described in these two studies were comparable to the previous studies. Moderate bleeding of 6\% in the TCB group and 3\% in the TBB group were described. Also, only one patient (1\%) developed pneumothorax in the TCB group, while $7 \%$ developed it in the TBB group [38, 25].

\section{Conclusions}

Bronchoscopy is a valuable diagnostic tool that is used as a surveillance and clinically indicated procedure. Diagnosis of rejection and infection in asymptomatic patients with lung transplantation could improve the long term survival and avoid sequelae. This method uses bronchoalveolar lavage, which performs tissue sampling to detect the presence of infection or rejection while assessing airway complications by direct visualization.

In conclusion, we recommend surveillance bronchoscopy protocol with BAL and TBB to be performed in all the centers at 3,6, and 12 months after the transplant. These procedures can allow us to collect specimens from lung allografts with an acceptable risk/benefit ratio and also treat asymptomatic patients with specific medical treatment to reduce the risk of chronic rejection. 


\section{Author Contributions}

Conception of the work: Shehab Mohamed, Davide Tosi, Lorenzo Rosso; Manuscript writing and editing: All authors; Acquisition, analysis, interpretation of data: Shehab Mohamed, Davide Tosi, Lorenzo Rosso

\section{Competing Interests}

The authors have declared that no competing interests exist.

\section{References}

1. Chambers DC, Cherikh WS, Harhay MO, Hayes D, Hsich E, Khush KK, et al. The international thoracic organ transplant registry of the international society for heart and lung transplantation: Thirty-sixth adult lung and heart-lung transplantation Report-2019; Focus theme: Donor and recipient size match. J Heart Lung Transplant. 2019; 38: 1042-1055.

2. Nunley DR, Gal AA, Vega JD, Perlino C, Smith P, Lawrence EC. Saprophytic fungal infections and complications involving the bronchial anastomosis following human lung transplantation. Chest. 2002; 122: 1185-1191.

3. Kumar D, Erdman D, Keshavjee S, Peret T, Tellier R, Hadjiliadis D, et al. Clinical impact of community-acquired respiratory viruses on bronchiolitis obliterans after lung transplant. Am J Transplant. 2005; 5: 2031-2036.

4. Kroshus TJ, Kshettry VR, Savik K, John R, Hertz MI, Bolman 3rd RM Risk factors for the development of bronchiolitis obliterans syndrome after lung transplantation. J Thorac Cardiovasc Surg. 1997; 114: 195-202.

5. D'Ovidio F, Singer LG, Hadjiliadis D, Pierre A, Waddell TK, de Perrot M, et al. Prevalence of gastroesophageal reflux in end-stage lung disease candidates for lung transplant. Ann Thorac Surg. 2005; 80: 1254-1260.

6. King BJ, lyer H, Leidi AA, Carby MR. Gastroesophageal reflux in bronchiolitis obliterans syndrome: A new perspective. J Heart Lung Transplant. 2009; 28: 870-875.

7. Valentine VG, Gupta MR, Walker Jr JE, Seoane L, Bonvillain RW, Lombard GA, et al. Effect of etiology and timing of respiratory tract infections on development of bronchiolitis obliterans syndrome. J Heart Lung Transplant. 2009; 28: 163-169.

8. Weigt SS, Copeland CF, Derhovanessian A, Shino MY, Davis WA, Snyder LD, et al. Colonization with small conidia Aspergillus species is associated with bronchiolitis obliterans syndrome: $A$ two-center validation study. Am J Transplant. 2013; 13: 919-927.

9. Bridevaux PO, Aubert JD, Soccal PM, Mazza-Stalder J, Berutto C, Rochat T, et al. Incidence and outcomes of respiratory viral infections in lung transplant recipients: A prospective study. Thorax. 2014; 69: 32-38.

10. Botha P, Archer L, Anderson RL, Lordan J, Dark JH, Corris PA, et al. Pseudomonas aeruginosa colonization of the allograft after lung transplantation and the risk of bronchiolitis obliterans syndrome. Transplantation. 2008; 85: 771-774.

11. Singh N. Fungal infections in the recipients of solid organ transplantation. Infect Dis Clin North Am. 2003; 17: 113-134. 
12. Stjärne AA, Hammarström $H$, Inghammar $M$, Larsson $H$, Hansson $L$, Riise $G C$, et al. Microbiological findings in bronchoalveolar lavage fluid from lung transplant patients in Sweden. Transpl Infect Dis. 2018; 20: e12973.

13. Stewart S, Fishbein MC, Snell GI, Berry GJ, Boehler A, Burke MM, et al. Revision of the 1996 working formulation for the standardization of nomenclature in the diagnosis of lung rejection. J Heart Lung Transplant. 2007; 2006: 1229-1242.

14. Levine DJ, Glanville AR, Aboyoun C, Belperio J, Benden C, Berry GJ, et al. Antibody-mediated rejection of the lung: $A$ consensus report of the international society for heart and lung transplantation. J Heart Lung Transplant. 2016; 35: 397-406.

15. Kulkarni HS, Bemiss BC, Hachem RR. Antibody-mediated rejection in lung transplantation. Curr Transplant Rep. 2015; 2: 316-323.

16. Roden AC, Aisner DL, Allen TC, Aubry MC, Barrios RJ, Beasley MB, et al. Diagnosis of acute cellular rejection and antibody-mediated rejection on lung transplant biopsies: A perspective from members of the pulmonary pathology society. Arch Pathol Lab Med. 2017; 141: 437-444.

17. Roux A, Levine DJ, Zeevi A, Hachem R, Halloran K, Halloran PF, et al. Banff lung report: Current knowledge and future research perspectives for diagnosis and treatment of pulmonary antibody-mediated rejection (AMR). Am J Transplant. 2019; 19: 21-31.

18. Verleden GM, Glanville AR, Lease ED, Fisher AJ, Calabrese F, Corris PA, et al. Chronic lung allograft dysfunction: Definition, diagnostic criteria, and approaches to treatment-A consensus report from the Pulmonary Council of the ISHLT. J Heart Lung Transplant. 2019; 38: 493-503.

19. Banga A., Sahoo D, Lane CR, Farver CF, Budev MM. Disease recurrence and acute cellular rejection episodes during the first year after lung transplantation among patients with sarcoidosis. Transplantation. 2015; 99: 1940-1945.

20. Collins J, Hartman MJ, Warner TF, Müller NL, Kazerooni EA, McAdams HP, et al. Frequency and CT findings of recurrent disease after lung transplantation. Radiology. 2001; 219: 503-509.

21. Ando K, Okada Y, Akiba M, Kondo T, Kawamura T, Okumura M, et al. Lung transplantation for lymphangioleiomyomatosis in Japan. PLoS One. 2016; 11: e0146749.

22. Zaki KS, Aryan Z, Mehta AC, Akindipe O, Budev M. Recurrence of lymphagioleiomyomatosis: Nine years after a double lung transplantation. World J Transplant. 2016; 6: 249-254.

23. Glanville AR. Physiology of chronic lung allograft dysfunction: Back to the future? Eur Respir J. 2017; 49: 1700187.

24. Benzimra M. Surveillance bronchoscopy: Is it still relevant? Semin Respir Crit Care Med. 2018; 39: 219-226.

25. Tosi D, Carrinola R, Morlacchi LC, Tarsia P, Rossetti V, Mendogni P, et al. Surveillance transbronchial biopsy program to evaluate acute rejection after lung transplantation: A single institution experience. Transplant Proc. 2019; 51: 198-201.

26. Valentine VG, Taylor DE, Dhillon GS, Fuchs DM, McFadden PM, Kantrow SP, et al. Success of lung transplantation without surveillance bronchoscopy. J Heart Lung Transplant. 2002; 21: 319-326.

27. Valentine VG, Gupta MR, Weill D, Lombard GA, LaPlace SG, Seoane L, et al. Single-institution study evaluating the utility of surveillance bronchoscopy after lung transplantation. J Heart Lung Transplant. 2009; 28: 14-20. 
28. McWilliams TJ, Williams TJ, Whitford HM, Snell Gl. Surveillance bronchoscopy in lung transplant recipients: Risk versus benefit. J Heart Lung Transplant. 2008; 27: 1203-1209.

29. Inoue M, Minami M, Wada N, Nakagiri T, Funaki S, Kawamura T, et al. Results of surveillance bronchoscopy after cadaveric lung transplantation: A Japanese single-institution study. Transplant Proc. 2014; 46: 944-947.

30. Takizawa DB, de Castro CC, Paiva MA, Campos SV, Carraro RM, Costa AN, et al. Surveillance bronchoscopy in lung transplantation recipients: A single center experience analysis. Transplant Proc. 2020; 52: 1380-1383.

31. Roden AC, Kern RM, Aubry MC, Jenkins SM, Yi ES, Scott JP, et al. Transbronchial cryobiopsies in the evaluation of lung allografts. Do the benefits outweigh the risks? Arch Pathol Lab Med. 2016; 140: 303-311.

32. Fruchter O, Fridel L, Rosengarten D, Raviv Y, Rosanov V, Kramer MR. Transbronchial cryobiopsy in lung transplantation patients: First report. Respirology. 2013; 18: 669-673.

33. Yarmus L, Akulian J, Girlbert C, Illei P, Shah P, Merlo C, et al. Cryoprobe transbronchial lung biopsy in patients after lung transplantation. Chest. 2013; 143: 621-626.

34. Montero MA, De Gracia J, Amigo MC, Mugnier J, Alvarez A, Berastegui C, et al. The role of transbronchial cryobiopsy in lung transplantation. Histopathology. 2018; 73: 593-600.

35. Gershman E, Ridman E, Fridel L, Shtraichman O, Pertzov B, Rosengarten D, et al. Efficacy and safety of transbronchial cryo in comparison with forceps biopsy in lung allograft recipients: Analysis of 402 procedures. Clin Transplant. 2018; 32: e13221.

36. Loor K, Culebras M, Sansano I, Alvarez A, Berastegui C, de Gracia J. Optimization of transbronchial cryobiopsy in lung transplant recipients. Ann Thorac Surg. 2019; 108: 10521058.

37. Mehta AC, Wang J, Abuqayyas S, Garcha P, Lane CR, Tsuang W, et al. New nodule-newer etiology. World J Transplant. 2016; 6: 215-219.

38. Mohamed S, Mendogni P, Tosi D, Carrinola R, Palleschi A, Righi I, et al. Transbronchial cryobiopsies in lung allograft recipients for surveillance purposes: Initial results. Transplant Proc. 2020; 52: 1601-1604.

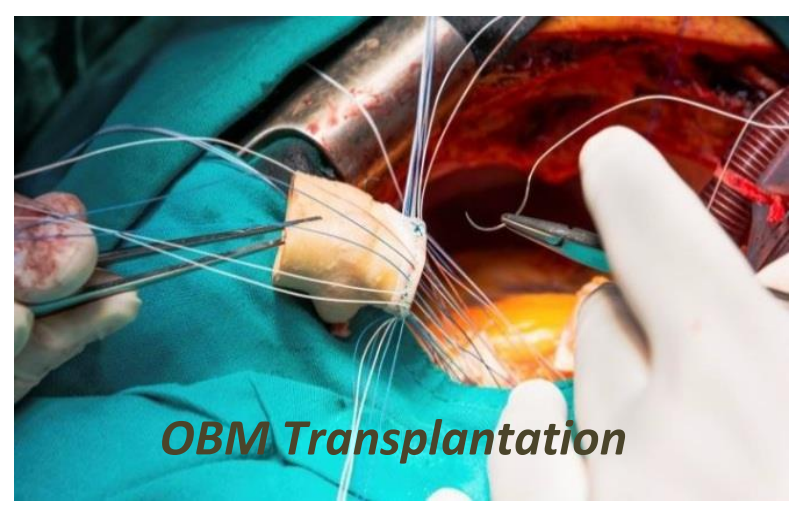

Enjoy OBM Transplantation by:

1. Submitting a manuscript

2. Joining in volunteer reviewer bank

3. Joining Editorial Board

4. Guest editing a special issue

For more details, please visit: http://www.lidsen.com/journals/transplantation 
Case Report

\title{
Donor Cell-Derived Acute Myeloid Leukaemia with 3q26.2 Involvement/MECOM Rearrangement - A Case Report and Literature Review
}

Jun Gu 1, Wei Wang 2, Guilin Tang 2, Gokce A. Toruner ${ }^{2}$, Ming Zhao ${ }^{1}$, Steven Sfamenos ${ }^{1}$, Zhenya Tang $^{2, *}$, Joseph D. Khoury ${ }^{2}$, L. Jeffrey Medeiros ${ }^{2}$

1. School of Health Professions, the University of Texas MD Anderson Cancer Centre, 1515 Holcombe Blvd., Houston, USA; E-Mails: jungu@mdanderson.org; mzhao@mdanderson.org; SMSfamenos@mdanderson.org.

2. Department of Hematopathology, the University of Texas MD Anderson Cancer Centre, 1515 Holcombe Blvd., Houston, USA; E-Mails: WWang13@mdanderson.org; GTang@mdanderson.org; GAToruner@mdanderson.org; ztang@mdanderson.org; JKhoury@mdanderson.org; limedeiros@mdanderson.org.

* Correspondence: Zhenya Tang; E-Mail: ztang@mdanderson.org

Academic Editor: Gerhard Hildebrandt

Special Issue: $\underline{\text { Bone Marrow Transplantation }}$

OBM Transplantation

2020, volume 4, issue 4

doi:10.21926/obm.transplant.2004128
Received: October 13, 2020

Accepted: November 29, 2020

Published: December 7, 2020

\begin{abstract}
Donor cell-derived leukaemia (DCL) is an uncommon complication of allogeneic hematopoietic stem cell transplantation (HSCT). DCL might represent up to $5 \%$ of the postHSCT disease relapses, but case numbers reported in the literature might underestimate the frequency. The leukemogenesis of DCL is not well understood due to the limited numbers of cases reported and lack of detailed molecular genetic information from recipients and donors. Although many theories have been proposed for leukemogenesis of $\mathrm{DCL}$, the underlying molecular genetic mechanism are likely heterogeneous. Here we report a case of donor cell-derived acute myeloid leukaemia with $3 q 26.2$ involvement/MECOM rearrangement and chromosome $20 \mathrm{q}$ deletion. We also reviewed the literature of previously
\end{abstract}

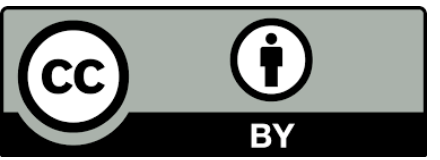

(C) 2020 by the author. This is an open access article distributed under the conditions of the Creative Commons by Attribution License, which permits unrestricted use, distribution, and reproduction in any medium or format, provided the original work is correctly cited. 
described $D C L$ cases, and we discussed the risk factors that might be important to the onset of DCL.

\section{Keywords}

Donor cell leukaemia; hematopoietic stem cell transplantation (HSCT); 3q26.2 involvement/MECOM rearrangement; del20q; leukemogenesis

\section{Introduction}

Donor cell-derived leukaemia $(D C L)$ is a rare complication of allogenic hematopoietic stem cell transplantation (HSCT). DCL might represent up to $5 \%$ of the post-transplant relapsed leukaemia cases [1-4]. To date, less than 200 DCL cases have been reported since its first recognition in 1971 [1-8]. However, the actual number of DCL cases might be higher due to the inconsistent use of chimeric testing on bone marrow transplant patients $[9,10]$. Many factors have been proposed as being associated with the initiation of DCL: donor genetic profile, genetic susceptibility of recipients and/or donors, microenvironment of the host, and therapeutic interventions - such as chemotherapy and some targeted therapies [1, 2, 5, 11, 12]. Although most of the donors are assumed to be genetically normal, there have been cases reported in which the donor had certain constitutional and/or somatic genetic abnormalities overlooked by current pre-transplant screening. In most of these cases, the abnormalities were investigated and detected only after recipients were identified with chromosomal aberration(s) and/or even developed DCL [1-3, 8]. There also have been case reports of donors remain free of genetic abnormalities, whereas their recipients developed $D C L$ with newly emerging genetic aberrations $[3,8]$.

The molecular genetic events among all reported DCL cases are heterogeneous. Here we report a case of donor cell-derived acute myeloid leukaemia (AML) with 3q26.2 involvement/MECOM rearrangement. We further explore the underlying mechanisms of $D C L$ initiation and progression along with a testing strategy.

\section{Case Report}

The patient was a 65-year-old woman immigrant to the United States who was diagnosed initially with AML in her native country 5 years ago. Her initial bone marrow aspiration and biopsy showed $30 \%$ blasts. Conventional cytogenetic analysis demonstrated a female complex karyotype (no detailed information available) and FISH analysis showed $5 q-, 7 q-,-7$, and +22 as well as loss of one copy of TP53; Sanger sequencing revealed a TP53 G443 frameshift mutation with a variant allele frequency (VAF) of $30 \%$ at that time. The patient was first treated with cytarabine plus daunorubicin and achieved complete remission. A post-chemotherapy bone marrow aspiration and biopsy specimen showed $1 \%$ blast and molecular analysis was negative for TP53 mutation. Conventional cytogenetic analysis and FISH tests were not repeated after therapy. The patient subsequently underwent allogeneic HSCT twice (9 months apart) from the same HLA-matched male sibling. Her first HSCT was complicated with cytomegalovirus (CMV) viremia. It is necessary to point out that according to our clinical notes and the discharge summary from her primary 
hospital the reason and the conditioning details for the second HSCT remain unknown. However, her second HSCT was complicated by graft-versus-host disease (GVHD) mainly in skin and gut. She experienced engraft chimerism and relapse of AML 16 months after the second transplant. She then received azacitidine for 6 courses and achieved a second remission. Seven month later, her disease relapsed again and bone marrow evaluation showed $8 \%$ blasts and an acquired PTPN11 mutation. She was then administered low-dose cytarabine with venetoclax (initially $800 \mathrm{mg}$, then reduced to $600 \mathrm{mg}$ ) for 3 cycles. Due to her persistent disease, she was then referred to our institution.

Initial workup at our institution demonstrated a persistent acute leukaemia with $18 \%$ bone marrow blasts. Flow-cytometry immunophenotyping studies showed aberrant myeloid blasts positive for CD7, CD13, CD33, CD34, CD117, CD123, and HLA-DR. The blasts were negative for CD3 (surface and cytoplasmic) and myeloperoxidase. CD19 was partially positive, but other B cell markers including CD22 and CD79a were negative. The overall immunophenotype supported the diagnosis for AML (Figure 1). Chromosome analysis exhibited a complex karyotype with XY identified in all malysed 46,XY, der(2)t(2;3)(p21;q26.2), der(3)t(3;3)(q10;q10)add(3)(q26.2)t(2;3), del(20)(q11.2q13.3)[13], indicating that these cells with chromosomal abnormalities were of donor cell origin (Figure 2). Due to unavailability of the donor's genetic fingerprint information, $X Y$ FISH tests (probe from Abbott Molecular, Inc., Abbott Park, IL) were performed in both bone marrow and peripheral blood specimens and demonstrated that all cells were XY (donor) type, suggesting that our patient might have $100 \%$ myeloid engraft. MECOM rearrangement derived from both $t(2 ; 3)(p 21 ; q 26.2)$ and add(3)(q26.2) was detected by interphase FISH, metaphase FISH using MECOM dual-colour, breakapart probe (Leica/Kreatech, Inc., Buffalo Grove, IL) as well as whole chromosomal painting (wcp) for chromosome 3 (Cytocell, Ltd, Tarrytown, NY). For detailed FISH probe and method information, please refer to our previous report [14] (Figure 3). The 20q deletion (referred as del20q thereafter) was also further confirmed by FISH using LSI D20S108 probe (Abbott Molecular, Inc., Abbott Park, IL) $[15,16]$. A next generation sequencing (NGS) study of the bone marrow aspirate specimen revealed several mutations with different variant allele frequency (VAF), e.g., BCOR: p.S771* (VAF: 86.8\%); FLT3: p.D835H (VAF: 87.1\%) and PIGA: p.I116V (VAF: $<3 \%)$. Our NGS study included an 81-gene panel which were designed specifically for myeloid malignancies. The NGS based sequencing was performed using the Illumina MiSeq (Illumina, San Diego, CA) sequencer as we have reported previously [17]. The FLT3 D835H mutation was further confirmed by a PCR-based method. The patient was then treated with cytarabine, daunorubicin and venetoclax for 1 cycle, and then cytarabine, daunorubicin, venetoclax and midostaturin for another cycle. However, her chromosomal and FISH analyses indicated a persistence of chromosomal abnormalities as well as 3q26.2 involvement/MECOM rearrangement, all in donor cells. NGS after treatment detected several new mutations, e.g., FLT3: p.N676K (VAF: < 3\%); PTPN11: p.A72T (VAF: 29.5\%) and p.G503A (VAF: < 3\%), in addition to those detected previously. The patient died 6 months later due to severe complications including lactic acidosis, renal failure and fungal pneumonia. 

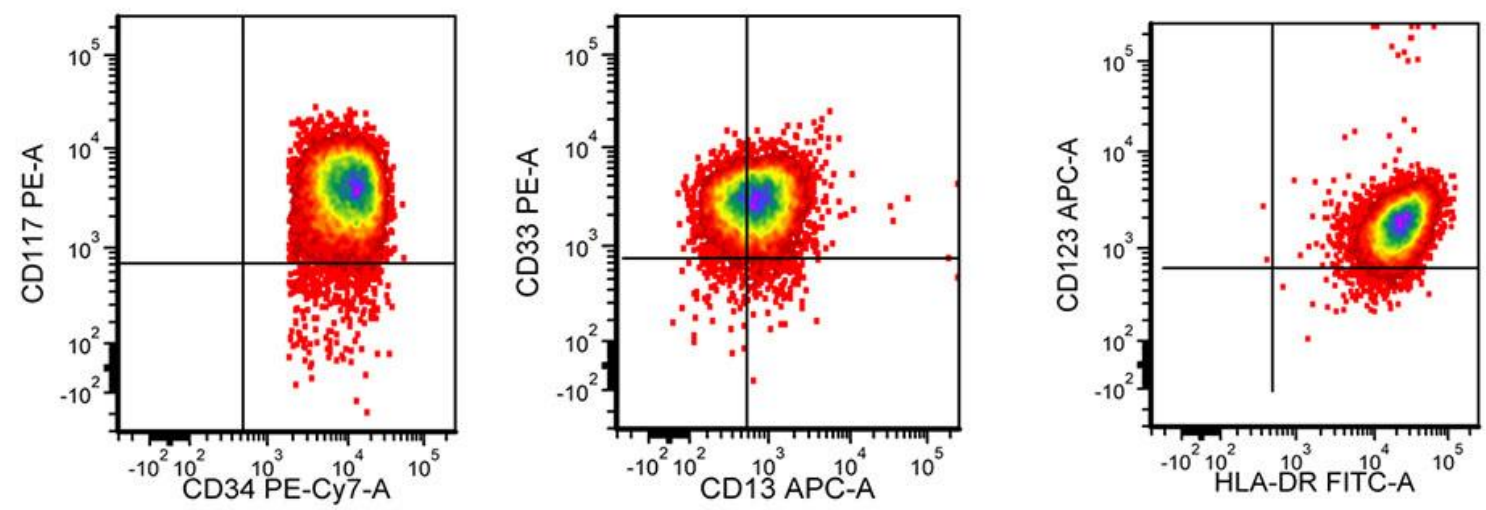

Figure 1 Results of immunophenotype analysis during the initial workup of the patient at our institution. The blasts in the bone marrow aspirate were positive for CD34, CD117, CD13, CD33, CD123 and HLA-DR, diagnostic of AML.
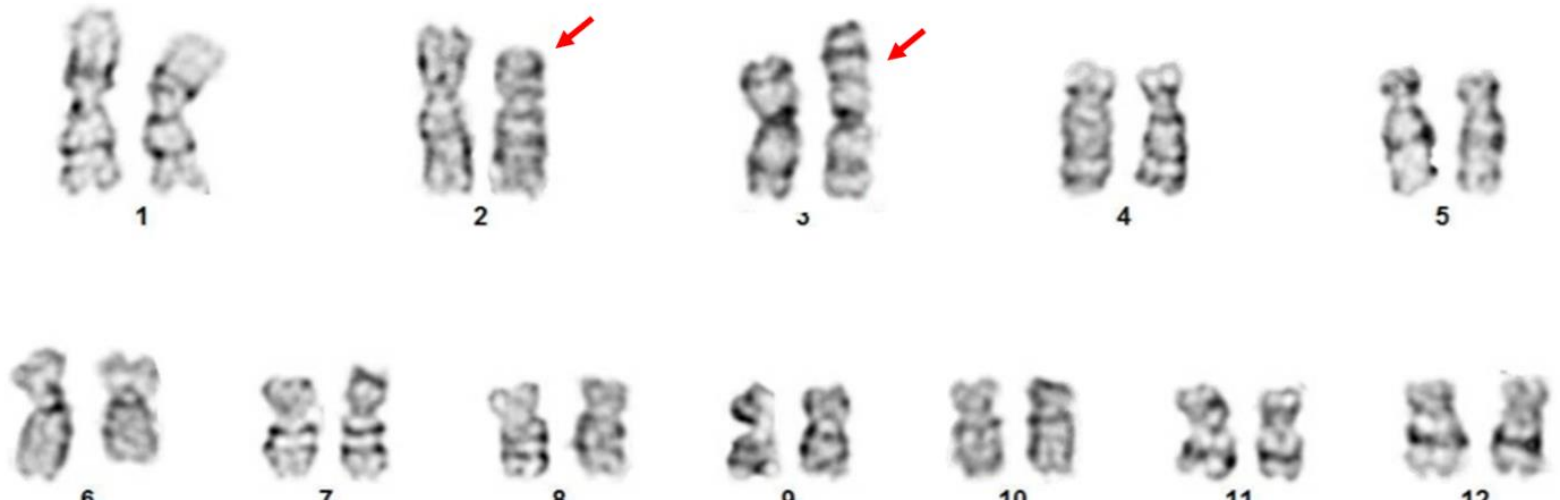

12
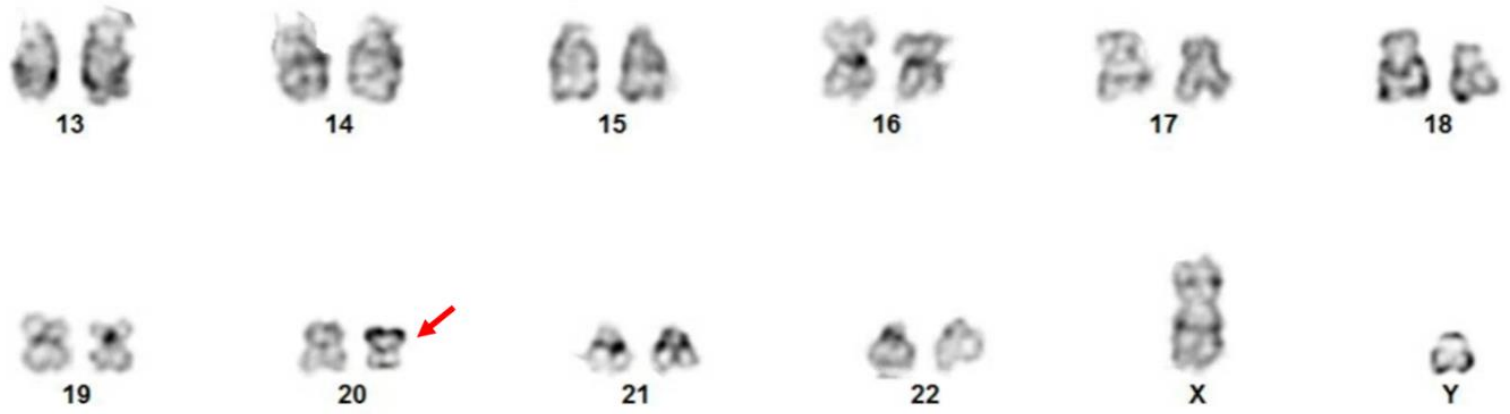

Figure 2 A representative karyotype image of this cases. The abnormal chromosomes were pointed out with red arrows. The ISCN description of this karyotype result as the following:

$/ / 46, X Y, \operatorname{der}(2) t(2 ; 3)(p 21 ; q 26.2), \operatorname{der}(3) t(3 ; 3)(q 10 ; q 10) \operatorname{add}(3)(q 26.2) t(2 ; 3), \operatorname{del}(20)(q 11.2$ q13.3). 

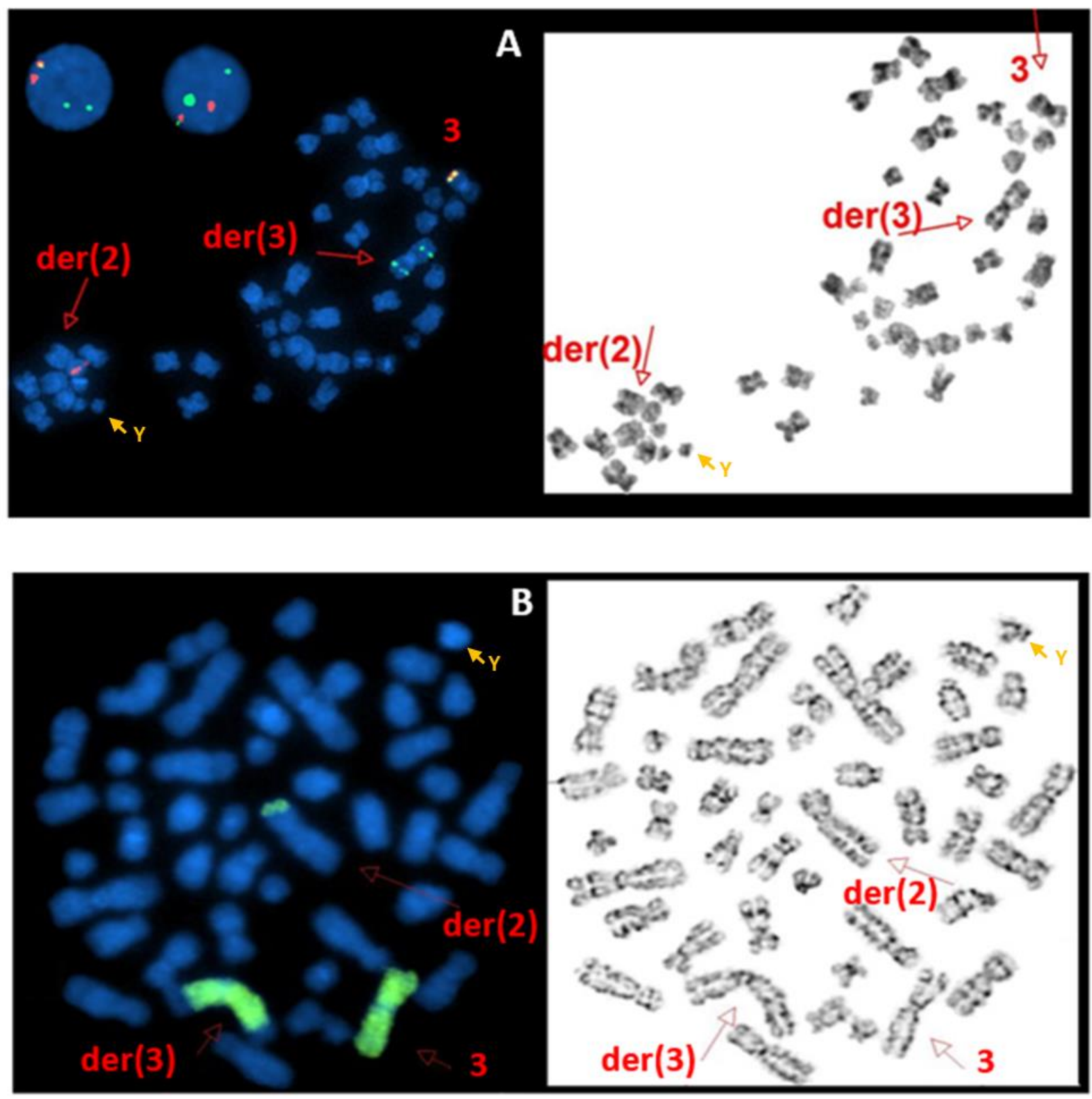

Figure $3 \mathrm{FISH}$ analyses in the initial bone marrow specimen in our institution. A. Interphase and metaphase FISH performed using MECOM (EVI1) Break-apart probe. The two interphases in left upper corner exhibited 1 R2G1F signal pattern indicating MECOM rearrangement. Correlating with a metaphase FISH image and G-banding image of the same metaphase (right side), the abnormal chromosome 2, der(2), hosted a $5^{\prime}$ MECOM (red) signal; the abnormal chromosome 3, der(3), had two 3'MECOM (green) signals on it, while the normal chromosome 3 had a fusion signal on it. These findings are consistent with the chromosomal analysis results, $\operatorname{der}(2) t(2 ; 3)(p 21 ; q 26.2)$ and $\operatorname{der}(3) t(3 ; 3)(q 10 ; q 10) \operatorname{add}(3)(q 26.2) t(2 ; 3) ;$ B. Whole chromosomal painting (wcp) for chromosomes 3 demonstrated that partial of chromosome 3 materials was located at the ptel of the abnormal der(2), while both ptel and qtel of the abnormal der(3) were not stained. The $Y$ chromosome was pointed out with a golden arrow and a " $Y$ " sign in each image to indicate that the cell was of donor cell origin. 


\section{Discussion}

To the best of our knowledge, this is the first DCL case with confirmed $3 q 26.2$ involvement/MECOM rearrangement reported in the literature [1-4]. Aldoss and Song reported a donor cell AML case with chromosome 3 involvement in 2017 [18]. The karyotype of that case was reported as $46, X X, t(3 ; 13)(p 10 ; q 10)$, inv(11)(p15q23)[13]/46,XX[2] and originated from donor cells, but without 3q26.2 involvement/MECOM rearrangement. The patient achieved complete remission and switched to a normal donor karyotype "46,XX[19]" after chemotherapy. Dias et al [8] reported a case with inv(3)(p26q25) after a sex-matched HSCT. Further intensive investigation revealed that the donor carried this constitutional chromosomal aberration. The recipient in their report remained a complete remission after HSCT and did not develop DCL, but his karyotype switched from 46,XY (recipient type) to 46,XY,inv(3)(p26q25) (donor type) during post-transplant follow-up interval of at least 18 months. Interestingly, the inv(3) was applied as an efficient biomarker for distinguishing donor cells from recipient cells in this circumstance.

Chromosomal aberrations involving 3q26.2 (with or without confirmed MECOM rearrangement) have been reported in cases with various myeloid malignancies such as AML, myelodysplastic syndrome (MDS) and chronic myeloid leukaemia (CML) $[13,14,20]$. These aberrations often present as acquired/additional chromosomal abnormalities, and their emergence usually implies for a poor prognosis. In the patient we report, the 3q26.2 involvement/MECOM rearrangement was detected at the initial diagnosis of donor cell-derived AML. During a follow-up of approximately 6 months, her karyotype analyses and MECOM FISH signal patterns varied slightly (data not included), but the $\mathrm{t}(2 ; 3)(\mathrm{p} 21 ; \mathrm{q} 26.2)$ derived chromosomal aberrations and positive MECOM rearrangement, referred as $\mathrm{t}(2 ; 3) / M E C O M$ rearrangement here, have been consistently detected. In general, the $t(2 ; 3) / M E C O M$ rearrangement comprised $6-9 \%$ of all MECOM rearrangement-deriving chromosomal aberrations, representing one of the atypical 3q26 aberrations associated with MECOM rearrangements in contrast to the typical $\operatorname{inv}(3)(q 21 q 26.2) / t(3 ; 3)(q 21 ; q 26.2)$ abnormalities $[13,14,19,20]$. Other studies have suggested that the thyroid adenoma-associated protein gene (THADA) located at 2p21 juxtaposed with MECOM located at 3q26.2 through $\mathrm{t}(2 ; 3)(\mathrm{p} 21 ; \mathrm{q} 26.2)$ translocation and the regulatory elements of THADA can be hijacked by MECOM, resulting in dysregulation of both EVI1 (active component of MECOM) and THADA. The dysregulation is characterized as overexpression of EVII and loss of THADA expression, resulting in a poor prognosis [20-22].

It should be noted that del20q occurred simultaneously with $3 q 26.2$ involvement/MECOM rearrangement after HSCT in this patient. Del20q is a recurrent cytogenetic abnormality observed rarely in the healthy aging population (approximately 0.1\%) [23], and more often in patients with myeloid malignancies including AML (1-2\%), MDS (5-7\%), and in myeloproliferative diseases (MPNs) (up to 10\%) [11, 15, 16]. Yoon et al [24] reported one case with a donor-derived del20q clone. Although the size of the clone expanded during a follow-up of 18 months in that case, neither disease relapse nor DCL or other donor cell-derived malignancy occurred. Isolated del20q is usually considered as an intermediate prognostic factor in myeloid malignancies $[11,14,15]$. Hence, it seems most likely that 3q26.2 involvement/MECOM rearrangement, rather than del20q, had the most impact on the poor prognosis of donor cell-derived AML in the patient we report.

HSCT is considered as the sole curative option for certain types of AML [25], but post-transplant disease relapse occurs. At the same time, relapsed disease may occasionally differ from the 
original disease at various levels, such as clinical presentation, subtypes of diseases (e.g., myeloid versus lymphoid malignancies due to lineage switch), and/or even different cell of origin (recipient cells versus donor cells). It has been reported that $\mathrm{DCL}$ may represent up to $5 \%$ of all posttransplant "relapsed" leukaemia cases, and it is critical to distinguish DCL from the truly relapsed diseases, especially if a second allogeneic HSCT is being considered as the next therapy option. In this case, a post-transplant "relapsed $A M L$ " would have been diagnosed if based only on the pathologic and immunophenotypic findings in the bone marrow and peripheral blood. However, the newly identified chromosomal abnormalities including 3q26.2 involvement/MECOM rearrangement were different from the initial disease, at least implying an emergence of different clone(s) of leukemic cells, and the male sex identified by chromosome and XY FISH analyses confirmed origin from donor cells. Mutations of BCOR, FLT3, PIGA and PTPN11 detected after transplant by NGS-based testing were mostly of donor cells, while her previously reported TP53 G443 frameshift mutation was no longer detected.

The factors underlying leukemogenesis of $D C L$ in this case remain unknown. It is believed that multiple factors from recipient, donor as well as therapeutic interventions may play independent and/or synergetic roles in the pathogenesis of donor cell AML (Figure 4) [1-3, 10]. The microenvironment after myeloablative conditioning in the recipient may be carcinogenic to donor cells, and the later can be transformed more easily, especially if any occult pre-leukaemic clones exist, which is normally suppressed by normally functioning immune system of the donor [12]. On the other hand, the recipient's compromised T-cell immunity and microenvironment may have facilitated the growth and expansion of the pre-leukaemic clones to a full-blown AML with distinct cytogenetic and molecular genetic characteristics [4, 7]. Our patient had CMV viremia that occurred after the first HSCT, and GVHD and relapsed AML after the second HSCT from the same donor, indicating a dramatically compromised post-transplant immune system and/or delayed immune reconstitution in the recipient.

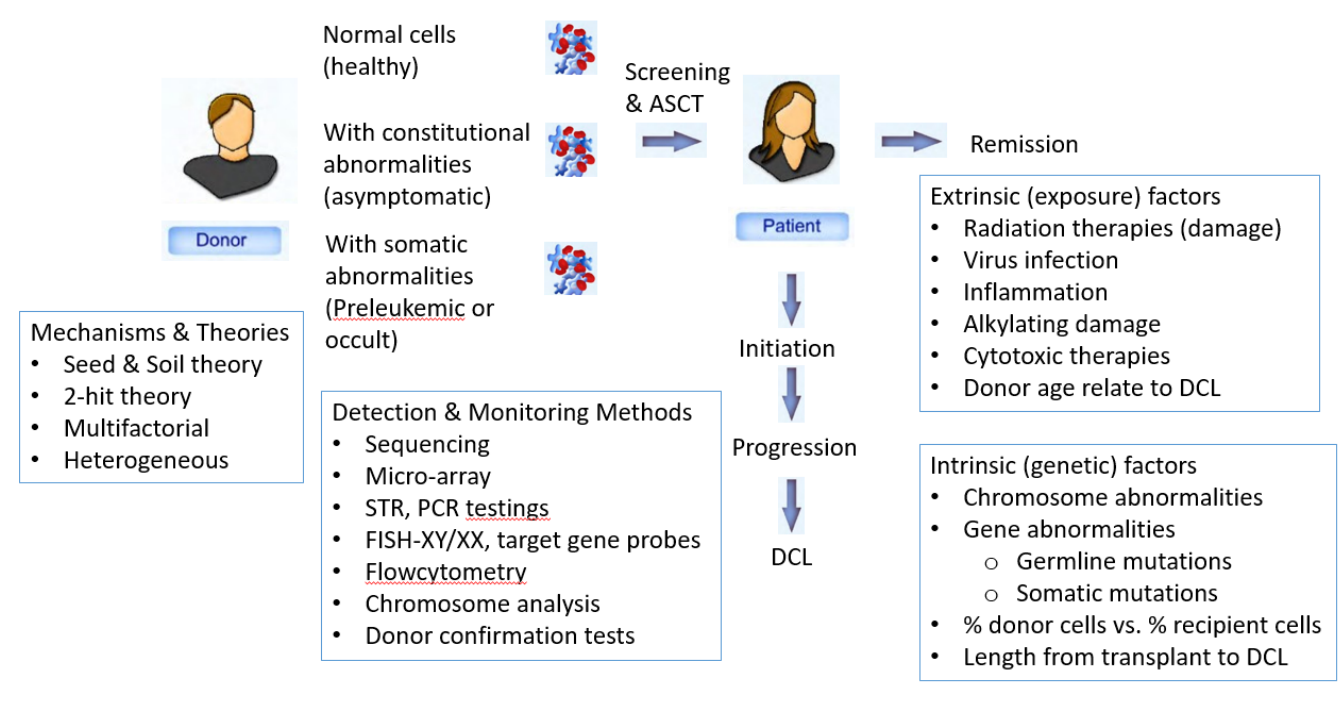

Figure 4. Schematic illustration of hypotheses of leukemogenesis of donor cell leukaemia (DCL) and proposed workup.

According to current clinical practice standards, bone marrow donors are evaluated for general health, but not for any apparent and/or occult comorbid conditions such as constitutional 
chromosomal aberration(s) and/or other cancer-predisposing genetic conditions. Some donors have been reported to carry constitutional chromosomal aberration(s), such as karyotype of $47, \mathrm{XXY}$ or $47, \mathrm{XXY}$, inversions involving chromosome(s) 3, 9, 10 and 12, trisomy 8, Robertsonian translocation(s), and/or other balanced reciprocal translocation(s) [8, 26]. These chromosomal aberrations are mostly detected after transplant, and the same and/or evolved chromosomal aberrations were detected in the recipients. It remains uncertain whether one or some of these constitutional chromosomal aberration(s) are directly associated with pathogenesis of DCL, but this always triggers the debate about whether bone marrow donors should be more intensively screened, including testing for known tumour-susceptible genetic conditions such as apparent chromosomal aberrations. Clonal haematopoiesis of indeterminate potential (CHIP) is a common occult condition characterized as expansion of age-acquired somatic mutations in hematopoietic lineages that are associated with tumorigenesis, persistence of measurable residual diseases, disease relapse as well as the development of DCL after HSCT in hematologic malignancies. It is believed that CHIP is a novel risk factor for DCL [27], especially if donor and/or recipient are aging individuals. The patient we report was over 60 years old at the time of her second HSCT. TP53 frameshift mutation and PTPN11 mutation have been detected prior to HSCT and during disease relapse post HSCT, respectively. The age of her sibling donor remains unknown to us. Some germline variants, particularly those involving ANKRD26, CEBPA, DDX41, ETV6, GATA2, and RUNX1, have been reported as hereditary predispositions to developing myeloid malignancies [28-30], including donor-cell derived malignancies [31]. All these six genes are included in our clinical NGSbased 81-gene leukaemia mutation panel, and none of them had variant alleles.

\section{Conclusions}

We report a case of donor cell-derived AML with 3q26.2 involvement/MECOM rearrangement. This genetic abnormality is often associated with a poor prognosis. Possible factors involved in leukemogenesis of $\mathrm{DCL}$ are also discussed. This case illustrates the importance of considering genetic evaluation of donors as part of screening for HSCT.

\section{Author Contributions}

Conceptualization, Jun Gu, Wei Wang and Zhenya Tang; data curation: Jun Gu, Wei Wang and Zhenya Tang; methodology, Wei Wang, Guilin Tang, Gokce A. Toruner, Ming Zhao, Steven Sfamenos, Zhenya Tang and L. Jeffrey Medeiros; writing-original draft preparation, Jun Gu, Wei Wang and Zhenya Tan; writing - review and editing, Jun Gu, Wei Wang, Ming Zhao, Zhenya Tang, Joseph D. Khoury, and L. Jeffrey Medeiros. All authors have read and agreed to the published version of the manuscript.

\section{Competing Interests}

The authors have declared that no competing interests exist.

\section{References}

1. Ruiz-Argüelles GJ, Ruiz-Argüelles A, Garces-Eisele J. Donor cell leukaemia: A critical review. Leuk Lymphoma. 2007; 48: 25-38. 
2. Wiseman DH. Donor cell leukaemia: A review. Biol Blood Marrow Transplant. 2011; 17: 771789.

3. Dietz AC, DeFor TE, Brunstein CG, Wagner Jr JE. Donor-derived myelodysplastic syndrome and acute leukaemia after allogeneic haematopoietic stem cell transplantation: Incidence, natural history and treatment response. Br J Haematol. 2014; 166: 209-212.

4. Suárez-González J, Martínez-Laperche C, Kwon M, Balsalobre P, Carbonell D, Chicano M, et al. Donor cell-derived hematologic neoplasms after hematopoietic stem cell transplantation: A systematic review. Biol Blood Marrow Transplant. 2018; 24: 1505-1513.

5. Goh KO, Fialkow PJ, Thomas ED, Bryant JI, Neiman PE. Leukaemic transformation of engrafted human cells in vivo. Lancet. 1971; 298: 101-102.

6. Kondo T, Tasaka T, Shimizu R, Hayashi K, Yamada S, Fukuda H, et al. Jumping translocations of $1 \mathrm{q}$ in donor cell-derived myelodysplastic syndrome after cord blood transplantation: Case report and review of the literature. Mol Clin Oncol. 2020; 12: 365-373.

7. Bouvier A, Ribourtout B, Francois S, Orvain C, Paz DL, Beucher A, et al. Donor cell-derived acute promyelocytic leukaemia after allogeneic hematopoietic stem cell transplantation. Eur J Haematol. 2018; 101: 570-574.

8. Dias A, Al-Kali A, Van Dyke D, Niederwieser D, Vucinic V, Lemke J, et al. Inversion 3 cytogenetic abnormality in an allogeneic hematopoietic cell transplant recipient representative of a donor-derived constitutional abnormality. Biol Blood Marrow Transplant. 2017; 23: 15821587.

9. Hertenstein B, Hambach L, Bacigalupo A, Schmitz N, McCann S, Slavin S, et al. Development of leukaemia in donor cells after allogeneic stem cell transplantation--A survey of the European Group for Blood and Marrow Transplantation (EBMT). Haematologica. 2005; 90: 969-975.

10. Dickson MA, Papadopoulos EB, Hedvat CV, Jhanwar SC, Brentjens RJ. Acute myeloid leukaemia arising from a donor derived premalignant hematopoietic clone: A possible mechanism for the origin of leukaemia in donor cells. Leuk Res Rep. 2014; 3: 38-41.

11. Courville EL, Singh C, Yohe S, Linden MA, Naemi K, Berger M, et al. Patients with a history of chemotherapy and isolated del(20q) with minimal myelodysplasia have an indolent course. Am J Clin Pathol. 2016; 145: 459-466.

12. Ogonek J, Juric KM, Ghimire S, Varanasi PR, Holler E, Greinix H, et al. Immune reconstitution after allogeneic hematopoietic stem cell transplantation. Front Immunol. 2016; 7: 507.

13. De Braekeleer M, Le Bris MJ, De Braekeleer E, Basinko A, Morel F, Douet-Guilbert N. 3q26/EVI1 rearrangements in myeloid hemopathies: A cytogenetic review. Future Oncol. 2015; 11: 1675-1686.

14. Tang Z, Tang G, Hu S, Patel KP, Yin CC, Wang W, et al. Deciphering the complexities of MECOM rearrangement-driven chromosomal aberrations. Cancer Genet. 2019; 233: 21-31.

15. Yin CC, Peng J, Li Y, Shamanna RK, Muzzafar T, DiNardo C, et al. Clinical significance of newly emerged isolated del(20q) in patients following cytotoxic therapies. Mod Pathol. 2015; 28: 1014-1022.

16. Tang G, Lopez JE, Wang SA, Hu S, Ma J, Pierce S, et al. Characteristics and clinical significance of cytogenetic abnormalities in polycythemia vera. Haematologica. 2017; 102: 1511-1518.

17. Tang Z, Toruner GA, Tang G, Yin CC, Wang W, Hu S, et al. Chronic myeloid leukaemia with insertion-derived BCR-ABL1 fusion: Redefining complex chromosomal abnormalities by correlation of FISH and karyotype predicts prognosis. Mod Pathol. 2020; 33: 2035-2045. 
18. Aldoss I, Song JY. Donor-derived myeloid neoplasm post allogeneic hematopoietic cell transplantation. Blood. 2017; 129: 1231.

19. Dowiak AV, Tirado CA. Cytogenetic characterization of myeloid neoplasms with $t(2 ; 3)(p 13-$ 25;q25-29): An analysis of 60 cases. J Assoc Genet Technol. 2017; 43: 64-69.

20. Ottema S, Mulet-Lazaro R, Beverloo HB, Erpelinck C, Herk SV, Helm RV, et al. Atypical $3 q 26 /$ MECOM rearrangements genocopy inv(3)/t(3;3) in acute myeloid leukaemia. Blood. 2020; 136: 224-234.

21. De Braekeleer M, Guéganic N, Tous C, Le Bris MJ, Basinko A, Morel F, et al. Breakpoint heterogeneity in $(2 ; 3)(p 15-23 ; q 26)$ translocations involving EVI1 in myeloid hemopathies. Blood Cells Mol Dis. 2015; 54: 160-163.

22. Trubia M, Albano F, Cavazzini F, Cambrin GR, Quarta G, Fabbiano F, et al. Characterization of a recurrent translocation $\mathrm{t}(2 ; 3)(\mathrm{p} 15-22 ; \mathrm{q} 26)$ occurring in acute myeloid leukaemia. Leukaemia. 2006; 20: 48-54.

23. Ravindran A, He R, Ketterling RP, Jawad MD, Chen D, Oliveira JL, et al. The significance of genetic mutations and their prognostic impact on patients with incidental finding of isolated del(20q) in bone marrow without morphologic evidence of a myeloid neoplasm. Blood Cancer J. 2020; 10: 1-9.

24. Yoon J, Yun JW, Jung CW, Kim HJ, Kim SH. Clonal dominance of a donor-derived del(20q) clone after allogeneic hematopoietic stem cell transplantation in an acute myeloid leukaemia patient with del(20q). J Clin Lab Anal. 2019; 33: e22951.

25. Dholaria B, Savani BN, Hamilton BK, Oran B, Liu HD, Tallman MS, et al. Hematopoietic cell transplantation in the treatment of newly diagnosed adult acute myeloid leukaemia: An evidence-based review from the american society of transplantation and cellular therapy. Biol Blood Marrow Transplant. 2020.

26. Nishihori T, El-Asmar J, Shah B, Hussaini M, Komrokji R, List A, et al. Donor-derived constitutional chromosomal abnormalities after allogeneic hematopoietic cell transplantation: A single-center experience and a review of the literature. Bone Marrow Transplant. 2015; 50: 1388-1392.

27. Burns SS, Kapur R. Clonal hematopoiesis of indeterminate potential as a novel risk factor for donor-derived leukaemia. Stem Cell Rep. 2020; 15: 279-291.

28. Berger G, van den Berg E, Sikkema-Raddatz B, Abbott KM, Sinke RJ, Bungener LB, et al. Reemergence of acute myeloid leukaemia in donor cells following allogeneic transplantation in a family with a germline DDX41 mutation. Leukaemia. 2017; 31: 520-522.

29. Kobayashi S, Kobayashi A, Osawa Y, Nagao S, Takano K, Okada Y, et al. Donor cell leukaemia arising from preleukemic clones with a novel germline DDX41 mutation after allogenic hematopoietic stem cell transplantation. Leukaemia. 2017; 31: 1020-1022.

30. Rafei H, DiNardo CD. Hereditary myeloid malignancies. Best Pract Res Clin Haematol. 2019; 32: 163-176.

31. Mangaonkar AA, Patnaik MM. Hereditary predisposition to hematopoietic neoplasms: When bloodline matters for blood cancers. Mayo Clinic Proc. 2020; 95: 1482-1498. 


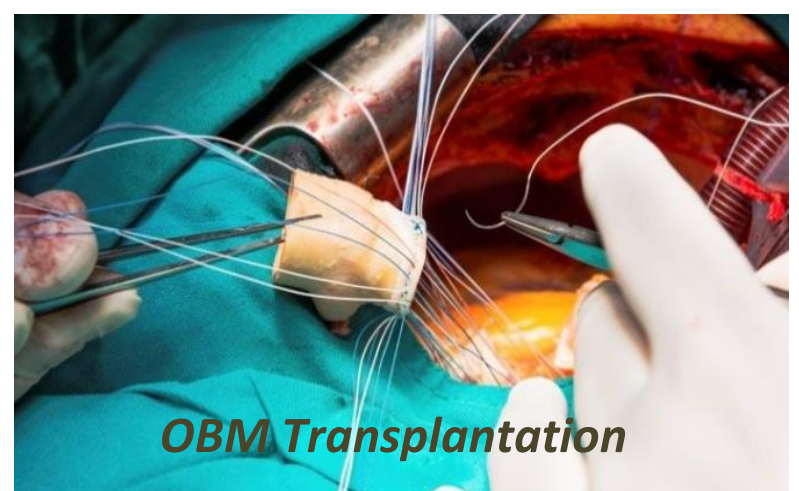

Enjoy OBM Transplantation by:

1. Submitting a manuscript

2. Joining in volunteer reviewer bank

3. Joining Editorial Board

4. Guest editing a special issue

For more details, please visit:

http://www.lidsen.com/journals/transplantation 
Review

\title{
The Roles of Collagen in Islet Transplantation
}

Naoaki Sakata ${ }^{1,2, *}$, Gumpei Yoshimatsu ${ }^{1,2}$, Shohta Koadama ${ }^{1,2}$

1. Department of Regenerative Medicine and Transplantation, Faculty of Medicine, Fukuoka University, 7-45-1 Nanakuma, Jonan, Fukuoka 814-0180, Japan; E-Mails: naoakisakata@fukuoka-u.ac.jp; gyoshimatsu@fukuoka-u.ac.jp; skodama@fukuoka-u.ac.jp

2. Center for Regenerative Medicine, Fukuoka University Hospital, 7-45-1 Nanakuma, Jonan, Fukuoka 814-0180, Japan

* Correspondence: Naoaki Sakata; E-Mail: naoakisakata@fukuoka-u.ac.jp

Academic Editors: Kenneth L. Brayman and Preeti Chhabra

Special Issue: Islet Cell Transplantation

OBM Transplantation

2020, volume 4, issue 4

doi:10.21926/obm.transplant.2004127
Received: October 02, 2020

Accepted: November 15, 2020

Published: November 27, 2020

\begin{abstract}
Islet transplantation is a cellular replacement therapy for severe diabetes mellitus. Although the clinical outcome of islet transplant has been improving, the transplant efficacy of this treatment is not superior to that of pancreatic organ transplantation, a similar transplant therapy. Various factors have been characterized as 'islet transplantation specific', which includes lack of revascularization and ischemia, innate inflammation, or autoimmunity, affect the therapeutic outcome of this treatment. Among them, the impairment of islets by digestion of extracellular matrix (ECM) via the islet isolation and transplantation process is one of the major factors to avoid islet engraftment. The islet is composed of endocrine cells aggregated by ECMs. Particularly, collagen is a target for the digestion of the pancreas for islet isolation. Furthermore, collagen improves endocrine functions, survival, and proliferation. In this study, we review the importance of collagen in islet transplantation.
\end{abstract}

\section{Keywords}

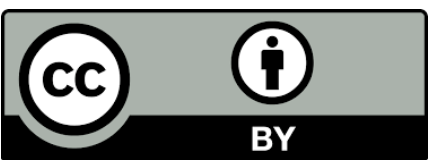

(C) 2020 by the author. This is an open access article distributed under the conditions of the Creative Commons by Attribution License, which permits unrestricted use, distribution, and reproduction in any medium or format, provided the original work is correctly cited. 
$\beta$ Cells; collagen; collagenase; extracellular matrix; insulin; islet; islet isolation; islet transplantation

\section{Introduction}

Islet transplantation is a cellular replacement therapy for severe diabetes mellitus (DM), including brittle type $1 \mathrm{DM}$, that stabilizes blood glucose control with appropriate insulin supplies. The clinical outcome of this treatment is improved significantly because of innovations in pancreas procurement, islet isolation, methods of transplantation, and regimen of immunosuppressive agents [1]. Recently, two phase 3 clinical trials of islet transplantation for type 1 DM were reported. The first clinical trial purified human pancreatic islets in patients with type 1 DM after kidney transplant (CIT-06), which indicated that $62.5 \%$ of patients achieved the primary endpoint of evading severe hypoglycemic events and between $1 \%$ and $6.5 \%$ reduction of $\mathrm{HbA} 1 \mathrm{c}$ level at 1 year after islet transplantation. The median hemoglobin $\mathrm{A} 1 \mathrm{c}(\mathrm{HbA} 1 \mathrm{c})$ level was ameliorated at 1 year compared with before transplant $(6.0 \%$ vs. $8.1 \%)$. Furthermore, this protocol preserved the kidney allograft function for three years after islet transplantation [2]. The second clinical trial transplanted allogeneic pancreatic islet in type $1 \mathrm{DM}$ patients complicated by severe hypoglycemia with normal renal function (CIT-07). This study demonstrated that $87.5 \%$ and $71 \%$ of patients achieved an $\mathrm{HbA} 1 \mathrm{c}$ of $7.0 \%$ or less and prevented severe hypoglycemic events at 1 and 2 years, respectively, after the first transplantation [3]. To date, islet transplantation has been widely recognized as one of the standard therapies for type 1 DM worldwide.

In contrast, the transplant efficacy of islet transplantation is not superior to that of pancreas organ transplantation, a similar transplant therapy. Pancreas organ transplantation is a major surgery that is characterized by arterial/venous reconstruction into the right external iliac artery/vein with pancreatic drainage route using the bladder or ileum [4]. The pancreatic organ transplantation gives good therapeutic outcomes. Indeed, the graft survival rates (i.e., insulin independent rate) are almost $85 \%$ at one year and $>60 \%$ at five years [5], while insulin independent rate at five years was $39 \%$ in islet transplantation [6]. The transplantation of the pancreas can be safely performed. However, this procedure is more invasive compared to islet transplantation, which is an outpatient procedure. An annual report by the Collaborative Islet Transplant Registry indicated that transplantation of a higher volume of islets $(>10,450$ islet equivalents per body weight $[\mathrm{kg}]$ ) results in successful prevention of severe hypoglycemic events in more than $80 \%$ of the recipients and restoration of the $\mathrm{HbA1c}$ level in more than $60 \%$ in both islet alone and islet after kidney transplantation for 5 years after transplantation (http://www.citregistry.org/). This means several (generally $>2$ ) islet transplantations are often needed, whereas only one transplantation enables the achievement of good endocrine function in pancreas transplantation. There are various factors, including lack of revascularization and ischemia [7, 8], innate inflammation [9], or autoimmunity [10], that affect the transplant outcome of islet transplantation. Among these factors, the impairment of the extracellular matrix (ECM) in the islet is a major reason for the prevention of islet engraftment. ECM is an extracellular component that plays a role as a scaffold that contributes to the formation of tissues and organs. Conversely, ECM regulates cell-to-cell interactions via the activation of various growth factors and 
cytokines [11]. The islet is composed of endocrine cells aggregated by ECM, like other tissues and organs. The breakdown of islet ECM by an enzyme is essential for the isolation of pancreatic islets from the donor pancreas. However, this leads to the destruction of islets and, as a consequence, may reduce islet dysfunction and survival.

ECM in islets comprises two macromolecules: glycosaminoglycans and fibrous proteins [11, 12]. Glycosaminoglycans are long, linear polysaccharides with a high molecular weight composed of repeating disaccharide units. Sulfated glycosaminoglycans are attached to a core protein at specific sites and form a compound known as proteoglycan. Proteoglycans are located in the interstitial tissues or the cellular membrane and provide hydrophilic conditions and interaction between the ligand and receptor via signaling molecules. There are several subtypes of glycosaminoglycans, including heparan sulfate, chondroitin sulfate, dermatan sulfate, and keratan sulfate [13]. Conversely, fibrous proteins, including collagen, elastin, fibronectin, and laminin, provide structural and functional benefits to cells, including islets [11]. Among them, we focus on collagen because it is not only a representative component of ECM but also its characteristics may affect the therapeutic outcome of islet transplantation. In this study, we review the importance of collagen in islet transplantation.

\section{Importance of Collagen in Islet Transplantation}

\subsection{Overview}

Collagen occupies approximately $30 \%$ of proteins in the human body $[11,14]$. The peptide chain of collagen comprises three repeating peptide triplets of glycine, amino acid $X$, and amino acid $Y$. Proline and hydroxyproline are often positioned in $X$ and $Y$, respectively. The three peptide chains, known as $\alpha$ chains, helically combine, and form collagen [14]. Presently, 28 different types of collagen are known and numbered from I to XXVIII [14]. Among them, collagens I, II, III, IV, and $\checkmark$ have been identified as common in the human body [15]. Collagen $I$ is the most abundant collagen and is a major component of the skin (>90\% of the mass), tendon, muscle, and bone [16, 17]. Collagen II is a major component of cartilage [18], collagen III is a major component of reticular fiber and commonly coexists with collagen I $[11,17]$, and collagen $V$ has primarily been detected in the cellular surface, hair, and placenta [11]. Although collagens I, II, III, V, and XI are classified as fibrillar collagen or fibril-forming collagen [17], collagen IV is categorized as nonfibrillar collagen. This is the most pivotal structural component of the basement membrane [11, 17]. Collagen $\mathrm{VI}$ is also classified as non-fibrillar collagen and comprises three different $\alpha$ chains [17]. There are two main reasons why collagen is important in islet transplantation, namely, as a target of pancreatic digestion for islet isolation and as a supporter of the endocrine function of islets.

\subsection{The Role of Collagen in Islet Transplantation: Target of Pancreatic Digestion for Islet Isolation}

As previously mentioned, collagen is a major target of enzymatic digestion for islet isolation. It is critical to digest collagen of peri-islet effectively and not to damage islets by digestion of intraislet collagen, leading to the acquisition of a large volume of islets with keeping original endocrine function from the donor pancreas [19]. Therefore, understanding the distribution of collagen in 
the pancreas is necessary. Some groups have previously elucidated that the regulation of collagenase blend might affect the acquired volume of islets in islet isolation [20,21].

Table 1 shows the distribution of collagen in the pancreas and islets. The distribution varies according to the species. In pigs, collagens I, III, and IV are expressed in peri-islet, and the expression level is higher in older pigs than that in younger pigs [22]. Hughes et al. revealed that collagen $\mathrm{VI}$ was abundant in the interlobular and intralobular of acinar cells, compared with collagens I, IV, and V in juvenile and adult pigs. Furthermore, collagens I and VI are prominently detected in peri-islet, especially collagen VI [23]. Similar results were reported by Van Deijnen et al., who showed that collagen I was weakly expressed in peri-islet and in the lobar, lobular, and acinar septa and that collagen $\mathrm{V}$ also reacted weakly in the lobar and lobular septa [24]. Similar findings were also shown by Vigier et al., who found that the expression of collagen in pig pancreas was weaker in IV and V than in I, III, and VI [25]. Conversely, Goto et al. revealed the importance of collagen $V$ digestion using collagenase $G$ (collagenase I) for the success of porcine islet transplantation [26].

Table 1 Distribution of collagen in the pancreas and islet.

\begin{tabular}{|c|c|c|c|}
\hline Type of collagen & $\begin{array}{l}\text { Author (year), } \\
\text { Reference }\end{array}$ & Specimen & Detailed results \\
\hline I, II, III, IV, V & $\begin{array}{c}\text { Meier } \\
\text { (2020), [27] }\end{array}$ & Human & $\begin{array}{l}\text { Evaluated the correlation between the degree of } \\
\text { collagen digestion and acquired human islets } \\
\text { volume }\end{array}$ \\
\hline $\mathrm{I}, \mathrm{IV}, \mathrm{VI}$ & $\begin{array}{l}\text { Spiers } \\
\text { (2019), [28] }\end{array}$ & Human & $\begin{array}{l}\text { Evaluated the profiles of ECMs in human } \\
\text { pancreatic tissue for developing the donor- } \\
\text { specific collagenase }\end{array}$ \\
\hline IV & $\begin{array}{l}\text { Spiers } \\
\text { (2018), [29] }\end{array}$ & Human & $\begin{array}{l}\text { Assessment of collagenase for digestion of } \\
\text { collagen IV and laminin in the human pancreas }\end{array}$ \\
\hline IV & $\begin{array}{l}\text { Cross } \\
(2017),[30]\end{array}$ & Human & $\begin{array}{l}\text { Collagen IV and laminin presented in peri-islet in } \\
\text { humans }\end{array}$ \\
\hline VI & $\begin{array}{l}\text { Cross } \\
(2006),[19]\end{array}$ & Human & $\begin{array}{l}\text { Collagenase penetrates the islet by the current } \\
\text { techniques and led to low islet yields }\end{array}$ \\
\hline VI, I, IV, V & $\begin{array}{l}\text { Hughes } \\
\text { (2006), [31] }\end{array}$ & Human & $\begin{array}{l}\text { Collagens IV, V, and VI were present throughout } \\
\text { the human islet-exocrine interface, whereas } \\
\text { collagen I was seen at more variable sites } \\
\text { The mean peri-islet collagen VI proportion was } \\
\text { significantly greater than that of collagen I or IV }\end{array}$ \\
\hline XVIII & $\begin{array}{c}\text { Choong } \\
\text { (2015), [32] }\end{array}$ & Mouse & Collagen XVIII was stained in mouse islets \\
\hline
\end{tabular}




\begin{tabular}{|c|c|c|c|}
\hline IV & $\begin{array}{l}\text { Irving-Rodgers } \\
\text { (2014), [33] }\end{array}$ & Mouse & $\begin{array}{l}\text { Mouse islet basement membrane, comprising } \\
\text { collagen IV and other ECMs, including laminin, } \\
\text { was completely lost during islet isolation }\end{array}$ \\
\hline V & $\begin{array}{l}\text { Shima } \\
\text { (2016), [26] }\end{array}$ & Pig & $\begin{array}{l}\text { Collagen } \mathrm{V} \text { is a target for collagenase } \mathrm{G} \text {, whereas } \\
\text { collagens I and III are targets for collagenase } \mathrm{H} \\
\text { (porcine islet isolation) }\end{array}$ \\
\hline V, III, I & $\begin{array}{l}\text { Miyazaki } \\
\text { (2019), [34] }\end{array}$ & Rat & $\begin{array}{l}\text { Collagens III and V were crucial for islet isolation, } \\
\text { and the population was different from the strains } \\
\text { of rat }\end{array}$ \\
\hline I, III & $\begin{array}{l}\text { Fujio } \\
\text { (2014), [35] }\end{array}$ & Rat & Collagenase $\mathrm{H}$ reacted to collagens I and III \\
\hline IV, V & $\begin{array}{l}\text { Vigier } \\
\text { (2017), [25] }\end{array}$ & $\begin{array}{l}\text { Mouse, } \\
\text { pig }\end{array}$ & $\begin{array}{l}\text { Collagens IV and } V \text { were stained peri- and intra- } \\
\text { islet in mouse }\end{array}$ \\
\hline I, III, V & $\begin{array}{l}\text { Van Deijnen } \\
(1994),[24]\end{array}$ & $\begin{array}{l}\text { Human, } \\
\text { pig, dog, } \\
\text { rat }\end{array}$ & $\begin{array}{l}\text { Collagen I was expressed in peri-islet and in the } \\
\text { lobar, lobular, and acinar septa weakly in pigs and } \\
\text { dogs and moderately in rats and humans } \\
\text { Collagen III is well developed on the lobar and } \\
\text { acinar septa in rats and dogs. The peri-islet } \\
\text { displays weakly in rats, dogs, and humans and } \\
\text { very weakly in pigs } \\
\text { Collagen V reacts moderately in rats, dogs, and } \\
\text { humans and weakly in pigs in the lobar and } \\
\text { lobular septa }\end{array}$ \\
\hline
\end{tabular}

It has been accepted that the distribution of pancreatic collagen in humans is similar to that in pigs. Hughes et al. revealed that collagens IV, V, and VI were distributed in the islet-exocrine interface and that the distribution of collagen I was widely observed. Particularly, peri-islet collagen VI was strongly expressed compared with collagens I and IV, as in pigs [28, 31]. They also certified that collagenase (Liberase HI; Roche Applied Science, Indianapolis, IN; Collagenase NB1 and neutral protease NB; Serva Electrophoresis, Heidelberg, Germany) digested collagen VI in not only exocrine tissues but also in peri- and intra-islets and caused damage to islets [19]. Furthermore, they showed that collagen IV was seen in the peri-islet basement membrane (periislet capsule) and was digested by collagenase [30]. It was digested more effectively using the blend of collagenase and neutral protease compared with single usage (collagenase or neutral protease) [29].

Regarding rodents, Irving-Rodgers et al. showed that collagen IV located in the peri- and intraislets was digested by the isolation process and recovered after engraftment in mice [33]. Vigier et al. also showed that collagens IV and V were seen around mouse islets [25]. Choong et al. revealed that collagen XVIII, as rare collagen, was strongly expressed in mouse islets [32]. Goto's group revealed that collagens I and III were located in the exocrine tissues of rat, especially collagen III, and that collagenase $\mathrm{H}$ (collagenase II) reacted to collagens I and III compared with collagenase $\mathrm{G}$ 
(collagenase I) [35]. Later, they revealed that the distribution between collagens I and III depends on the difference in rat strains [34].

In summary, there are some varieties in the distribution of the types of collagen among species. We consider that the understanding of the distribution is important to select suitable collagenase and acquire more islets with good qualities in islet isolation.

\subsection{The Role of Collagen in Islet Transplantation: Supporter for the Improvement of the Endocrine Function of Islets}

Table 2 summarizes the important roles of collagen in islet transplantation regarding the improvement of the endocrine function of islets. Many studies have revealed that collagen, like laminin and fibronectin, contributed to the improvement of the viability of $\beta$ cells, prevented apoptosis of $\beta$ cells, and improved glucose-stimulated insulin secretion of $\beta$ cells with the expression of insulin-associated genes, especially in collagens I and IV [36-53].

Table 2 The roles of collagen in islet transplantation regarding the endocrine function.

\begin{tabular}{|c|c|c|c|}
\hline $\begin{array}{l}\text { Type of } \\
\text { collagen }\end{array}$ & $\begin{array}{c}\text { Author } \\
\text { (year), } \\
\text { Reference }\end{array}$ & $\begin{array}{l}\text { Role in islet } \\
\text { transplantation }\end{array}$ & Detailed results \\
\hline VI & $\begin{array}{c}\text { Wang } \\
(2020),[36]\end{array}$ & $\begin{array}{l}\text { Improved } \\
\text { viability, insulin- } \\
\text { releasing } \\
\text { function, and } \\
\text { reduced islet } \\
\text { immunogenicity }\end{array}$ & $\begin{array}{l}\text { Rat islets cultured with decellularized 3-D } \\
\text { ECM improved the survival, insulin content, } \\
\text { and glucose-stimulated insulin secretion } \\
\text { The ECM restored basement membrane- } \\
\text { related collagen VI associated with an } \\
\text { attenuation in islet immunogenicity }\end{array}$ \\
\hline IV & $\begin{array}{l}\text { Hadavi } \\
\text { (2019), [37] }\end{array}$ & $\begin{array}{l}\text { Improved } \\
\text { insulin-releasing } \\
\text { function }\end{array}$ & $\begin{array}{l}\text { Collagen IV and laminin scaffolds improved } \\
\text { the endocrine function of human islets }\end{array}$ \\
\hline IV & $\begin{array}{c}\text { Hadavi } \\
\text { (2018), [38] }\end{array}$ & $\begin{array}{l}\text { Improved } \\
\text { insulin-releasing } \\
\text { function }\end{array}$ & $\begin{array}{l}\text { Fibronectin and collagen IV improved insulin } \\
\text { secretion } \beta \text { cells }\end{array}$ \\
\hline III & $\begin{array}{l}\text { Olaniru } \\
\text { (2018), [39] }\end{array}$ & $\begin{array}{c}\text { Improved } \\
\text { viability and } \\
\text { insulin-releasing } \\
\text { function }\end{array}$ & $\begin{array}{l}\text { Collagen III prevented cytokine-induced } \\
\text { apoptosis and preserved insulin secretion } \\
\text { function in human islets }\end{array}$ \\
\hline I & $\begin{array}{l}\text { Stephens } \\
\text { (2018), [40] }\end{array}$ & $\begin{array}{c}\text { Improved } \\
\text { viability and } \\
\text { insulin-releasing } \\
\text { function }\end{array}$ & $\begin{array}{l}\text { Mouse islets encapsulated with collagen I } \\
\text { improved the viability and insulin secretion } \\
\text { Succeeded subcutaneous islet transplantation }\end{array}$ \\
\hline $\mathrm{I}, \mathrm{IV}$ & $\begin{array}{l}\text { Nakashima } \\
\text { (2018), [54] }\end{array}$ & $\begin{array}{l}\text { Improved } \\
\text { adhesive ability }\end{array}$ & $\begin{array}{l}\text { The adhesive ability to fibronectin was better } \\
\text { than other ECMs for porcine exocrine tissues }\end{array}$ \\
\hline VI & $\begin{array}{l}\text { Llacua } \\
\text { (2018), [41] }\end{array}$ & $\begin{array}{l}\text { Improved } \\
\text { viability and }\end{array}$ & $\begin{array}{l}\text { Collagen VI improved the viability and insulin- } \\
\text { releasing function of encapsulated human }\end{array}$ \\
\hline
\end{tabular}




\begin{tabular}{|c|c|c|c|}
\hline & & $\begin{array}{l}\text { insulin-releasing } \\
\text { function }\end{array}$ & islets \\
\hline IV & $\begin{array}{l}\text { Llacua } \\
\text { (2018), [42] }\end{array}$ & $\begin{array}{l}\text { Improved islet } \\
\text { survival }\end{array}$ & $\begin{array}{l}\text { Survival including reductions of necrosis and } \\
\text { apoptosis of islets encapsulated with collagen } \\
\text { IV and laminin }\end{array}$ \\
\hline 1 & $\begin{array}{c}\text { Forget } \\
\text { (2017), [43] }\end{array}$ & $\begin{array}{l}\text { Improved islet } \\
\text { survival }\end{array}$ & $\begin{array}{l}\text { Improved cultured islet survival in the IGF-2 } \\
\text { coated porous collagen microwells }\end{array}$ \\
\hline IV, I & $\begin{array}{l}\text { Llacua } \\
\text { (2016), [44] }\end{array}$ & $\begin{array}{l}\text { Improved } \\
\text { insulin-releasing } \\
\text { function }\end{array}$ & $\begin{array}{l}\text { Collagen IV improved the insulin-releasing } \\
\text { function of human islets, whereas there was } \\
\text { no effect in collagen I }\end{array}$ \\
\hline IV & $\begin{array}{l}\text { Liu } \\
\text { (2015), [45] }\end{array}$ & $\begin{array}{l}\text { Improved } \\
\text { viability and } \\
\text { insulin-releasing } \\
\text { function }\end{array}$ & $\begin{array}{l}\text { Collagen IV and fibronectin enhanced insulin } \\
\text { secretion and expression of } \beta \text { cell-associated } \\
\text { genes via the integrin/ focal adhesion } \\
\text { kinase/extracellular signal-regulated kinase } \\
\text { pathway }\end{array}$ \\
\hline IV & $\begin{array}{c}\text { Yap } \\
\text { (2013), [46] }\end{array}$ & $\begin{array}{l}\text { Improved } \\
\text { viability and } \\
\text { insulin-releasing } \\
\text { function }\end{array}$ & $\begin{array}{l}\text { Collagen IV-modified scaffold promoted islet } \\
\text { cell viability that enhanced insulin secretion }\end{array}$ \\
\hline IV & $\begin{array}{c}\text { Beenken- } \\
\text { Rothkopf } \\
\text { (2013), [47] }\end{array}$ & $\begin{array}{l}\text { Improved } \\
\text { insulin-releasing } \\
\text { function }\end{array}$ & $\begin{array}{l}\text { Encapsulated } \beta \text { cell line improved the insulin- } \\
\text { releasing function under the presence of } \\
\text { collagen IV, fibronectin, or laminin }\end{array}$ \\
\hline IV & $\begin{array}{l}\text { Gibly } \\
\text { (2013), [48] }\end{array}$ & $\begin{array}{l}\text { Improved } \\
\text { viability and } \\
\text { insulin-releasing } \\
\text { function }\end{array}$ & $\begin{array}{l}\text { Scaffolds using collagen IV supported } \\
\text { extrahepatic human islet transplantation with } \\
\text { the improvement of the engraftment and } \\
\text { function }\end{array}$ \\
\hline IV, I & $\begin{array}{c}\text { Sojoodi } \\
\text { (2013), [55] }\end{array}$ & N/A & $\begin{array}{l}\text { Laminin, but not collagens I, IV, or fibronectin, } \\
\text { induced comparable expression of the Ins1 } \\
\text { and Ins } 2 \text { genes in rat adult } \beta \text { cells }\end{array}$ \\
\hline IV & $\begin{array}{l}\text { Davis } \\
\text { (2012), [56] }\end{array}$ & $\begin{array}{l}\text { Improved } \\
\text { insulin-releasing } \\
\text { function }\end{array}$ & $\begin{array}{l}\text { Collagen IV and/or laminin-encapsulated } \\
\text { mouse islets with mesenchymal stem cells } \\
\text { improved the insulin-releasing function and } \\
\text { expression of insulin-associated genes }\end{array}$ \\
\hline I & $\begin{array}{c}\text { Jalili } \\
\text { (2011), [50] }\end{array}$ & $\begin{array}{l}\text { Improved } \\
\text { viability and } \\
\text { insulin-releasing } \\
\text { function }\end{array}$ & $\begin{array}{l}\text { A scaffold comprising collagen I and } \\
\text { fibroblasts improved the survival and insulin- } \\
\text { releasing function of mouse islets and } \\
\text { improved the long-term of islet isograft } \\
\text { function }\end{array}$ \\
\hline IV & $\begin{array}{l}\text { Salvay } \\
\text { (2008), [51] }\end{array}$ & $\begin{array}{l}\text { Improved } \\
\text { insulin-releasing } \\
\text { function }\end{array}$ & $\begin{array}{l}\text { Mice transplanted islets onto scaffolds with } \\
\text { collagen IV achieved euglycemia fastest }\end{array}$ \\
\hline
\end{tabular}




\begin{tabular}{|c|c|c|c|}
\hline IV & $\begin{array}{l}\text { Kaido } \\
\text { (2006), [57] }\end{array}$ & N/A & $\begin{array}{l}\text { Collagen IV induced a decline of insulin mRNA } \\
\text { and a significant loss of insulin content in } \\
\text { human fetal } \beta \text { cells }\end{array}$ \\
\hline IV, I & $\begin{array}{l}\text { Pinkse } \\
\text { (2006), [52] }\end{array}$ & $\begin{array}{l}\text { Improved islet } \\
\text { survival }\end{array}$ & $\begin{array}{l}\text { Islets that had been cultured on collagen IV } \\
\text { showed better islet survival than collagen I }\end{array}$ \\
\hline I & $\begin{array}{l}\text { Edamura } \\
\text { (2003), [32] }\end{array}$ & N/A & $\begin{array}{l}\text { The insulin-releasing function of cultured } \\
\text { porcine islets was seen with laminin but not } \\
\text { with collagen I }\end{array}$ \\
\hline I, IV & $\begin{array}{l}\text { Sakurai } \\
\text { (2003), [58] }\end{array}$ & $\begin{array}{l}\text { Promoted } \\
\text { angiogenesis }\end{array}$ & $\begin{array}{l}\text { Implantation of collagen I- or IV-coated } \\
\text { foreign body promoted neovascularization }\end{array}$ \\
\hline I, IV & $\begin{array}{l}\text { Nagata } \\
\text { (2001), [53] }\end{array}$ & $\begin{array}{l}\text { Improved } \\
\text { viability and } \\
\text { insulin-releasing } \\
\text { function }\end{array}$ & $\begin{array}{l}\text { Insulin secretion of cultured islets with } \\
\text { collagen I or a mixture of collagen I and IV was } \\
\text { improved }\end{array}$ \\
\hline I, IV & $\begin{array}{c}\text { Jiang } \\
\text { (1999), [59] }\end{array}$ & N/A & $\begin{array}{l}\text { Collagens I and IV inhibited } \beta \text { cell survival } \\
\text { Laminin contributed to the proliferation of } \beta \\
\text { cells }\end{array}$ \\
\hline
\end{tabular}

N/A: not applicable

Collagen IV is a major component of the peri- and intra-islet basement membrane [33]. The collagen works as a niche for transplanted islets and supports the improvement of insulin secretion [37, 46]. For example, Yap et al. evaluated the condition of islets seeded into polymer scaffold with ECM, including collagen IV, laminin, and fibronectin, and elucidated that collagen IV improved the insulin-releasing function and viability of $\beta$ cells compared with other ECMs and shortened the time to normoglycemia in islet transplantation [46]. Salvay et al. also revealed that islet transplantation with collagen IV-coated scaffold was superior to other ECMs such as fibronectin and laminin in controlling the blood glucose level [51]. Furthermore, BeenkenRothkopf et al. conducted a similar study using MIN6 $\beta$ cells embedded in polymer and showed that collagen IV improved the insulin-releasing function of the cells, the same as other ECMs such as laminin and fibronectin [47]. Other previous studies also revealed the contribution of collagen IV in greater insulin release of islets $[44,48,54,56,60]$, and the therapeutic effects were better than those of other ECMs [44]. Collagen IV also contributed to islet cell survival, prevention of apoptosis, and oxygen consumption rate of immunoisolating encapsulated islets [41, 42]. Immunoisolating encapsulation is a technology that protects the containing islets in polymers, such as alginate, by preventing the infiltration of immunocompetent cells and antibodies.

Collagen I, which is also localized within and around islets such as collagen IV [24], promoted islet cellular survival and differentiation and also improved the $\beta$ cell function [61-63]. For example, Stephens et al. conducted the encapsulation of isolated mouse islets using collagen I oligomer and demonstrated the improvement of viability and insulin secretion of the encapsulated islets, as well as successful subcutaneous islet transplantation in both syngeneic and allogeneic models [40]. A similar trial was conducted by Jalili et al., who used a scaffold comprising collagen I and mouse fibroblasts to improve the survival and insulin-releasing function of mouse islets and improve the long-term islet isograft function [50]. Nagata et al. also reported similar results using rat islets [53]. 
Conversely, some groups have indicated that neither collagen I nor IV contributed to the improvement in endocrine function [32, 55, 57, 59].

These benefits of collagen in endocrine function are provided via the activation of the intracellular signaling pathway activated by ligation between collagen and integrin (Figure 1) [61]. Integrin is a transmembrane receptor that includes 24 different types and is known as an adhesion factor that combines various ECMs such as collagen, laminin, and RGD (Arg-Gly-Asp) motif [11]. Integrin is a heterodimer comprising two polypeptide chains known as $\alpha$ and $\beta$ subunits. There are $18 \alpha$ and $8 \beta$ subunits known [64]. Previous studies have revealed that integrin receptors for collagen in islets contained $\beta 1$ subunit ( $\alpha 1 \beta 1, \alpha 2 \beta 1, \alpha 3 \beta 1, \alpha v \beta 1, \alpha 10 \beta 1$, and $\alpha 11 \beta 1)[14,57,60$, 65-69]. Integrin $\beta 1$ plays a pivotal role in the regulation of islet cell biology, survival, and function [70-72]. In other words, collagen contributes to the improvement of endocrine function via integrin $\beta 1$. For example, integrin $\alpha 3 \beta 1$ improves human $\beta$ cell survival [71] and insulin secretion of rat $\beta$ cell [72] by attaching ECMs. Integrin $\alpha v \beta 1$ promotes human $\beta$ cell adhesion [73], and integrin $\alpha 1 \beta 1$ also contributes to the adhesion, motility, and insulin secretion of human $\beta$ cell by binding to collagen IV [60]. Furthermore, collagen IV is localized to integrins $\alpha 3 \beta 1, \alpha 5 \beta 1$, and $\alpha 6 \beta 1$ during the development of the human fetal pancreas [67].

After binding collagen (especially collagen IV) and integrin $\beta 1$, the intracellular signaling pathways associated with focal adhesion kinase (FAK), which regulates cell proliferation, differentiation, and apoptosis, are activated (Figure 1). The activation of FAK promotes the two represented downstream signaling pathways: mitogen-activated protein kinase/extracellular signal-regulated kinase (ERK) and phosphoinositide 3-kinase/Akt pathways. Liu et al. evaluated the endocrine function of rat $\beta$ cell line encapsulated with their developed conditioned peptide containing fibronectin and collagen IV motif and the mechanism. They revealed that fibronectinand collagen IV-encapsulated cells improved their insulin-releasing function, and the proliferation and expressions of $\beta$ cell-associated genes (Ins1, MafA, and $P d x-1$ ) were enhanced in the cells. Furthermore, phosphorylated FAK and ERK were detected, but there was no enhancement of Akt protein in the encapsulated cells. The expression of integrin $\beta 1$ cyclin protein was also certified. They concluded that these improvements of endocrine function were caused by the activation of the FAK/ERK/cyclin signaling pathway via ligation between ECMs (including collagen) and integrin $\beta 1$ [45]. Other groups also showed similar results regarding the mechanism of improvement of endocrine function. Hammar et al. showed that the activation of the mitogen-activated protein kinase/ERK pathway by the activation of FAK via integrin $\beta 1$ improved the survival of rat isolated $\beta$ cells [74]. Saleem et al. demonstrated that the activation of FAK/ERK by integrin $\beta 1$ promoted differentiation and prolonged the survival of human fetal pancreatic islet cells [62]. Conversely, it was elucidated that the activation of the FAK/phosphoinositide 3-kinase/Akt pathway via interaction between collagen and integrin inhibited the cleavage of caspase 3 in the MIN6 $\beta$ cell line cultured with collagen IV [75] and promoted the proliferation of $\beta$ cells $[76,77]$. 


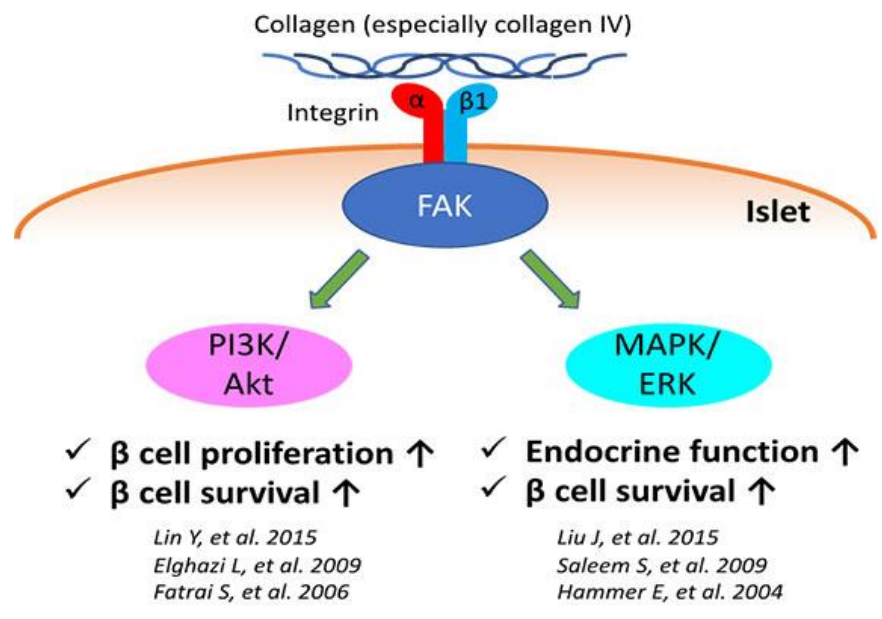

Figure 1 Interaction between collagen and integrin, and the resulting therapeutic effects.

\subsection{New strategy for Improving Islet Transplantation Using Collagen}

Some research groups have attempted to show the possibility of collagen for the improvement of islet transplantation (Table 3). One strategy is to adopt a scaffold for developing new islet cells with additional values. Carvalho Oliverira et al. attempted to form swine islets with low immunogenicity by culturing single islet cells silenced by swine leucocyte antigen using collagen VI. Xenogeneic $T$ cell immune responses were significantly prevented in swine leucocyte antigensilenced islet cells, and the clusters constructed of the silenced cells harbored similar levels in the expression of the insulin gene and insulin-releasing function compared with control islets [78]. This strategy may contribute to the resolution of limited donor supplies by using xenogeneic islets with low immunogenicity. Yang et al. also attempted to form islet-like clusters from murine $\beta$ cell line by culturing in collagen IV-treated culture dish. They form 100-150 $\mu \mathrm{m}$-sized pseudoislets with high survival rate and good glucose-stimulated insulin secretion and revealed the improvement of the endocrine function of diabetic animals by transplantation [79]. Recently, Kogawa, Mochizuki, and colleagues showed that the encapsulation technique using human recombinant collagen I (Cellsaic) with mesenchymal stem cells contributed to the improvement of transplant efficacy of islet xenotransplantation by promoting angiogenesis [80, 81].

Another strategy is the adoption of a scaffold for differentiation into $\beta$ cells from pluripotent or somatic stem cells. This also aims to clear the problem of limited donor supplies by forming new islets. Regarding this strategy, collagens I and IV contribute to supporting the differentiation from mesenchymal stem cells [82] and pancreatic precursor cells [83, 84].

Collagen can also be used for making bioengineered islets. For example, Gibly et al. conducted the transplantation of human islets seeded into bioscaffold using collagen IV to diabetic immunodeficient mice and succeeded in achieving normoglycemia for more than four months [48]. Hiscox et al. certified the improvement of insulin-releasing function of subcutaneously transplanted islets covered by collagen gel with prevascular treatment [85]. Furthermore, it is believed that the combination of collagen with other biomaterials that have the ability of immune isolation and growth factors can be a valuable trial for the success of islet transplantation [61]. 
Table 3 Other possibilities of collagen.

\begin{tabular}{|c|c|c|c|}
\hline $\begin{array}{l}\text { Type of } \\
\text { collagen }\end{array}$ & $\begin{array}{l}\text { Author (year), } \\
\text { Reference }\end{array}$ & $\begin{array}{l}\text { Role of } \\
\text { collagen }\end{array}$ & Detailed results \\
\hline I & $\begin{array}{l}\text { Kogawa, } \\
\text { Mochizuki } \\
(2020),[80,81]\end{array}$ & $\begin{array}{l}\text { Material for } \\
\text { bioengineered } \\
\text { islets }\end{array}$ & $\begin{array}{l}\text { The encapsulation technique using human } \\
\text { recombinant collagen I (Cellsaic) with } \\
\text { mesenchymal stem cells contributed to the } \\
\text { improvement of transplant efficacy of islet } \\
\text { xenotransplantation (rat to mouse) by promotion } \\
\text { of angiogenesis. }\end{array}$ \\
\hline VI & $\begin{array}{l}\text { Carvalho } \\
\text { Oliverira } \\
\text { (2020), [78] }\end{array}$ & $\begin{array}{l}\text { Material for } \\
\text { the formation } \\
\text { of newly islets }\end{array}$ & $\begin{array}{l}\text { Porcine single islet cells silenced by swine } \\
\text { leucocyte antigen were cultured with collagen VI } \\
\text { Formed islets acquired low immunogenicity }\end{array}$ \\
\hline IV & $\begin{array}{l}\text { Pokrywczynska } \\
\text { (2015), [82] }\end{array}$ & $\begin{array}{l}\text { Promoted } \beta \\
\text { cell } \\
\text { differentiation }\end{array}$ & $\begin{array}{l}\text { Collagen IV contributed to the differentiation of } \\
\text { rat mesenchymal stem cells into islet-like cells }\end{array}$ \\
\hline IV & $\begin{array}{l}\text { Yang } \\
\text { (2013), [79] }\end{array}$ & $\begin{array}{l}\text { Material for } \\
\text { the formation } \\
\text { of newly islets }\end{array}$ & $\begin{array}{l}\text { Formed pseudoislets from } \beta \text { cell line with } \\
\text { improved insulin-releasing function using collagen } \\
\text { IV-treated culture dish }\end{array}$ \\
\hline I & $\begin{array}{c}\text { Vernon } \\
\text { (2012), [86] }\end{array}$ & $\begin{array}{l}\text { Material for } \\
\text { bioengineered } \\
\text { islets }\end{array}$ & $\begin{array}{l}\text { Used for bioengineered islets as a cushion aiming } \\
\text { to prevent physical damage of the islets }\end{array}$ \\
\hline I & $\begin{array}{c}\text { Mason } \\
\text { (2009), [83] }\end{array}$ & $\begin{array}{l}\text { Promoted } \beta \\
\text { cell } \\
\text { differentiation }\end{array}$ & $\begin{array}{l}\text { Hydrogels containing collagen I promoted } \\
\text { differentiation of a glucose-responsive } \beta \text { cell } \\
\text { population from dissociated precursor cells of rat }\end{array}$ \\
\hline IV & $\begin{array}{c}\text { Cirulli } \\
\text { (2000), [84] }\end{array}$ & $\begin{array}{l}\text { Development } \\
\text { of endocrine } \\
\text { progenitor cells }\end{array}$ & $\begin{array}{l}\text { Integrin } \alpha \mathrm{v} \beta 3 \text { and } \alpha \mathrm{v} \beta 5 \text { contributed to the } \\
\text { development of human pancreatic endocrine cells } \\
\text { by binding to collagen IV and fibronectin }\end{array}$ \\
\hline
\end{tabular}

\section{Conclusions}

We believe that the study on collagen will support the improvement of islet transplantation. For example, knowledge on the distribution of collagen in the pancreas is essential to select preferred collagenase, which digests pancreatic tissue without impairing islets, for islet isolation. This will lead not only to the increasing volume of acquired islets with good quality but also for designing suitable collagenase blends per pancreas for custom-made islet isolation. Furthermore, the benefit of collagen in improving the endocrine function of $\beta$ cells can be adopted for the development of bioengineering islets using collagen with good reactivity to glucose change, producing a suitable volume of insulin and resistance to apoptosis in transplantation. These innovations using collagen may provide a further evolution of this treatment. 


\section{Acknowledgments}

We thank ENAGO (www.enago.jp) for English proofreading service.

\section{Author Contributions}

Naoaki Sakata planned the theme and described the first draft of this review. Gumpei Yoshimatsu revised the manuscript. Shohta Koadama revised the final version of this review.

\section{Funding}

This study was funded by a Grant-in-Aid for Scientific Research (C) (19K09839, NS) from the Ministry of Education, Culture, Sports, Science and Technology of Japan.

\section{Competing Interests}

The authors declare that no competing interests exist.

\section{References}

1. Shapiro AM, Lakey JR, Ryan EA, Korbutt GS, Toth E, Warnock GL, et al. Islet transplantation in seven patients with type 1 diabetes mellitus using a glucocorticoid-free immunosuppressive regimen. N Engl J Med. 2000; 343: 230-238.

2. Markmann JF, Rickels MR, Eggerman TL, Bridges ND, Lafontant DE, Qidwai J, et al. Phase 3 trial of human islet-after-kidney transplantation in type 1 diabetes. Am J Transplant. 2020. DOI: 10.1111/ajt.16174

3. Hering BJ, Clarke WR, Bridges ND, Eggerman TL, Alejandro R, Bellin MD, et al. Phase 3 trial of transplantation of human islets in type 1 diabetes complicated by severe hypoglycemia. Diabetes Care. 2016; 39: 1230-1240.

4. Monroy-Cuadros M, Salazar A, Yilmaz S, McLaughlin K. Bladder vs enteric drainage in simultaneous pancreas-kidney transplantation. Nephrol Dial Transplant. 2006; 21: 483-487.

5. Gruessner RW, Gruessner AC. The current state of pancreas transplantation. Nat Rev Endocrinol. 2013; 9: 555-562.

6. Vantyghem MC, Chetboun M, Gmyr V, Jannin A, Espiard S, Le Mapihan K, et al. Ten-year outcome of islet alone or islet after kidney transplantation in type 1 diabetes: A prospective parallel-arm cohort study. Diabetes Care. 2019; 42: 2042-2049.

7. Smink AM, Li S, Hertsig DT, de Haan BJ, Schwab L, van Apeldoorn AA, et al. The efficacy of a prevascularized, retrievable poly (D, L, -lactide-co-epsilon-caprolactone) subcutaneous scaffold as transplantation site for pancreatic Islets. Transplantation. 2017; 101: e112-e119.

8. Sakata N, Hayes P, Tan A, Chan NK, Mace J, Peverini R, et al. MRI assessment of ischemic liver after intraportal islet transplantation. Transplantation. 2009; 87: 825-830.

9. Kourtzelis I, Kotlabova K, Lim JH, Mitroulis I, Ferreira A, Chen LS, et al. Developmental endothelial locus-1 modulates platelet-monocyte interactions and instant blood-mediated inflammatory reaction in islet transplantation. Thromb Haemost. 2016; 115: 781-788. 
10. Piemonti L, Everly MJ, Maffi P, Scavini M, Poli F, Nano R, et al. Alloantibody and autoantibody monitoring predicts islet transplantation outcome in human type 1 diabetes. Diabetes. 2013; 62: 1656-1664.

11. Kuehn C, Vermette P, Fülöp T. Cross talk between the extracellular matrix and the immune system in the context of endocrine pancreatic islet transplantation. A review article. Pathol Biol. 2014; 62: 67-78.

12. Schaefer L, Schaefer RM. Proteoglycans: From structural compounds to signaling molecules. Cell Tissue Res. 2010; 339: 237-246.

13. Smink AM, de Vos $P$. Therapeutic strategies for modulating the extracellular matrix to improve pancreatic islet function and survival after transplantation. Curr Diab Rep. 2018; 18: 39.

14. Gordon MK, Hahn RA. Collagens. Cell Tissue Res. 2010; 339: 247-257.

15. Di Lullo GA, Sweeney SM, Korkko J, Ala-Kokko L, San Antonio JD. Mapping the ligand-binding sites and disease-associated mutations on the most abundant protein in the human, type I collagen. J Biol Chem. 2002; 277: 4223-4231.

16. Smith K, Rennie MJ. New approaches and recent results concerning human-tissue collagen synthesis. Curr Opin Clin Nutr Metab Care. 2007; 10: 582-590.

17. Gelse K, Poschl E, Aigner T. Collagens-structure, function, and biosynthesis. Adv Drug Deliv Rev. 2003; 55: 1531-1546.

18. Bakilan F, Armagan O, Ozgen M, Tascioglu F, Bolluk O, Alatas O. Effects of native type II collagen treatment on Knee osteoarthritis: A randomized controlled trial. Eurasian J Med. 2016; 48: 95-101.

19. Cross SE, Hughes SJ, Partridge CJ, Clark A, Gray DW, Johnson PR. Collagenase penetrates human pancreatic islets following standard intraductal administration. Transplantation. 2008; 86: 907-911.

20. Balamurugan AN, Green ML, Breite AG, Loganathan G, Wilhelm JJ, Tweed B, et al. Identifying effective enzyme activity targets for recombinant class I and class II collagenase for successful human islet isolation. Transplant Direct. 2016; 2: e54.

21. Brandhorst $H$, Brandhorst $D$, Hesse $F$, Ambrosius $D$, Brendel $M$, Kawakami $Y$, et al. Successful human islet isolation utilizing recombinant collagenase. Diabetes. 2003; 52: 1143-1146.

22. Meyer T, Czub S, Chodnewska I, Beutner U, Hamelmann W, Klock G, et al. Expression pattern of extracellular matrix proteins in the pancreas of various domestic pig breeds, the Goettingen Minipig and the Wild Boar. Ann Transplant. 1997; 2: 17-26.

23. White SA, Hughes DP, Contractor $\mathrm{HH}$, London NJ. An investigation into the distribution of different collagen types within adult and juvenile porcine pancreata. J Mol Med. 1999; 77: 7982.

24. Van Deijnen JH, Van Suylichem PT, Wolters GH, Van Schilfgaarde R. Distribution of collagens type I, type III and type V in the pancreas of rat, dog, pig and man. Cell Tissue Res. 1994; 277: 115-121.

25. Vigier S, Gagnon H, Bourgade K, Klarskov K, Fulop T, Vermette P. Composition and organization of the pancreatic extracellular matrix by combined methods of immunohistochemistry, proteomics and scanning electron microscopy. Curr Res Transl Med. 2017; 65: 31-39. 
26. Shima $H$, Inagaki $A$, Imura $T$, Yamagata $Y$, Watanabe $K$, Igarashi $K$, et al. Collagen $V$ is a potential substrate for clostridial collagenase $G$ in pancreatic islet isolation. J Diabetes Res. 2016; 2016: 4396756.

27. Meier RP, Meyer J, Muller YD, Szot GL, Bédat B, Andres A, et al. Pancreas collagen digestion during islet of Langerhans isolation. Transpl Int. 2020. DOI: $10.1111 /$ tri.13725

28. Spiers RM, Marzi J, Brauchle EM, Cross SE, Vaughan RH, Bateman PA, et al. Donor age significantly influences the Raman spectroscopic biomolecular fingerprint of human pancreatic extracellular matrix proteins following collagenase-based digestion. Acta Biomater. 2019; 99: 269-283.

29. Spiers RM, Cross SE, Brown HL, Bateman PA, Vaughan RH, Hughes SJ, et al. Development of a simple in vitro assay to assess digestion of the extracellular matrix of the human pancreas by collagenase enzyme blends. Cell Transplant. 2018; 27: 1039-1046.

30. Cross SE, Vaughan RH, Willcox AJ, McBride AJ, Abraham AA, Han B, et al. Key matrix proteins within the pancreatic islet basement membrane are differentially digested during human islet isolation. Am J Transplant. 2017; 17: 451-461.

31. Hughes SJ, Clark A, McShane P, Contractor HH, Gray DW, Johnson PR. Characterisation of collagen VI within the islet-exocrine interface of the human pancreas: Implications for clinical islet isolation? Transplantation. 2006; 81: 423-426.

32. Edamura K, Nasu K, Iwami Y, Ogawa H, Sasaki N, Ohgawara H. Effect of adhesion or collagen molecules on cell attachment, insulin secretion, and glucose responsiveness in the cultured adult porcine endocrine pancreas: A preliminary study. Cell Transplant. 2003; 12: 439-446.

33. Irving-Rodgers HF, Choong FJ, Hummitzsch K, Parish CR, Rodgers RJ, Simeonovic CJ. Pancreatic islet basement membrane loss and remodeling after mouse islet isolation and transplantation: Impact for allograft rejection. Cell Transplant. 2014; 23: 59-72.

34. Miyazaki Y, Murayama K, Fathi I, Imura T, Yamagata Y, Watanabe K, et al. Strategy towards tailored donor tissue-specific pancreatic islet isolation. PLoS One. 2019; 14: e0216136.

35. Fujio A, Murayama K, Yamagata $Y$, Watanabe $K$, Imura T, Inagaki A, et al. Collagenase $H$ is crucial for isolation of rat pancreatic islets. Cell Transplant. 2014; 23: 1187-1198.

36. Wang H, Li S, Dai Q, Gonzalez A, Tran ON, Sun H, et al. Culture on a native bone marrowderived extracellular matrix restores the pancreatic islet basement membrane, preserves islet function, and attenuates islet immunogenicity. FASEB J. 2020; 34: 8044-8056.

37. Hadavi E, Leijten J, Engelse $M$, de Koning $E$, Jonkheijm $P$, Karperien $M$, et al. Microwell scaffolds using collagen-IV and laminin-111 lead to improved insulin secretion of human islets. Tissue Eng Part C Methods. 2019; 25: 71-81.

38. Hadavi E, Leijten J, Brinkmann J, Jonkheijm $P$, Karperien $M$, van Apeldoorn A. Fibronectin and collagen IV microcontact printing improves insulin secretion by INS1E cells. Tissue Eng Part C Methods. 2018; 24: 628-636.

39. Olaniru OE, Pingitore A, Giera S, Piao X, Castanera Gonzalez R, Jones PM, et al. The adhesion receptor GPR56 is activated by extracellular matrix collagen III to improve beta-cell function. Cell Mol Life Sci. 2018; 75: 4007-4019.

40. Stephens CH, Orr KS, Acton AJ, Tersey SA, Mirmira RG, Considine RV, et al. In situ type I oligomeric collagen macroencapsulation promotes islet longevity and function in vitro and in vivo. Am J Physiol Endocrinol Metab. 2018; 315: E650-E661. 
41. Llacua LA, Hoek A, de Haan BJ, de Vos P. Collagen type VI interaction improves human islet survival in immunoisolating microcapsules for treatment of diabetes. Islets. 2018; 10: 60-68.

42. Llacua LA, de Haan BJ, de Vos P. Laminin and collagen IV inclusion in immunoisolating microcapsules reduces cytokine-mediated cell death in human pancreatic islets. J Tissue Eng Regen Med. 2018; 12: 460-467.

43. Forget A, Waibel M, Rojas-Canales DM, Chen S, Kawazoe N, Harding FJ, et al. IGF-2 coated porous collagen microwells for the culture of pancreatic islets. J Mater Chem B. 2017; 5: 220225.

44. Llacua A, de Haan BJ, Smink SA, de Vos P. Extracellular matrix components supporting human islet function in alginate-based immunoprotective microcapsules for treatment of diabetes. J Biomed Mater Res A. 2016; 104: 1788-1796.

45. Liu J, Liu S, Chen Y, Zhao X, Lu Y, Cheng J. Functionalized self-assembling peptide improves INS-1 beta-cell function and proliferation via the integrin/FAK/ERK/cyclin pathway. Int J Nanomedicine. 2015; 10: 3519-3531.

46. Yap WT, Salvay DM, Silliman MA, Zhang X, Bannon ZG, Kaufman DB, et al. Collagen IVmodified scaffolds improve islet survival and function and reduce time to euglycemia. Tissue Eng Part A. 2013; 19: 2361-2372.

47. Beenken-Rothkopf LN, Karfeld-Sulzer LS, Davis NE, Forster R, Barron AE, Fontaine MJ. The incorporation of extracellular matrix proteins in protein polymer hydrogels to improve encapsulated beta-cell function. Ann Clin Lab Sci. 2013; 43: 111-121.

48. Gibly RF, Zhang X, Lowe WL, Shea LD. Porous scaffolds support extrahepatic human islet transplantation, engraftment, and function in mice. Cell Transplant. 2013; 22: 811-819.

49. Davis NE, Beenken-Rothkopf LN, Mirsoian A, Kojic N, Kaplan DL, Barron AE, et al. Enhanced function of pancreatic islets co-encapsulated with ECM proteins and me senchymal stromal cells in a silk hydrogel. Biomaterials. 2012; 33: 6691-6697.

50. Jalili RB, Moeen Rezakhanlou A, Hosseini-Tabatabaei A, Ao Z, Warnock GL, Ghahary A. Fibroblast populated collagen matrix promotes islet survival and reduces the number of islets required for diabetes reversal. J Cell Physiol. 2011; 226: 1813-1819.

51. Salvay DM, Rives CB, Zhang X, Chen F, Kaufman DB, Lowe WL, et al. Extracellular matrix protein-coated scaffolds promote the reversal of diabetes after extrahepatic islet transplantation. Transplantation. 2008; 85: 1456-1464.

52. Pinkse GG, Bouwman WP, Jiawan-Lalai R, Terpstra OT, Bruijn JA, de Heer E. Integrin signaling via RGD peptides and anti-beta1 antibodies confers resistance to apoptosis in islets of Langerhans. Diabetes. 2006; 55: 312-317.

53. Nagata N, Gu Y, Hori H, Balamurugan AN, Touma M, Kawakami Y, et al. Evaluation of insulin secretion of isolated rat islets cultured in extracellular matrix. Cell Transplant. 2001; 10: 447451.

54. Nakashima Y, Miyagi-Shiohira C, Kobayashi N, Saitoh I, Watanabe M, Noguchi H. Adhesion characteristics of porcine pancreatic islets and exocrine tissue to coating materials. Islets. 2018; 10: e1460294.

55. Sojoodi M, Farrokhi A, Moradmand A, Baharvand $H$. Enhanced maintenance of rat islets of Langerhans on laminin-coated electrospun nanofibrillar matrix in vitro. Cell Biol Int. 2013; 37: 370-379. 
56. Davis NE, Beenken-Rothkopf LN, Mirsoian A, Kojic N, Kaplan DL, Barron AE, et al. Enhanced function of pancreatic islets co-encapsulated with ECM proteins and mesenchymal stromal cells in a silk hydrogel. Biomaterials. 2012; 33: 6691-6697.

57. Kaido T, Yebra M, Cirulli V, Rhodes C, Diaferia G, Montgomery AM. Impact of defined matrix interactions on insulin production by cultured human beta-cells: Effect on insulin content, secretion, and gene transcription. Diabetes. 2006; 55: 2723-2729.

58. Sakurai T, Satake A, Nagata N, Gu Y, Hiura A, Doo-Hoon K, et al. The development of new immunoisolatory devices possessing the ability to induce neovascularization. Cell Transplant. 2003; 12: 527-535.

59. Jiang FX, Cram DS, DeAizpurua HJ, Harrison LC. Laminin-1 promotes differentiation of fetal mouse pancreatic beta-cells. Diabetes. 1999; 48: 722-730.

60. Kaido T, Yebra M, Cirulli V, Montgomery AM. Regulation of human beta-cell adhesion, motility, and insulin secretion by collagen IV and its receptor alpha1beta1. J Biol Chem. 2004; 279: 53762-53769.

61. Riopel M, Wang R. Collagen matrix support of pancreatic islet survival and function. Front Biosci. 2014; 19: 77-90.

62. Saleem S, Li J, Yee SP, Fellows GF, Goodyer CG, Wang R. Beta1 integrin/FAK/ERK signalling pathway is essential for human fetal islet cell differentiation and survival. J Pathol. 2009; 219: 182-192.

63. Lucas-Clerc C, Massart C, Campion JP, Launois B, Nicol M. Long-term culture of human pancreatic islets in an extracellular matrix: Morphological and metabolic effects. Mol Cell Endocrinol. 1993; 94: 9-20.

64. Hynes RO. Integrins: Bidirectional, allosteric signaling machines. Cell. 2002; 110: 673-687.

65. Cheng JY, Raghunath M, Whitelock J, Poole-Warren L. Matrix components and scaffolds for sustained islet function. Tissue Eng Part B Rev. 2011; 17: 235-247.

66. Kuhn K, Eble J. The structural bases of integrin-ligand interactions. Trends Cell Biol. 1994; 4: 256-261.

67. Wang R, Li J, Lyte K, Yashpal NK, Fellows F, Goodyer CG. Role for beta1 integrin and its associated alpha3, alpha5, and alpha6 subunits in development of the human fetal pancreas. Diabetes. 2005; 54: 2080-2089.

68. Wang RN, Paraskevas S, Rosenberg L. Characterization of integrin expression in islets isolated from hamster, canine, porcine, and human pancreas. J Histochem Cytochem. 1999; 47: 499506.

69. Llacua LA, Faas MM, de Vos P. Extracellular matrix molecules and their potential contribution to the function of transplanted pancreatic islets. Diabetologia. 2018; 61: 1261-1272.

70. Kantengwa S, Baetens D, Sadoul K, Buck CA, Halban PA, Rouiller DG. Identification and characterization of alpha 3 beta 1 integrin on primary and transformed rat islet cells. Exp Cell Res. 1997; 237: 394-402.

71. Ris F, Hammar E, Bosco D, Pilloud C, Maedler K, Donath MY, et al. Impact of integrin-matrix matching and inhibition of apoptosis on the survival of purified human beta-cells in vitro. Diabetologia. 2002; 45: 841-850.

72. Bosco D, Meda P, Halban PA, Rouiller DG. Importance of cell-matrix interactions in rat islet beta-cell secretion in vitro: Role of alpha6beta1 integrin. Diabetes. 2000; 49: 233-243. 
73. Kaido T, Perez B, Yebra M, Hill J, Cirulli V, Hayek A, et al. Alphav-integrin utilization in human beta-cell adhesion, spreading, and motility. J Biol Chem. 2004; 279: 17731-17737.

74. Hammar E, Parnaud G, Bosco D, Perriraz N, Maedler K, Donath M, et al. Extracellular matrix protects pancreatic beta-cells against apoptosis: Role of short- and long-term signaling pathways. Diabetes. 2004; 53: 2034-2041.

75. Lin Y, Sun Z. Antiaging gene klotho attenuates pancreatic beta-cell apoptosis in type 1 diabetes. Diabetes. 2015; 64: 4298-4311.

76. Fatrai S, Elghazi L, Balcazar N, Cras-Méneur C, Krits I, Kiyokawa H, et al. Akt induces beta-cell proliferation by regulating cyclin D1, cyclin D2, and p21 levels and cyclin-dependent kinase-4 activity. Diabetes. 2006; 55: 318-325.

77. Elghazi L, Bernal-Mizrachi E. Akt and PTEN: Beta-cell mass and pancreas plasticity. Trends Endocrinol Metab. 2009; 20: 243-251.

78. Carvalho Oliveira M, Valdivia E, Verboom M, Yuzefovych Y, Sake HJ, Pogozhykh O, et al. Generating low immunogenic pig pancreatic islet cell clusters for xenotransplantation. J Cell Mol Med. 2020; 24: 5070-5081.

79. Yang KC, Wu CC, Yang SH, Chiu CC, Sumi S, Lee HS. Investigating the suspension culture on aggregation and function of mouse pancreatic beta-cells. J Biomed Mater Res A. 2013; 101: 2273-2282.

80. Kogawa R, Nakamura K, Mochizuki Y. A new islet transplantation method combining mesenchymal stem cells with recombinant peptide pieces, microencapsulated islets, and mesh bags. Biomedicines. 2020; 8: 299.

81. Mochizuki Y, Kogawa R, Takegami R, Nakamura K, Wakabayashi A, Ito T, et al. Comicroencapsulation of islets and MSC cellsaics, mosaic-like aggregates of MSCs and recombinant peptide pieces, and therapeutic effects of their subcutaneous transplantation on diabetes. Biomedicines. 2020; 8: 318.

82. Pokrywczynska M, Lewandowska MA, Krzyzanowska S, Jundzill A, Rasmus M, Warda K, et al. Transdifferentiation of bone marrow mesenchymal stem cells into the islet-like cells: The role of extracellular matrix proteins. Arch Immunol Ther Exp. 2015; 63: 377-384.

83. Mason MN, Arnold CA, Mahoney MJ. Entrapped collagen type 1 promotes differentiation of embryonic pancreatic precursor cells into glucose-responsive beta-cells when cultured in three-dimensional PEG hydrogels. Tissue Eng Part A. 2009; 15: 3799-3808.

84. Cirulli V, Beattie GM, Klier G, Ellisman M, Ricordi C, Quaranta V, et al. Expression and function of alpha(v)beta(3) and alpha(v)beta(5) integrins in the developing pancreas: Roles in the adhesion and migration of putative endocrine progenitor cells. J Cell Biol. 2000; 150: 14451460.

85. Hiscox AM, Stone AL, Limesand S, Hoying JB, Williams SK. An islet-stabilizing implant constructed using a preformed vasculature. Tissue Eng Part A. 2008; 14: 433-440.

86. Vernon RB, Preisinger A, Gooden MD, D'Amico LA, Yue BB, Bollyky PL, et al. Reversal of diabetes in mice with a bioengineered islet implant incorporating a type I collagen hydrogel and sustained release of vascular endothelial growth factor. Cell Transplant. 2012; 21: 20992110. 


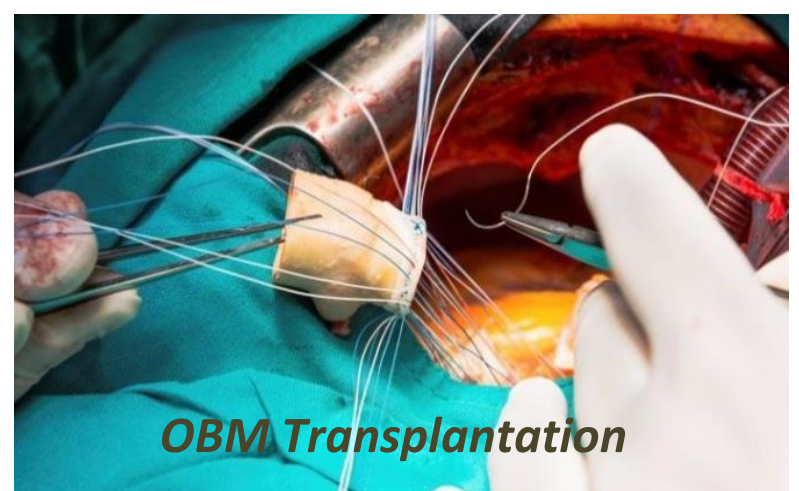

Enjoy OBM Transplantation by:

1. Submitting a manuscript

2. Joining in volunteer reviewer bank

3. Joining Editorial Board

4. Guest editing a special issue

For more details, please visit:

http://www.lidsen.com/journals/transplantation 
Editorial

\title{
Challenges of Organ Transplantation in COVID-19 Era
}

\author{
Kamal Kant Sahu*
}

Divisionof Hematology and Oncology, Department of Internal Medicine, Saint Vincent Hospital, Worcester, MA 01608, USA; E-Mail: drkksahu85@gmail.com

* Correspondence: Kamal Kant Sahu; E-Mail: drkksahu85@gmail.com

Academic Editor: Kamal Kant Sahu

Special Issue: COVID-19 and Organ Transplantation

OBM Transplantation

2020, volume 4, issue 4

doi:10.21926/obm.transplant.2004126
Received: November 01, 2020

Accepted: November 02, 2020

Published: November 19, 2020

COVID-19 pandemic has shattered world with its innumerable challenges. In addition to the saturation of the medical and health care facilities, physicians and patients are struggling to manage the chronic and acute health care issues in addition to COVID-19 [1].

Patients suffering from hematological and oncological malignancies are amongst the worst hit due to the interruption in the treatment of various cancers. Similarly, recipients of various solid organ transplants are at the mercy of fate due to COVID-19 surge. It takes enormous effort to find a right donor, ensure the eligibility of the recipients, and to manage the post-transplant complications [2]. However, during the COVID-19 pandemic, the challenges associated with every step for a successful transplantation has increased exponentially. The COVID-19 pandemic has led to reduction in organ donation and transplantation in various countries including the United States and other European countries [3, 4]. For instance, In Australia, the percentage of kidney transplantation has gone down by $27 \%$ as compared to 2019 [2].

Various oncologists and transplant physicians and surgeons are trying to gather as much information as possible based on individual and/or institutional experiences. There is a constant attempt to formulate interim guidelines by various medical societies to help physicians from different specialties [5-8].

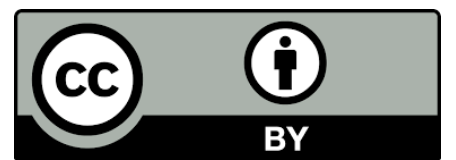

(C) 2020 by the author. This is an open access article distributed under the conditions of the Creative Commons by Attribution License, which permits unrestricted use, distribution, and reproduction in any medium or format, provided the original work is correctly cited. 
In addition to the drop in the number of donors, the concerns of recipients catching the COVID19 during peri-transplant period, use of immunosuppressive agents, follow up care also needs immediate attention. Other factors that is also impacting transplant services is the saturation and unavailability of the critical intensive care beds for the recipients in case they fall sick [9]. Similarly, other ancillaries like availability of blood transfusion products like red blood cell packets, platelets etc. are in scarcity due to decline in blood donation drives [10]. Staff, physician assistants, nurses, pathologists, radiologists, and many more are involved in the transplant team whose wellbeing and availability are essential to ensure a successful transplantation during this pandemic.

To conclude, we are in an incredibly challenging situation where a fine balance is required to diligently make decisions for our patients on transplant waitlist. Case to case basis decision making considering the factors like disease severity, risks and benefits involved in waiting vs proceeding with the transplant should be made for the best outcomes.

\section{Author Contributions}

Kamal Kant Sahu did all work.

\section{Competing Interests}

The author has declared that no competing interests exist.

\section{References}

1. Sahu KK, Siddiqui AD, Cerny J. Mesenchymal stem cells in COVID-19: A journey from bench to bedside. Lab Med. 2020; Imaa049.

2. Chadban SJ, McDonald M, Wyburn K, Opdam H, Barry L, Coates PT. Significant impact of COVID-19 on organ donation and transplantation in a low-prevalence country: Australia. Kidney Int. 2020.

3. Loupy A, Aubert O, Reese PP, Bastien O, Bayer F, Jacquelinet C. Organ procurement and transplantation during the COVID-19 pandemic. Lancet. 2020; 395: e95-e96.

4. Manara A, Mumford L, Callaghan C., Ravanan R, Gardiner D. Donation and transplantation activity in the UK during the COVID-19 lockdown. Lancet. 2020; 396: 465-466.

5. Home: COVID-19 Information. Available From: https://www.myast.org/covid-19-information.

6. Jindal V, Sahu KK, Gaikazian S, Siddiqui AD, Jaiyesimi I. Cancer treatment during COVID-19 pandemic. Med Oncol. 2020; 37: 58.

7. Home: American society for transplantation and cellular therapy. Available From: https://www.astct.org/home.

8. Kant S, Menez SP, Hanouneh M, Fine DM, Crews DC, Brennan DC, et al. The COVID-19 nephrology compendium: AKI, CKD, ESKD and transplantation. BMC Nephrol. 2020; 21: 449.

9. Bhatla A, Ryskina KL. Hospital and ICU patient volume per physician at peak of COVID pandemic: State-level estimates. Healthc (Amst). 2020; 8: 100489.

10. Sahu KK, Raturi M, Siddiqui AD, Cerny J. "Because every drop counts": Blood donation during the COVID-19 pandemic. Transfus Clin Biol. 2020; 27: 105-108. 


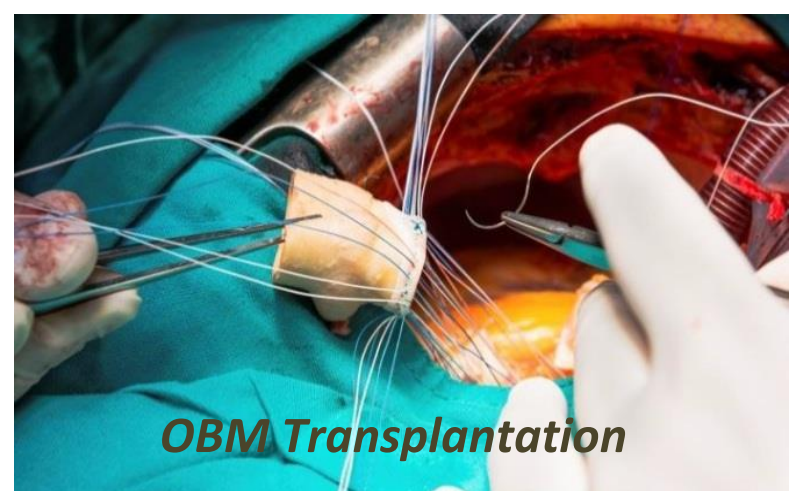

Enjoy OBM Transplantation by:

1. Submitting a manuscript

2. Joining in volunteer reviewer bank

3. Joining Editorial Board

4. Guest editing a special issue

For more details, please visit:

http://www.lidsen.com/journals/transplantation 
Review

\title{
Current Assessment of Clinical Pancreatic Islet Allotransplantation
}

\author{
Preeti Chhabra ${ }^{\dagger}$, Kenneth L. Brayman ${ }^{\dagger}, *$
}

Department of Surgery, Transplantation Division, University of Virginia, Charlottesville, VA, USA; EMails: pc6n@hscmail.mcc.virginia.edu; klb9r@hscmail.mcc.virginia.edu

$\dagger$ These authors contributed equally to this work.

* Correspondence: Kenneth L. Brayman; E-Mail: klb9r@hscmail.mcc.virginia.edu

Academic Editors: Kenneth L. Brayman and Preeti Chhabra

Special Issue: Islet Cell Transplantation

OBM Transplantation

2020, volume 4, issue 4

doi:10.21926/obm.transplant.2004125
Received: September 20, 2020

Accepted: November 4, 2020

Published: Novemeber 16, 2020

\begin{abstract}
Clinical islet allotransplantation represents a minimally invasive, efficacious alternative to pancreas transplantation for restoring glycemic control and insulin independence in select patients with type 1 diabetes that is complicated by intractable impaired hypoglycemia awareness and/or severe hypoglycemic events refractory to stabilization by other means. Over the last decade, islet transplantation outcomes have steadily improved in part due to refinements in the selection of optimal donors, islet isolation techniques, safer engraftment methods, and effective immunomodulatory and anti-inflammatory therapies. Insulin independence rates at five years post-transplantation at select centers have reached parity with pancreas alone transplantation, and marked progress has been achieved in islet transplantation outcomes using single-donor pancreas. However, widespread application of the procedure is still hindered due to a limited supply of donor pancreases, inadequate engraftment, and the harmful side effects of chronic immunosuppression. Strategies to address some of these challenges involve the use of alternative sources of beta cells or islets, extrahepatic sites of implantation, encapsulation of islets and novel therapies to induce tolerance. While several countries have now transitioned islet transplantation from
\end{abstract}

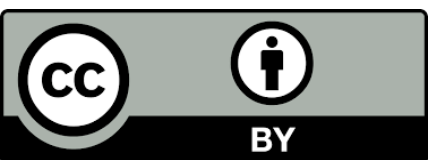

(C) 2020 by the author. This is an open access article distributed under the conditions of the Creative Commons by Attribution License, which permits unrestricted use, distribution, and reproduction in any medium or format, provided the original work is correctly cited. 
experimental status to a funded clinical cure for patients with brittle type 1 diabetes that cannot be stabilized by more conventional means, in the US it still awaits regulatory approval and a financial mechanism for sustainable reimbursement. This review details the history and the current status of clinical islet allotransplantation while summarizing improvements that have been made in techniques involving isolation, purification, culture and assessment of human islets as well as the islet transplantation process itself. Furthermore, it discusses the limitations encountered that prevent its widespread application, strategies that address those limitations, and last but not least, clinical trials being conducted that will help position islet transplantation as a mainstay treatment for the cure of type 1 diabetes.

\section{Keywords}

The collaborative islet transplant registry; islet isolation; intra-hepatic portal vein clinical islet transplantation; allosensitization; shortage of donor pancreata; immunosuppression; graft function; islet/beta cell encapsulation strategies; islet transplantation in extrahepatic sites

\section{Introduction}

Pancreas or islet transplantation is currently the only known cure for Type 1 Diabetes (T1D) [1, 2], a chronic, progressive autoimmune disease that affects an estimated 1.25 million American children and adults $[3,4]$. Classic symptoms of the disease include polydipsia, polyuria, and polyphagia, while diagnosis is usually confirmed by hyperglycemia, low or undetectable serum Cpeptide levels, elevated glycosylated hemoglobin ( $\mathrm{HbA1c}$ ), and the presence of one or more positive autoantibody markers [5]. The current treatment for T1D consists of intensive diet management coupled with exogenous insulin therapy $[6,7]$. Multiple daily injections of insulin, continuous glucose monitoring systems and insulin pumps, or an artificial pancreas device such as Medtronic's MiniMed 670G system constitute the latter [7-10]. Although the tightened glycemic control resulting from insulin therapy has proved highly successful in reducing secondary complications, unfortunately the treatment often renders patients susceptible to increased risk of hypoglycemic episodes and unawareness [11]. To date, allotransplantation of beta cells remains the most reliable and consistent approach for curing T1D.

Pancreatic islet transplantation is a beta cell replacement strategy for clinically restoring glycometabolic control in type 1 diabetic patients that suffer from complications of recalcitrant glycemic lability or debilitating incidences of hypoglycemic episodes and unawareness [12-14]. The procedure first gained credibility as a viable cure in the year 2000, when Shapiro et al demonstrated that transplantation of an adequate mass of islets combined with glucocorticoidfree immunosuppression could result in insulin independence with excellent metabolic control [15]. Since then, incremental advances in a number of parallel fields such as donor selection, islet product quality, anti-rejection/anti-inflammatory agents and state-of-art technology helped evolve islet transplantation into an efficacious clinical means for routinely achieving normoglycemia. Currently, select centers (University of Minnesota (UMN), University of Alberta, 
Edmonton (UAlberta), University of Geneva (UNIGE), University of Lille (ULille) and University of California San Francisco (UCSF)) have demonstrated achievement of insulin independence in nearly $50 \%$ of recipients at the five years post-transplantation mark using T-cell depletional induction therapies, bringing it on par with the results observed with whole pancreas transplantation [14, 16-22]. The procedure also offers substantial benefits when compared to pancreatic transplantation, being minimally invasive while improving the patient's overall metabolic homeostasis as well as quality of life. However, despite the significant progress that has been made in this field during the past decade, it is still not considered as a mainstream treatment option for patients with T1D. Factors such as the requirement of multiple donors, graft rejection, the recurrence of autoimmunity, the harmful side-effects of chronic diabetogenic and nephrotoxic immunosuppression, as well as financial and regulatory approval issues still need to be overcome in order to allow its inclusion into the clinical repertoire as a cure for T1D. This review explores the current status of islet transplantation and the steps that are being taken to expand the availability of this procedure as a fundable clinical option for curing T1D.

\subsection{Historical Perspective of Islet Transplantation}

The use of insulin as a treatment for T1D was first reported in 1922 by Banting and colleagues [23]. However, the theory that pancreatic extracts contained a vital substance that could relieve diabetic symptoms had already been a topic of debate before this report. As early as in 1892, von Merring and Minkowski demonstrated that mortality associated with total pancreactomy could be prevented by subcutaneous transplantation of autologous pancreatic fragments into a diabetic canine recipient [24]. Soon after in 1894, Watson-Williams and Harsant transplanted fragments of sheep pancreas into a teenage boy with end-stage diabetes and demonstrated temporary improvement in glycosuria [25]. In 1916, Frederick Charles Pybus transplanted human allogeneic cadaveric pancreatic fragments subcutaneously into two diabetic patients with no success [26].

The concept of physically separating exocrine and endocrine pancreas had first been contemplated by Leonid Ssobolew [27] as early as in 1902, and continued to gain momentum in the years that followed as numerous techniques to isolate islets were investigated. Moskalewsky was the first to use a discontinuous gradient to purify pig pancreatic islets with Ficoll in 1965 [28]; and the technique was subsequently perfected in Paul Lacy's laboratory [29]. They used a novel technique to isolate rat islets that involved distending the pancreas with saline followed by enzymatic digestion. Ground-breaking experiments by Ballinger and Lacy in rodents followed in the period 1972-1973 that demonstrated reversal of chemically induced diabetes in rats by intact islet transplantation [30]. These early preclinical studies paved the way for using the technique as a potential clinical treatment option for T1D. The same team also demonstrated the vital impact of the site of transplantation on transplantation outcomes, demonstrating islet embolization into the liver through the portal vein, a clinically relevant site that still remains the preferred site for islet transplantation [31]. Between 1979 to 1980, Sutherland and Najarian performed both autologous and allogeneic islet transplantations using dispersed pancreatic islet microfragments following pancreactomy [32-34]. They performed intraportal islet transplantations in 10 patients with surgical induced diabetes using islet autografts that were infused back following islet isolation. Three of these patients achieved insulin independence for 1, 9 and 38 months respectively. 
While working in Paul Lacy's laboratory, Camillo Ricordi and colleagues developed the Ricordi ${ }^{\circledR}$ Chamber and perfected the semi-automated method for islet isolation that enabled successful harvesting of sufficient numbers of human islets for transplantation [35, 36]. Briefly, the Ricordi ${ }^{\circledast}$ Chamber consisted of lower and upper stainless steel chambers separated by a stainless steel screen (280 um mesh). The lower cylindrical chamber had two inlet ports and a third opening on the side for a temperature probe. The upper chamber was conical with one output opening. Both chambers were held together by three screws and the device was connected to a shaker (Model 75, Burrel, Pittsburgh, PA) by a stainless steel bar. Enzyme infused pancreas was loaded into the lower chamber along with seven glass marbles. The chamber was filled with additional collagenase solution, the screen placed in position and the device closed. The shaker was then activated (320 oscillations/minute) and the peristaltic pump turned on with a flow rate of $40 \mathrm{~mL} / \mathrm{min}$. Digestion of the pancreas was conducted in a closed system in which Hanks' solution was aspirated through a filter (94 um mesh) placed in the upper portion of the recirculation cylinder, passed through the pump to a heating circuit and finally reached the lower chamber of the isolator progressively diluting the collagenase solution inside the chamber. The heating circuit allowed the temperature in the digestion chamber to progressively increase $\left(1^{\circ} \mathrm{C} / \mathrm{min}\right)$ until $37^{\circ} \mathrm{C}$ was reached, following which a heating circuit bypass was switched on and off to maintain a stable temperature. From the lower chamber, the solution then passed through the 280 um screen to a cooling circuit that inactivated the collagenase and finally returned to the lower portion of the recirculation cylinder. Both the cooling circuit and the recirculation cylinder were placed in an ice bath in order to inactivate the collagenase and preserve the islets. The solution was then drawn from the top of the recirculation cylinder through the 94um filter while the islets remain settled at the bottom of the cylinder. The islet preparation was sampled every two minutes from a stopcock near the output opening of the digestion chamber to monitor the digestion. When free islets were detected, the recirculation cylinder and the heating circuit were bypassed and the islet separation conducted on an open system in which the temperature progressively decreased, and the collagenase solution was diluted by fresh Hanks' solution. The islet preparation was then collected in 2-Liter flasks. The flow rate in the open system phase increased up to $200 \mathrm{~mL} / \mathrm{min}$, allowing a faster turnover of the digestion chamber content. The isolation procedure was generally terminated after 30-60 min, when islets were no longer detected in the samples [35].

By 1990, the first successful series of clinical human islet allotransplantation was reported by the Pittsburgh group wherein long-term insulin independence could be attained using a steroidfree immunosuppressive regimen that included FK506 (Prograf) [37, 38]. These exciting results invigorated efforts in the field. During that decade, several centers including those at University of Miami (UM), UAlberta, Washington University, University of Pennsylvania (UPenn), UMN, and San Raffaele University, Milan (UniSR) incorporated innovative changes to existing protocols to improve islet transplantation outcomes [39-41]. However it was in the year 2000 that the islet transplantation group consisting of Shapiro and colleagues at UAlberta demonstrated achievement of insulin independence for $>1$ year post-transplantation with sustained C-peptide production in all seven consecutive participants who had received islets transplants, using what is now famously known as the "Edmonton protocol" [15]. The protocol briefly consisted of a corticosteroid free immunosuppressive protocol consisting of a combination of two potent immunosuppressants: rapamycin and low-dose tacrolimus, together with an anti-CD25 antibody to protect against rejection and recurrent autoimmunity. Using this protocol, the islet mass was 
augmented with islet preparations harvested from two or more pancreata, infusing a total islet dose substantially higher than previously used in clinical islet trials ( $>13,000$ islet equivalents (IEQs) per kilogram (kg) recipient body weight) [42]. Although the Edmonton protocol consistently achieved short-term outcomes on par with pancreas transplantation at 1 year follow-up, insulin independence was frequently lost in the graft recipients by the 3-5 year mark, with only $10 \%$ demonstrating insulin independence at the five year mark [43]. However, partial graft function (defined as partial insulin dependence) consistently persisted in $80 \%$ of graft recipients contributing to decreased episodes of severe hypoglycemia, reduced $\mathrm{HbA1c}$ levels, and improved cardiovascular function [44]. Furthermore, stabilization of diabetic retinopathy and neuropathy was observed, resulting in improved quality of life with increased glycemic awareness. From 20062012, a spate of activity ensued with several centers worldwide and as well as independent Clinical Islet Transplantation (CIT) centers (for example, UAlberta, UMN, UCSF, Geneva-GRAGIL, and ULille) reporting insulin-independence rates of more than $50 \%$ at five years using T-cell depletion induction therapies [21, 22, 45-50]. Importantly, their results closely approximated the International Pancreas Transplant Registry data of solitary vascularized pancreas transplant [21, 22, 51-54]. Noteworthy was that these results demonstrated that the procedure was not associated with the incumbent risks that attend a major surgical intervention like pancreas transplantation $[21,22,54]$.

\subsection{The Collaborative Islet Transplant Registry}

The Collaborative Islet Transplant Registry (CITR) was established in 2001 by the National Institute of Diabetes \& Digestive \& Kidney Diseases to compile data from all islet transplant programs in North America from 1999 to the present. Additional funding was granted by the Juvenile Diabetes Research Foundation (JDRF) to include JDRF-funded European and Australian centers from 2006-2015. The cumulated data from North American, European and Australian centers are pooled for analyses and are included in the annual reports.

Briefly, data is collected from the following groups of study subjects: A) Islet allotransplantation performed as either islet transplant alone or islet after kidney (IAK) [55]. A small number of cases have been performed as islet simultaneous with kidney or kidney-after-islet; and B) Autologous islet transplantation, performed after total pancreatectomy. The CITR 10th Annual Report focuses on the islet allotransplantation recipients. It states that 1086 islet allotransplant recipients (877 islet alone, 183 islet after kidney, 24 simultaneous islet kidney, and 2 kidney after islet) have received 2,150 islet allograft infusions, representing a $7 \%$ increase in the number of recipients, a $12 \%$ increase in the number of infusion procedures, and $8 \%$ increase in donors, compared to the 9th Report during the period from 1999 to 2015. Also, a total of 827 autologous islet transplant recipients were registered in CITR, as of Sept 30, 2015. In North America 33 out of 42 programs have performed islet allograft transplantations with 669 total recipients and 1,321 total infusions.

\section{The Islet Transplantation Process}

\subsection{Indications for Clinical Islet Transplantation}

The main indication for an allogeneic islet transplant is undetectable C-peptide levels $(<0.3 \mathrm{ng} / \mathrm{mL}$ ) with severe glycemic lability complicated with recurrent hypoglycemic episodes and 
impaired hypoglycemic awareness [2,39]. Also included are patients refractory to efforts aimed at stabilizing glycometabolic control such as intensive insulin therapy, improved monitoring, insulin pumps, or continuous glucose monitoring systems. Evidence of T1D (C-peptide $<0.3 \mathrm{ng} / \mathrm{mL}$ ) with sufficient duration ( $>5$ years) is required to justify that adequate opportunity for optimized medical management has been provided. Age is restricted to $>18$ years, and subjects $>90 \mathrm{~kg}$ and/or with daily insulin requirement $>1.0 \mathrm{U} / \mathrm{kg}$ and/or with a high body mass index $\left(\mathrm{BMI}>30 \mathrm{~kg} / \mathrm{m}^{2}\right)$ are usually avoided to prevent the futility of transplantation in the presence of marked insulin resistance or excessively high insulin requirements [14].

Stringent selection criteria have been put in place to justify replacing injectable insulin with lifelong immunosuppression. Usually an objective selection criteria for islet transplantation alone include a Clark score of $\geq 4$ ( $0=$ no hypoglycemia, $\geq 4=$ hypoglycemia unawareness), HYPO score $\geq 1000$; lability index (LI) score $\geq 400 \mathrm{mmol} / \mathrm{L} 2 / \mathrm{h} / \mathrm{wk}$, or a combination of these variables $[2,21,51]$. Patients having subcutaneous insulin resistance requiring intraperitoneal or intravenous infusions are also considered. Also included are patients that do not qualify as candidates for wholepancreas transplantation or are unable to accept the risks associated with major surgery.

According to latest CITR annual report [55], at the time of their first Islet transplant, islet transplant alone recipients were 14-74 years of age (mean 46 \pm 10.5 years), had T1D for 2-61 years (mean $29 \pm 11.5$ years), and $77 \%$ had very poor diabetes control including hypoglycemia unawareness. Poor glycemic control was defined as frequent episodes of critically low blood sugar levels (which often result as a reaction to injected insulin, and require the assistance of another person to avert a possibly life-threatening loss of consciousness), wide swings in blood sugar levels (blood glucose lability), or consistently high HbA1c levels (>8\% of total hemoglobin). Typically, those selected displayed frequent metabolic instability involving hypo-and hyperglycemia, ketoacidosis despite intensive insulin therapy; hypoglycemic unawareness $(<54 \mathrm{mg} / \mathrm{dL})$; and severe metabolic lability (mean amplitude of glycemic excursion $>11.1 \mathrm{mmol} / \mathrm{L}$ or $200 \mathrm{mg} / \mathrm{dL}$ ).

There is less agreement on the exclusion criteria, however absolute contraindications is detectable C-peptide levels $(>0.3 \mathrm{ng} / \mathrm{mL}$ ). Relative contraindications include insulin requirements (>0.7units $/ \mathrm{kg} /$ day) or $<15$ units/day, $\mathrm{HbA} 1 \mathrm{c}>10 \%, \mathrm{BMI}>26 \mathrm{~kg} / \mathrm{m}^{2}$ or weight $<50 \mathrm{~kg}$, Creatinine $>1.5 \mathrm{mg} / \mathrm{dL}$ and/or albuminuria $>300 \mathrm{mg} / 24 \mathrm{~h}$ or measured glomerular filtration rate (GFR) $<80 \mathrm{~mL} / \mathrm{min} / 1.73 \mathrm{~m}^{2}$, untreated arterial disease, history of panel reactive anti-human leukocyte antigen (HLA) antibodies, inability to comply with immunosuppression and significant comorbidities, as well as the presence of infections or psychiatric diseases $[14,56,57]$.

\subsection{Islet Isolation}

The islet transplantation process begins with procurement of the pancreas, usually from a heart-beating, brain-dead organ donor or in the case of autologous islet transplantation, from a recipient undergoing therapeutic pancreactomy [2]. The pancreas is transported in University of Wisconsin (UW) or histidine-tryptophan-ketoglutarate (HTK) preservation solution to a sterile good manufacturing practice (GMP) facility, avoiding prolonged cold storage of the pancreas [12]. Multiple reports indicate that other preservation solutions may be used as effective alternatives to UWS and HTK $[58,59]$. For example, Celsior is an extracellular, low-viscosity preservation solution that was originally designed for cardiac transplantation. A study comparing Celsior with UWS for pancreas preservation demonstrated that two-year recipient survival rates, two-year graft survival 
rates, pancreas leakage rates, and clinical graft pancreatitis rates were similar in both groups [58]. However, colloid-free preservation solutions were reported to be inferior to UWS for preservation of pancreases intended to be used for islet isolation. Islet isolation yields from pancreases preserved with Celsior solution were found to be 2.1-fold lower than those obtained when UWS was used $[59,60]$. Solution de conservation d'organes et de tissus (SCOT), an extracellular solution containing polyethylene glycol (PEG) has been shown to have some immunoprotective effects on islet cells [61]. Cell swelling and pancreas edema were not significant following 12 hours of cold storage with SCOT when compared with UWS, and SCOT could improve islet yield when used during isolation and could prolong islet allograft survival without immunosuppression when used for culture, as compared to control solutions [59,61]. Perfluorohexyloctane/Polydimethylsiloxane 5 (F6H8S5) too has been demonstrated to be a suitable preservation solution for pancreases intended for islet isolation, allowing for extended cold ischemic time without inflicting islet function and numbers [62]. A technique known as the two-layer method (TLM) for pancreas preservation was reported to enhance islet yield and quality by improving pancreas oxygenation during preservation [62]. Following reports in 2002 by UMN [63], UM [64], and UAlberta [65, 66] that indicated improved islet yields and increased islet transplantation opportunities using TLM, this technique was widely used by islet transplant centers worldwide. However, several clinical studies since have demonstrated no beneficial effect of the TLM with preoxygenated perfluorocarbon on islet isolation and islet transplant outcomes [67-69].

Once received, the pancreas is cleaned and cannulated and infused with enzyme in the GMP facility. The distended pancreas is cut into seven to ten pieces and subjected to continuous, temperature controlled, mechanically enhanced enzymatic digestion in a dissociation or filtration chamber known as the Ricordi ${ }^{\circledR}$ Chamber that allows immediate cooling and removal of the dissociated islets to avoid overdigestion, thus preserving their morphologic and functional islet integrity [2]. Liberase $\mathrm{H} 1$ was the commonly used enzyme until the discovery of potential safety risks regarding the contraction of bovine spongiform encephalopathy [2, 12, 70]. Consequently, collagenase NB1 supplemented with neutral protease (NP) (SERVA Electrophoresis GmbH, Heidelberg, Germany) was adopted by many centers globally as an alternative despite its lower islet isolation outcomes $[2,12,70,71]$. The latter was attributed to degradation of collagenase C1 into various breakdown products with reduced activity [72]. The combination of Clzyme collagenase HA (containing nondegradable class I [60\%] and II [40\%]) and NP although effective in isolating islets for transplantation, however were not GMP grade products [73]. Currently, liberase mammalian tissue-free collagenase/ thermolysin (MTF C/T) (Roche Diagnostics) is being used routinely for human islet isolation for clinical islet transplantation [73].

Pooled tissue containing islets are purified on a Ficoll, Biocoll, lodixanol, or UW-Biocoll density gradient in a COBE2991 processor (Terumo BCT, Gambro BCT, Inc., Lakewood, CO) under cold conditions, which separates them from exocrine and other non-islet tissue $[2,12,14,21]$. The purified islets are washed, pelleted and resuspended, following which an aliquot is removed to quantify islet yield (dithizone-stained islets), evaluate islet size and perform islet count (using light microscopy), assess viability (fluorescein diacetate-propidium iodide staining), sterility and pyrogenicity (endotoxin assay, gram stain and tests for aerobic and anaerobic microbial, fungal, and mycoplasmal contamination), purity (visual morphometric examination of dithizone-stained acinar-free islets using light microscopy) and function (perifusion, glucose-stimulated insulin 
secretion assay) [2]. Within 24 hours of isolation, the resuspended islets are loaded into a gravityfed transfer bag for intraportal vein infusion into the eligible transplant recipient [2].

A healthy human pancreas contains up to 4-15 million islets [57, 74]. However, the yield and purity of isolated purified islets are highly variable with islet equivalents count ranging from 100,000 to 300,000 per pancreas $[57,75]$. The isolated islets are then infused into the hepatic portal system of the recipient. A target islet mass of approximately 11,000 islet IEQs per $\mathrm{kg}$ of recipient body weight is aimed for, translating into two or three islet infusions from multiple donors [21]. However the minimum requirements include $>30 \%$ purity of the preparation being islets, membrane integrity-viability $\geq 70 \%$, a final enriched islet cell product in $<5 \mathrm{~cm}^{3}$ of tissue pellet, negative Gram stain, content $\leq 5$ endotoxin $\mathrm{U} / \mathrm{kg}$ (recipient body weight) and most importantly, adequate number of islets i.e. $\geq 5,000$ islet equivalent recipient body weight for the first infusion and $\geq 3,000$ for further infusions [76-79]. According to the latest CITR annual report [55], the total cell volume infused has declined appreciably over the eras (4.0 \pm 0.1 in 1999-2002 to $3.1 \pm 0.1$ in 2011-2014), while total IEQs and IEQ/kg recipient have remained remarkably stable. Total beta cells and beta cells/kg were higher for IAK (5.3 \pm 0.6 vs. $3.6 \pm 0.2)$ and have increased over the eras $(3.0 \pm 0.3$ to $4.5 \pm 0.4$ ). Endotoxin (both total and $/ \mathrm{kg}$ ) has declined sharply over the eras $(0.5 \pm 0.1$ to $0.1 \pm 0.05)$ as has the Stimulation index $(3.6 \pm 0.3$ to $2.8 \pm 0.2)$. The eras consist of 1999 2002, 2003-2006, 2007-2010, 2011-2014 and 2015-2018.

\subsection{Intra-hepatic Portal Vein Islet Transplantation}

The hepatic parenchyma through the portal system of the recipient is the implantation site that is routinely used although other sites are being explored [76]. The final islet-cell product suspended in transplant media containing 70 units heparin/kg recipient body weight is loaded into a gravity-fed transfer bag for infusion following percutaneous catheterization of the portal vein [14]. This is a minimally invasive procedure performed under local anesthesia in a radiology suite by an interventional radiologist under ultrasonographic and fluoroscopic guidance [14, 80]. The procedure begins with measurement of portal pressure to ensure absence of portal hypertension. The islets ( $5 \mathrm{~mL}$; up to $10 \mathrm{~mL}$ tissue pellet) are suspended in 200 to $400 \mathrm{~mL}$ transplant media with heparin and human albumin contained in a plastic infusion bag [78]. Briefly, a small (7-French) catheter is inserted into the main portal vein and the islets are dripped slowly through the intravenous line connecting the harvested islet bag with the portal catheter. Both, at the midpoint and at the conclusion of the infusion which typically takes 30 to 45 minutes, the portal pressure is measured. If percutaneous access via the portal vein fails, then the procedure can also be performed under general anesthesia during a limited mini-laparotomy with intravenous delivery through the mesocolonic vein [78] or by recanalization of the obliterated left umbilical vein to enable access to the left portal system. In these instances, a dual-lumen 9 French Broviac-type central-line catheter is advanced into the main portal vein for simultaneous monitoring of portal pressure (through the smaller lumen while islets are infused [14, 81, 82].

Following transplantation, subcutaneous heparin and insulin are administered for at least two weeks to promote islet engraftment [78]. The rationale being that patients receiving peritransplant insulin and heparin infusions are more likely to become insulin independent and have a significantly greater percent reduction in insulin requirement [48]. This could be attributed to protection from the instant blood-mediated inflammatory reaction (IBMIR) combined with islet 
rest and other anti-inflammatory effects $[21,48]$. IBMIR is a thrombotic reaction characterized by the activation of coagulation and complement cascades and by platelet consumption that results in the disruption of islet morphology and function [13]. Heparin may be beneficial due to its ability to reduce inflammation via inhibition of complement activation, reduce the generation of reactive oxygen species and secretion of proinflammatory cytokines, inhibit transcription factor nuclear factor kappa-light-chain-enhancer of activated B cells (NFKB), and limit macrophage migration [2, 48]. The benefits of injecting insulin would include protection of the grafted islets from hyperglycemia, resulting in rest and gain vascular supply $[2,48,83]$. Insulin may also suppress the generation of reactive oxygen species and the binding of transcription factor NFKB [2, 48]. By reducing plasma levels of tissue factor and plasminogen early activator inhibitor-1, insulin may also exert an antithrombotic effect, protecting against IBMIR [48].

\subsection{Intra-portal Vein Infusion-related Complications}

Complications that could arise as a result of intra-portal vein infusion are a transient elevation of transaminase, post-infusion portal vein thrombosis and hepatic infarct $[14,78,80]$. With the optimization of the access technique wherein smaller catheters are used and the puncture tract sealed off, the risk of bleeding has significantly decreased [78, 84, 85]. This in turn allows for a more aggressive use of heparin, which combined with limited tissue pellet volume infused (packed cell volume $<5 \mathrm{~mL}$ ) further reduces the risk of portal vein thrombosis close to zero. Complications arising due to partial portal vein thrombosis are also very rare $[85,86]$. A theoretical increased risk of allosensitization also exists since islet allotransplantation requires islet infusions from 2 to 3 donors. It has been clinically observed that discontinuation of immunosuppression due to graft failure or side effects, results in approximately $70 \%$ of the patients developing donor-specific antibody and high panel-reactive antibody (PRA) (>50\%) [87-89]. However, in the presence of adequate immunosuppression, this risk remains very small even after their fourth and fifth islet infusion [88, 90]. Moreover, the risk of sensitization remains the same as after one islet infusion despite increased number of HLA class I mismatches with each infusion [91]. In fact, exposure to repeat HLA class I mismatch in subsequent islet infusions results in less frequent development of de novo HLA class I antibodies compared with new class I mismatch. Poor graft outcome and increased risk for donor-specific antibodies is associated with $>20 \%$ PRA [78]. Posttransplant monitoring of intraportal islets has proven difficult. Positron emission tomography combined with computed tomography may have the potential to assess the early posttransplant loss of islets [92].

\section{Limitations of Clinical Islet Transplantation and Strategies to Address the Limitations}

Widespread application of clinical islet transplantation is hindered by a shortage of donor pancreata, the harmful side effects associated with chronic immunosuppressive therapy, innate and alloimmune graft rejection, and the recurrence of autoimmunity.

\subsection{Shortage of Donor Pancreata}

Usually, islet transplant recipients require islets from two or more pancreata to regain permanent glycometabolic control, which becomes a problem due to the shortage of donor pancreata. In order for clinical islet transplantation to prove cost effective, and to increase 
availability of islets for transplantation and minimize the risk of donor allosensitization, the best scenario would be to use islets from a single donor similar to whole-pancreas transplantation. While several groups have met with limited success using single-donor islet transplants, routine single-donor islet engraftment success has not been observed universally $[2,51,57,93]$.

Several strategies have been investigated to address the issue of shortage of donor tissue. These include amongst others, obtaining islets from donors after cardiac death (DCD), from partial pancreactomized living donors, as well as from alternate, sustainable sources of islets such as porcine islets. Another avenue that has been explored is the directed differentiation of stem or progenitor cells (e.g. embryonic stem cells) or induced pluripotent stem cells into insulinproducing beta cells [2, 94-96]. Apart from these obvious stem cell choices, others such as mesenchymal stem cells, adipose tissue-derived stem cells, umbilical cord blood-derived stem cells, as well as organ-specific facultative progenitor cells from the liver and the pancreas, have also been tested for their ability to differentiate into bona fide insulin-secreting beta cells. Additionally, the generation of insulin-producing beta cells by transdifferentiation of alpha cells, non-islet pancreatic ductal cells, acinar cells, hepatic cells, and bile duct epithelial cells into insulinproducing beta cells as well as agents such as Exenatide that stimulate regeneration of beta cells have also been studied [2, 94-96].

Apart from the overall shortage of cadaveric donor pancreata, the quality of a donor pancreas also plays an important role in determining transplant outcomes, with factors such as donor age and $\mathrm{BMI}$, cause of death, duration of hospital stay, organ procurement team and cold ischemia time acting as major contributors [97-102]. Currently, the islet transplantation procedure is hindered by the quality of pancreas allocated. For example, donor pancreases unsuitable for whole-pancreas transplantation such as pancreas from older, overweight donors that are associated with decreased survival when utilized in whole-organ pancreas transplant are allocated for islet transplantation $[2,103]$. In order to better long-term islet transplantation outcomes, this disparity in organ allocation will definitely need to be addressed.

Another important point is the ischemic, mechanical, and enzymatic stress that islets are subjected to during the isolation process [12]. Efforts to protect islets by either tweaking isolation techniques or by treating the islets are ongoing. Currently many clinical trials are focusing on cytoprotective strategies to enhance transplantation outcomes. Some of these are listed below:

- Phase I/II clinical trial \# NCT02520076 studies the use of Serine protease inhibitor Alpha-1 Antitrypsin (AAT) in islet transplant to decrease the amount of cell death caused by general inflammation and improve single donor success rate in clinical islet transplantation. \#NCT02464878 is another multicenter trial that focuses on the effect of AAT on islet transplant engraftment and durability after renal transplant. In the clinical trial \#NCT02713997, following removal of pancreas from patients with chronic pancreatitis, autoislets are transplanted back into patient's liver along with three inflammatory therapies arms: Tumor necrosis factor (TNF)-alpha, AAT and standard care in order to see if anti-inflammatory therapy improves outcomes after total pancreatectomy with islet autotransplantation (TPIAT).

- In clinical trial \#NCT03073577, the use of supplementing islet preservation medium during islet isolation process with anti-aging glycopeptide (PKX-001) is being studied. Islets are maintained for minimal 6-72 $\mathrm{h}$ in supplemented CMRL1066-based media containing PKX-001 until the time of transplant. 
- Islet Isolation using MnTE-2-PyP (BMX-010) is a phase I pilot study (\#NCT02457858) that has been completed. The investigators hypothesized that addition of antioxidant BMX-010 to perfusion solution, digestion solution and culture medium during the islet isolation process could lead to greater preservation of islet mass and metabolic function, such as improved islet yield, viability and functional potency.

- Clinical trial \# NCT00678990 is a phase I, open study (not yet recruiting) to evaluate safety and efficacy of allogenic islet transplantation using islets coated with immobilized heparin. In this study, prior to transplantation, islets will be surface modified to carry immobilized heparin. The primary objective is to investigate safety and efficacy of islet allotransplantation using islets coated with immobilized heparin. The modification with heparin is anticipated to protect islets from blood (coagulation and inflammation) as a means to preserve a larger portion of the islets in the initial transplant phase.

- The effect of selective complement inhibition using complement inhibitor Eculizumab combined with standard anticoagulation during and after transplantation, in reducing the extent of early tissue loss after portal infusion of islets, has also been studied in completed clinical trial \# NCT02727608.

- The C-X-C Motif Chemokine Ligand 8 (CXCL8) plays a key role in the recruitment and activation of polymorphonuclear neutrophils in post ischemia reperfusion injury after organ transplantation. Reparixin is a low molecular weight blocker of CXCL8 biological activity in clinical development. Reparixin can be used to immunomodulate and control of nonspecific inflammatory events surrounding the early phases of pancreatic islet transplantation. A phase II/III clinical trial (\#NCT01967888) is being conducted to assess whether reparixin leads to improved transplant outcome as measured by the proportion of insulin-independent patients following TPIAT.

- In a terminated clinical trial \#NCT00853944, the effect of Sitagliptin on graft function following islet transplantation was being studied to evaluate whether administration of Sitagliptin to islet transplant recipients could enhance engraftment when administered up to one-year post transplant. The study was terminated due to lack of enrollment.

- Investigator initiated, Phase I/II clinical trial \#NCT01653899 studies Caspase inhibition in islet transplantation. In this study, type 1 diabetic participants receive a 14-day oral treatment of the investigational caspase inhibitor drug IDN-6556 following their first islet transplant.

- Combinatorial cellular immunotherapy approaches are also being investigated in the field of islet autotransplantation. For example, clinical trial \# NCT02384018 is a mesenchymal stem cell and islet co-transplantation study aimed to evaluate safety and tolerability of autologous bonemarrow derived mesenchymal stromal cells (BM-MSCs) in chronic pancreatitis patients who concurrent to receiving autoislets following total pancreatectomy, are also infused with autologous BM-MSCs.

\subsection{Immunosuppression}

In any allogeneic organ transplant, immunosuppression acts as a double-edged sword, preventing or delaying the graft rejection by the host, but simultaneously increasing the risk for infection and cancer [104-106]. Routinely, during both peri- and post-allotransplantation, multiple induction and maintenance immunosuppressive agents are administered to the graft recipient to prevent graft rejection. The most commonly used component of immunosuppression regimens 
are the Calcineurin-Inhibitors (CNIs) Cyclosporine or Tacrolimus. Interestingly, both have been implicated in renal dysfunction and beta cell toxicity [107-110]. Therefore alternative CNI-free immunosuppression methods that prevent rejection while avoiding the toxicity of CNIs have been thoroughly investigated in islet allotransplantation [111, 112]. Following the spectacular results obtained by the Edmonton group using the corticosteroid-free immunosuppressive regimen, more than $90 \%$ of islet programs adopted their protocol [15] i.e Rapamycin-based therapy with low doses of tacrolimus and anti-interleukin-2 receptor (IL2R) antibody (Daclizumab) as induction therapy. This approach was designed to improve the survival and function of islets while protecting the kidney function by minimizing CNIs. Induction with IL2R antagonists only, which comprised about 54\% of all initial infusions in 1999-2002, was subsequently replaced or supplemented with regimens that included T-cell depletion with/without TNF antagonists in about $68 \%$ of new infusions performed by 2011 to 2014 [55]. However, the most successful immunosuppressive regimens involved T-cell depletion induction therapy in the form of Thymoglobulin, anti-CD52 antibody (Alemtuzumab), or anti-CD3 humanized antibody [78].

Another trend that emerged to improve outcomes, tolerability and patient compliance was to replace Sirolimus with Tacrolimus and Mycophenolate Mofetil (MMF) [84]. According to the latest CITR annual report, the maintenance immunosuppression in 1999-2002 consisting predominantly of (65\%) CNI plus mammalian target of rapamycin (mTOR) inhibitors has been increasingly replaced or supplemented throughout the eras by a CNI and Inosine Monophosphate Dehydrogenase (IMPDH)-inhibitor combination [55]. In the most recent era (2015-2018), CNI plus mTOR inhibitors were used in 15\% of new infusions while CNI plus IMPDH inhibitors were used in about 56\% [55]. Table 1-2 list active and completed clinical trials that focus on immunosuppressive approaches aimed at improving graft outcomes. Table 3 lists clinical trials that are actively recruiting. Despite their limitations, these studies confirm that it is possible to achieve singledonor insulin independence without using $\mathrm{CNI}$ and steroids. 
Table 1 IMMUNOSUPPRESSION FOR ISLET TRANSPLANTATION. CLINICAL TRIALS: ACTIVE, NOT RECRUITING.

\begin{tabular}{|c|c|c|c|}
\hline NCT NUMBER & PHASE & STUDY TITLE & INTERVENTION \\
\hline NCT00006505 & $\begin{array}{l}\text { Phase II } \\
\text { November } \\
2000 \text {-June } \\
2020\end{array}$ & $\begin{array}{lr}\text { Solitary } & \text { Islet } \\
\text { Transplantation for } \\
\text { Type } 1 \text { Diabetes } \\
\text { Mellitus } \quad \text { Using } \\
\text { Steroid } \quad \text { Sparing } \\
\text { Immunosuppression }\end{array}$ & $\begin{array}{l}\text { Examines efficacy of the Edmonton protocol. } \\
\text { Patients will receive } 10,000 \text { IEQs/kg of body weight. This will likely } \\
\text { require two separate transplant procedures from two donors } \\
\text { Before the first surgery, patients will be given anti-rejection } \\
\text { (immune suppressing) drugs, including FK506 and rapamycin } \\
\text { (orally) and daclizumab (intravenously). }\end{array}$ \\
\hline NCT00306098 & $\begin{array}{l}\text { Phase II } \\
\text { December } \\
2000-M a y \\
2021\end{array}$ & $\begin{array}{l}\text { Islet Cell } \\
\text { Transplantation } \\
\text { Alone in Patients } \\
\text { With Type } 1 \\
\text { Diabetes Mellitus: } \\
\text { Steroid-Free } \\
\text { Immunosuppression }\end{array}$ & $\begin{array}{l}\text { Assesses the effect of infliximab (anti-TNF) in preventing early islet } \\
\text { destruction, and thereby eliminating the need for a second } \\
\text { donor's islet cells; the effect of etanercept (anti-TNF) in preventing } \\
\text { early islet destruction; the effect of exenatide (GLP-1) to improve } \\
\text { islet graft function and survival in subjects that have returned to } \\
\text { using exogenous insulin; and the ability of exenatide to improve } \\
\text { islet survival at time of transplantation. This is in addition to } \\
\text { standard immunosuppression (Daclizumab, Sirolimus, and } \\
\text { Tacrolimus) and without steroids. }\end{array}$ \\
\hline NCT00679042 & $\begin{array}{l}\text { Phase III } \\
\text { June } 2007- \\
\text { July } 2027\end{array}$ & $\begin{array}{l}\text { Islet Transplantation } \\
\text { in Type } 1 \text { Diabetic } \\
\text { Patients Using the } \\
\text { University of Illinois } \\
\text { at Chicago (UIC) } \\
\text { Protocol }\end{array}$ & $\begin{array}{l}\text { Each subject may receive } 1-3 \text { transplantations of allogeneic human } \\
\text { islets of Langerhans and the following medications: Basiliximab } 20 \\
\mathrm{mg} \text { iv } 2 \text { hours before transplant and } 20 \mathrm{mg} \text { iv } 2 \text { weeks post- } \\
\text { transplant; Tacrolimus } 1 \mathrm{mg} \text { p.o. bid adjusted to reach target } \\
\text { trough levels of } 3-6 \mathrm{ng} / \mathrm{mL} \text {; Sirolimus } 0.2 \mathrm{mg} / \mathrm{kg} \text { loading dose, then } \\
0.1 \mathrm{mg} / \mathrm{kg} \text { p.o. daily adjusted to reach target trough levels of } 10-15 \\
\mathrm{ng} / \mathrm{mL} \text { during the first } 3 \mathrm{months} \text { post-transplant and } 7-10 \mathrm{ng} / \mathrm{mL} \\
\text { thereafter; Etanercept } 50 \mathrm{mg} \text { iv } 1 \text { hour before transplant and } 25 \\
\mathrm{mg} \text { s.c. on days } 3,7 \text { and } 10 \text { post-transplant; Exenatide } 5-\mathrm{mcg} \text { s.c } \\
\text { bid for } 1 \text { week, then } 10 \mathrm{mcg} \text { bid for } 6 \text { months after each transplant }\end{array}$ \\
\hline
\end{tabular}

\section{LOCATION}

NIH clinical center

Maryland, USA

University of Miami, Diabetes Research Institute, Miami, USA

University of Illinois at Chicago Medical

Center, Illinois, USA 


\begin{tabular}{|c|c|c|c|c|}
\hline \multirow[b]{3}{*}{ NCT00706420 } & \multirow{3}{*}{$\begin{array}{l}\text { Phase I } \\
\text { January 2002- } \\
\text { December } \\
2019\end{array}$} & \multicolumn{3}{|l|}{$\begin{array}{l}\text { Islet } \\
\text { Transplantation }\end{array}$} \\
\hline & & $\begin{array}{lr}\text { Alone } & \text { (ITA) in } \\
\text { Patients } & \text { With }\end{array}$ & $\begin{array}{l}\text { This study is being performed to confirm the results of the } \\
\text { Edmonton study to see if islet transplantation alone (ITA) is a safe }\end{array}$ & City of Hope Medical \\
\hline & & $\begin{array}{l}\text { Difficult to Control } \\
\text { Type I Diabetes } \\
\text { Mellitus Using a } \\
\text { Glucocorticoid-free } \\
\text { Immunosuppressive } \\
\text { Regimen }\end{array}$ & $\begin{array}{l}\text { and effective way of treating subjects with type } 1 \text { diabetes. This } \\
\text { study uses a few additional medications and vitamin supplements } \\
\text { that were not included in the original Edmonton study. } \\
\text { Sirolimus/Tacrolimus, daclizumab }\end{array}$ & $\begin{array}{c}\text { California, } \\
\text { USA }\end{array}$ \\
\hline \multirow[b]{2}{*}{ NCT01897688 } & & $\begin{array}{l}\text { A Phase } 3 \text { Single } \\
\text { Center Study of Islet }\end{array}$ & \multirow{2}{*}{$\begin{array}{l}\text { To demonstrate the safety and efficacy of islet transplantation } \\
\text { under alemtuzumab induction for treatment of Type- } 1 \text { Diabetes } \\
\text { (T1D) in subjects with hypoglycemia unawareness and a history of } \\
\text { severe hypoglycemic episodes. }\end{array}$} & $\begin{array}{l}\text { Northwestern } \\
\text { University }\end{array}$ \\
\hline & $\begin{array}{l}\text { June 2012- } \\
\text { March } 2027\end{array}$ & $\begin{array}{l}\text { Transplantation in } \\
\text { Non-uremic } \\
\text { Diabetic Patients }\end{array}$ & & $\begin{array}{l}\text { University, } \\
\text { Illinois, USA }\end{array}$ \\
\hline \multirow{4}{*}{ NCT02821026 } & Phase I and & \multirow{4}{*}{$\begin{array}{l}\text { Omental Islet } \\
\text { Transplant }\end{array}$} & \multirow{4}{*}{$\begin{array}{l}\text { The new procedure involves transplanting the islets into an } \\
\text { omental pouch instead of into the liver. Immunosuppression with } \\
\text { anti-thymocyte globulin, tacrolimus, mycophenolic acid, sirolimus } \\
\text { and etanercept will be used in this study. }\end{array}$} & Clinical Islet \\
\hline & Phase II & & & Transplant \\
\hline & May 2016- & & & Program, Alberta \\
\hline & Sept. 2020 & & & Canada \\
\hline \multirow{4}{*}{ NCT00160732 } & Phase I and & \multirow{4}{*}{$\begin{array}{l}\text { Allogeneic Islet cell } \\
\text { transplantation }\end{array}$} & \multirow{4}{*}{$\begin{array}{l}\text { The purpose of this study is to determine the safety of } \\
\text { transplanting human islet cells for controlling hyperglycemia in } \\
\text { brittle and/or complex patients with type } 1 \text { diabetes. The } \\
\text { "Edmonton Protocol" of specific anti-rejection drugs without } \\
\text { steroids is also being evaluated. }\end{array}$} & \multirow{4}{*}{$\begin{array}{l}\text { The University of } \\
\text { Chicago Hospitals, } \\
\text { Illinois USA }\end{array}$} \\
\hline & Phase II & & & \\
\hline & $\begin{array}{l}\text { October } \\
\text { 2003- }\end{array}$ & & & \\
\hline & October2025 & & & \\
\hline
\end{tabular}


Table 2 IMMUNOSUPPRESSION FOR ISLET TRANSPLANTATION. CLINICAL TRIALS: COMPLETED.

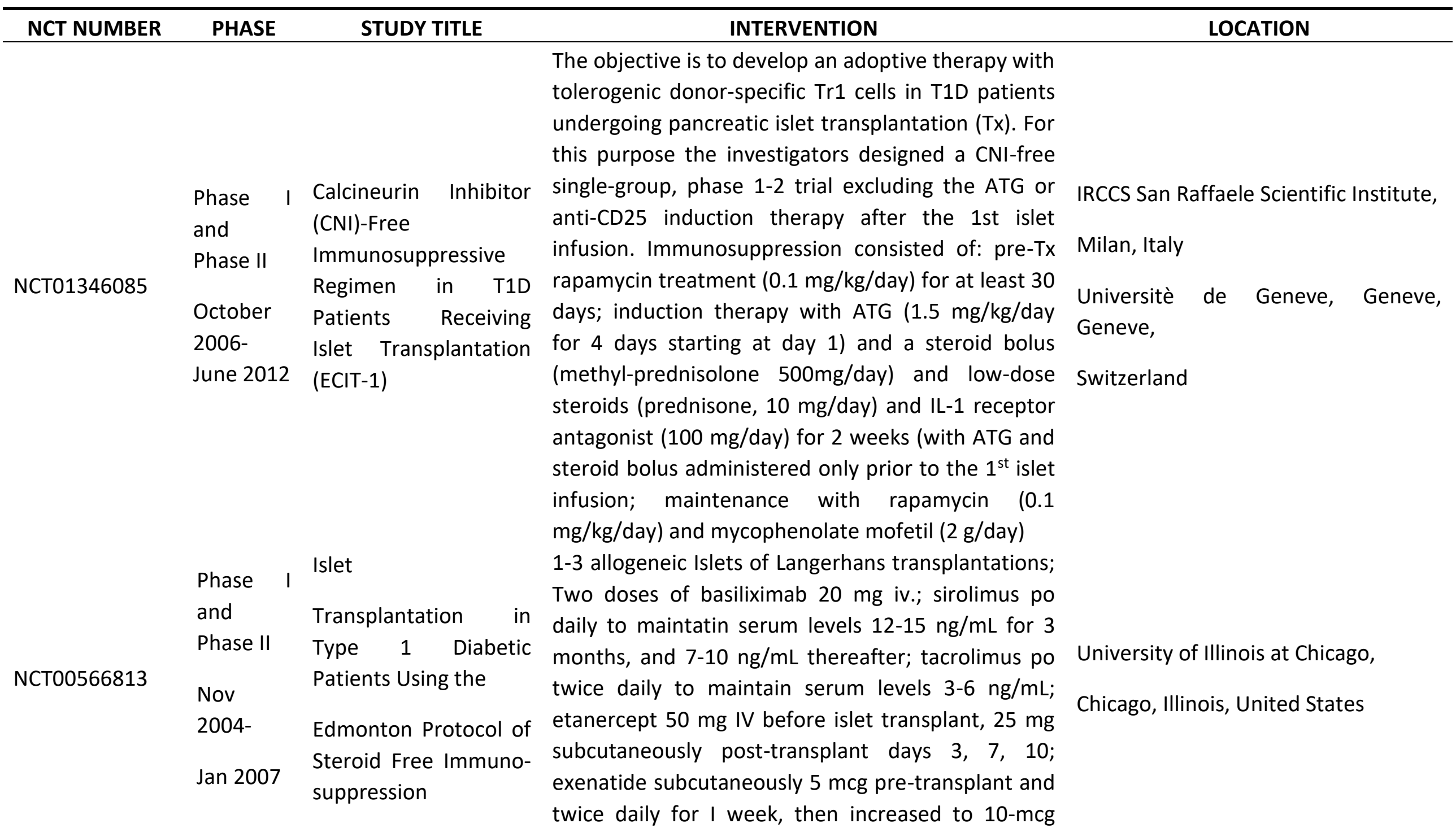


NCT00014911

Islet Transplantation for Type 1 Diabetes

Phase II

Dec Islet Transplantation

2005- Using Abatacept

Dec 2014

Phase II

NCT01220856 July 2010

June 2014

Reparixin in Pancreatic

NCT00175253 Phase II Alemtuzumab twice daily for 6 months after the last islet transplant.

This study extends the results obtained from the Edmonton study, which used islet transplantation in Type 1 diabetic patients with steroid-free immunosuppression. In addition to standard Drug: Sirolimus, Tacrolimus and Daclizumab immunosuppression, Sulfamethoxazole, Ganciclovir, Trimethoprim and Pentamidine is given to the patients.

Islet transplantation in type 1 diabetics with hypoglycemic unawareness using abatacept as a part of a novel calcineurin-inhibitor-sparing immunosuppressive regimen. In addition to Efalizumab and Belatacept, Abatacept was administered monthly for the duration of functioning islet allografts.

This study is designed to explore the efficacy of reparixin (in concert with standard immunosuppression) in preventing graft dysfunction after islet transplantation in type 1 diabetes patients.

In this study, alemtuzumab induction pretransplant, is combined with tacrolimus and
University of Miami, Florida; Massachusetts General Hospital Massachusetts; University of Minnesota, Minnesota; Washington University, Missouri; and Benaroya Research Inst at Virginia Mason Research Center, Washington in USA University of Alberta Alberta in Canada; Justus-Leibig University, Giessen in Germany.University of Milan, Milan in Italy and University of Geneva Geneva, Switzerland.

\section{Emory University, Atlanta, Georgia,}

United States

- University Hospital Carl Gustav CarusDresden, Dresden, Germany

- Ospedale San Raffaele, Milan, Italy

University of Alberta - Clinical Islet 


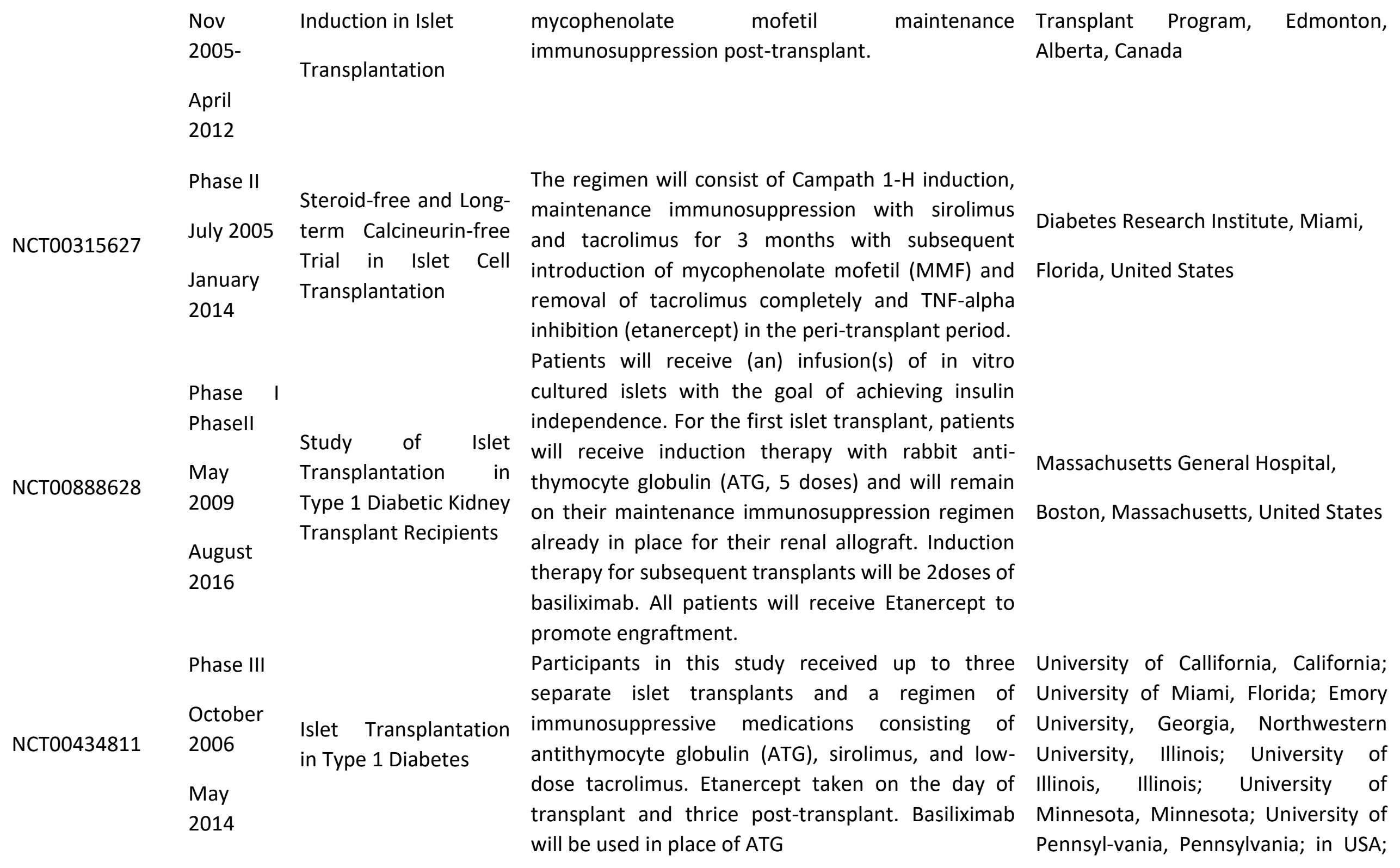


for the second and third transplants.

Participants in this study received up to three Phase II

NCT00468403 2008

April

2013

NCT00434850

\section{Phase II Peritransplant}

Deoxyspergualin

Oct 2006-

Islet transplantation in

Nov 2013 Type 1 Diabetes

NCT00285233

separate islet transplants and a regimen of

The purpose of this study is to assess the safety and efficacy of deoxyspergualin (DSG), an immunosuppressant drug, on post-transplant islet

in function in people with type 1 diabetes who have not responded to intensive insulin therapy. Participants in this study will receive up to three separate islet transplants. They will also receive ATG, sirolimus, Tacrolimus, and Etanercept.

Phase I \&

Delayed

Phase II

Mycophenolate
October LEA29Y (Belatacept) Emory Edmonton

Protocol immunosuppressive medications consisting of belatacept, basiliximab (an IL-2 monoclonal antibody receptor blocker), and mycophenolate mofetil.
Univer- sity of Alberta, Alberta, Canada.

Emory University, Atlanta, Georgia,

United States

University of Alberta, Edmonton, Alberta, Canada

University of Californinia, San Francisco,

- University of

Sept Donor Islet Mofetil in Single-

Allotransplantation in
The objective of this study was to assess the safety and efficacy of islet allotransplantation for the reestablishment of stable glycemic control in patients with type 1 diabetes, using anti-thymocyte globulin induction immunosuppression with sirolimus, mycophenolate mofetil and low dose
Minneapolis,

Minnesota, United States

San Francisco, California, United States

-Northwestern University, Chicago,

Illinois, United States

Minnesota,

University of Minnesota, Minneapolis,

Minnesota, United States 


\begin{tabular}{|c|c|c|c|c|}
\hline & 2005 & Type 1 Diabetes & tacrolimus maintenance immunosuppression. & \\
\hline NCT00285194 & $\begin{array}{l}\text { Phase I \& } \\
\text { Phase II } \\
\text { April } \\
2000 \\
\text { January } \\
2004\end{array}$ & $\begin{array}{l}\text { hOKT3y1 (Ala-Ala) } \\
\text { Combined With } \\
\text { Sirolimus and Delayed } \\
\text { Tacrolimus in Type } 1 \\
\text { Diabetic Islet Allograft } \\
\text { Recipients }\end{array}$ & $\begin{array}{l}\text { This was an open-label, one-year follow-up study of } \\
\text { type } 1 \text { diabetic islet allograft recipients who receive } \\
\text { FcR non-binding OKT3 antibody hOKT3y1 (Ala-Ala) } \\
\text { plus sirolimus induction immunotherapy combined } \\
\text { with sirolimus and delayed tacrolimus maintenance } \\
\text { immunosuppression. Six subjects were } \\
\text { transplanted. }\end{array}$ & $\begin{array}{l}\text { Universtiy of Minnesota, Minneapolis, } \\
\text { Minnesota, United States }\end{array}$ \\
\hline
\end{tabular}


Table 3 IMMUNOSUPPRESSION FOR ISLET TRANSPLANTATION. CLINICAL TRIALS: RECRUITING.

\begin{tabular}{|c|c|c|c|c|}
\hline NCT NUMBER & PHASE & STUDY TITLE & INTERVENTION & LOCATION \\
\hline NCT01909245 & $\begin{array}{l}\text { Phase II } \\
\text { October } \\
2013 \\
\text { July } 2021\end{array}$ & $\begin{array}{l}\text { Islet Cell Transplant } \\
\text { for Type } 1 \text { Diabetes } \\
\text { (TCD) }\end{array}$ & $\begin{array}{l}\text { The purpose of this study is to determine if islet cell } \\
\text { transplantation using ATG or alemtuzumab, along with additional } \\
\text { medications to prevent the body from rejecting the transplanted } \\
\text { cells, is a safe and effective treatment for type } 1 \text { diabetes. Study } \\
\text { participants may receive up to three islet transplants and will be } \\
\text { followed for five years to monitor blood sugar control, islet } \\
\text { transplant function, and changes in quality of life. } \\
\text { The primary goal is to assess the safety and feasibility of } \\
\text { intravenous infusion of ex vivo-selected and ex vivo-expanded } \\
\text { autologous PolyTregs in islet transplant patients. }\end{array}$ & $\begin{array}{l}\text { City of Hope } \\
\text { Medical Center, } \\
\text { Duarte, } \\
\text { California, United } \\
\text { States }\end{array}$ \\
\hline NCT03444064 & $\begin{array}{l}\text { Phase I } \\
\text { February } \\
\text { 2018- } \\
\text { March } 2021\end{array}$ & $\begin{array}{l}\text { PolyTreg } \\
\text { Immunotherapy in Islet } \\
\text { Transplantation }\end{array}$ & $\begin{array}{l}\text { The control group will receive the current Edmonton islet } \\
\text { transplant induction therapy (Alemtuzumab with Etanercept and } \\
\text { Anakinra). The intervention group will receive islet transplant with } \\
\text { same induction therapy as control group and PolyTregs ( } 400-1600 \\
\text { million) six weeks post- transplant. All participants will be } \\
\text { maintained on low dose tacrolimus and sirolimus } \\
\text { immunosuppression. }\end{array}$ & $\begin{array}{l}\text { University of } \\
\text { Alberta, } \\
\text { Edmonton, } \\
\text { Alberta, Canada }\end{array}$ \\
\hline NCT01630850 & $\begin{array}{l}\text { May } 2012 \\
\text { June } 2030\end{array}$ & $\begin{array}{l}\text { Islet Transplantation } \\
\text { in Patients With } \\
\text { "Brittle" Type I } \\
\text { Diabetes }\end{array}$ & $\begin{array}{l}\text { The purpose of this study is to learn about the safety of islet } \\
\text { transplantation for Type } 1 \text { diabetes mellitus. Immunosuppression } \\
\text { may include remicade, thymoglobulin, prograf, solu-medrol, and } \\
\text { cellcept. Dosage will vary per patient based on weight. }\end{array}$ & $\begin{array}{l}\text { University of } \\
\text { Chicago Medical } \\
\text { Center, } \\
\text { Chicago, Illinois, } \\
\text { United States }\end{array}$ \\
\hline NCT01241864 & $\begin{array}{l}\text { Phase II } \\
\text { Dec } 2010- \\
\text { Dec } 2025\end{array}$ & $\begin{array}{l}\text { Islet Transplantation } \\
\text { in Type } 1 \text { Diabetic } \\
\text { Kidney Allograft }\end{array}$ & $\begin{array}{l}\text { The purpose of this study is to learn about the safety of islet } \\
\text { transplantation when performed after kidney transplantation. } \\
\text { Immunosuppression varies but may include prograf, cellcept, } \\
\text { sirolimus, prednisone. Dosage will vary per patient based on } \\
\text { weight. }\end{array}$ & $\begin{array}{l}\text { The University of } \\
\text { Chicago, Chicago, } \\
\text { Illinois, United } \\
\text { States }\end{array}$ \\
\hline
\end{tabular}


More recently, Salk Institute scientists have generated the first immune-evasive, glucose responsive human islet-like organoids (HILOs) from induced pluripotent stem cells that provide a promising alternative to cadaveric and device-dependent therapies in the treatment of diabetes [113]. They demonstrated that non-canonical WNT4 signaling drives the metabolic maturation of HILOs necessary for robust ex vivo glucose-stimulated insulin secretion. HILOs are able to reestablish glucose homeostasis in diabetic immunodeficient NOD/SCID mice following transplantation. Furthermore, overexpression of programmed death-ligand 1 (PD-L1) promotes the survival of HILO xenograft, restoring glucose homeostasis in Streptozotocin-induced, immunocompetent diabetic mice for 50 days. In vitro stimulation with interferon- $\gamma$ (IFN- $\gamma$ ) induces endogenous PD-L1 expression and restricts T cell activation and graft rejection. Extensive research and preclinical testing to confirm the durability, safety and efficacy of this system for use in humans is still required to advance this system to clinical trials.

\subsection{Graft Function}

Currently, approximately $30-50 \%$ of original islet mass can be recovered from a cadaveric pancreas for transplantation [78]. Of this, approximately half of the transplanted islets are further destroyed by the IBMIR, a serious obstacle to successful islet engraftment. First achievement of insulin independence measured from initial islet infusion with or without subsequent infusion, is an indicator of the rate of engraftment under real-time conditions that include early graft loss, islet resource availability, patient/doctor decisions and myriad other factors [55]. The first islet infusion usually results in partial islet function correlating with detectable serum C-peptide, lowering of insulin requirements in $40-60 \%$ of the recipients, immediate improvement in glucose control with $\mathrm{HbA} 1 \mathrm{c}$ at $<7 \%$ and prevention of severe hypoglycemic episodes and hypoglycemic unawareness, resulting in an instant improvement in quality of life [14, 78, 114]. Using the original Edmonton Protocol, a steep loss of insulin independence was observed by the third year, but in most of the transplanted patients a persistent C-peptide and continuous longitudinal protection from hypoglycemia was observed [43]. Apart from allograft rejection and the recurrence of autoimmunity exacerbated by marginal initial islet mass engraftment, a number of factors played a contributory role in the long-term loss of insulin independence. However since then, advances in donor selection, islet isolation, antirejection and anti-inflammatory agents have yielded clinical islet transplant outcomes that mirror whole-organ pancreas transplantation outcomes, achieving greater than $\sim 70 \%$ and $\sim 50 \%$ insulin independence rates in select centers at one year and five years post-transplantation $[14,16,17,45,47,56,94,115-121]$. According to the latest CITR report, it is notable that the cumulative rate of achievement of insulin independence follows the general shape of engraftment curves for solid organs, but with a slower initial slope, indicative of multiple infusions [55]. While the overall rate of first achievement of insulin independence is, remarkably, nearly identical between islet transplantation alone and islet after kidney recipients, the most predictive factors of this endpoint for islet transplantation alone were, immunosuppression with IL2R antagonists and recipient age $\geq 35$. Factors that result in optimized outcomes post last infusion included, induction immunosuppression with T cell depletion and/or TNF-alpha inhibitor, maintenance immunosuppression with mTOR inhibitor and CNI, IEQ's $\geq 325,000$ [55]. The CITR report also demonstrates that even moderate amounts of endogenous Cpeptide significantly improves $\mathrm{HbA1c}$ which in turn contributes to reducing the risk of long-term 
complications such as those affecting the vasculature and peripheral nerves. Additionally, a complete abolition of severe hypoglycemic episodes and impaired awareness of hypoglycemia is observed in most cases indicating that islet transplantation offers an alternative form of cure for patients who cannot achieve adequate glycemic control using intensive exogenous insulin treatment and suffer from debilitating and recurrent hypoglycemic events [56].

\subsection{Islet/beta Cell Encapsulation Strategies}

Islet encapsulation strategies involve encapsulation of human or pig islets with a semipermeable barrier consisting of a semi-porous device (micro- or macro-encapsulation/bioartificial pancreas) [5]. The device needs to support the exchange of nutrients and oxygen as well as allow the encapsulated islets to sense fluctuations in blood glucose and respond by secreting insulin. It should also physically isolate the islets from the host's immune responses potentially eliminating the requirement for toxic systemic immunosuppression [5, 102]. Despite the progress in biomaterial strategies for encapsulation, the host's immune responses to foreign materials remains a major limitation hindering their potential for clinical transplantation. Clinical trials of porcine islets conducted in New Zealand and Argentina [122-127] have met with limited success, however there is still a considerable amount of work involving optimization of encapsulation methods and materials that needs to be accomplished before the technique can be used in large clinical trials in the US.

Clinical trials that are currently looking into islet encapsulation strategies are listed below:

- ClinicalTrial \# NCT03513939 is a Phase I/II trial that studies the safety, tolerability and efficacy of implanting the Sernova's Cell Pouch ${ }^{\mathrm{TM}}$ subcutaneously. The Cell Pouch $^{\mathrm{TM}}$ is designed as a scaffold made of non-degradable polymers, formed into small cylindrical chambers which, when placed in the subcutaneous site, becomes incorporated with tissue and microvessels to the circumference of removable plugs within as early as two weeks as demonstrated in preclinical studies. After tissue incorporation, the plugs are removed, leaving fully formed tissue chambers with central void spaces for the transplantation of therapeutic cells including islets. The Cell Pouch $^{\text {TM }}$ forms a natural environment, rich in microvessels that allows the transplanted islets to engraft with intravascular microvessels. It is believed that this engraftment will enable long-term survival and function of transplanted islets. Immunosuppression is initiated after a minimum of three weeks after Cell Pouch ${ }^{\mathrm{TM}}$ implantation, and optimized for another three weeks. This allows for proper vascularization of the Cell Pouch ${ }^{\mathrm{TM}}$ chambers and the patient to be stabilized on immunosuppression prior to transplantation. A mass of highly purified islets (>3,000 IEQs per $\mathrm{kg}$ of patient body weight) can be transplanted in the Cell Pouch ${ }^{\mathrm{TM}}$.

- Clinical trial \# NCT00790257 is a phase I clinical trial to study the safety and efficacy study of encapsulated human islet allotransplantation to treat T1D. With the view to avoid immunosuppression, this protocol tests the safety and the efficacy of encapsulated human islets in a "Monolayer Cellular Device" for islet allotransplantation in type 1 diabetic patients, performed at the University clinical hospital Saint-Luc, Brussels. Encapsulated human islets will be transplanted in the subcutaneous tissue as a "safety procedure" for patients.

- Clinical trial \# NCT01379729 is a phase I clinical trial that studies an alginate embedded human beta cell graft in a "therapeutic" dose in the intraperitoneal cavity of type 1 diabetic patients under immunosuppression with Tacrolimus/MMF. 
- Clinical trial \# NCT02064309 is a phase I/II clinical trial to assess the safety and efficacy of transplantation of macro-encapsulated human islets within the Bioartificial Pancreas Beta-Air implanted subcutaneously in patients with T1D without immunosuppression.

Based on the futuristic prospect that human stem cell derived islets may be used for islet transplantation thereby addressing the limitation of shortage of donor organs to provide islets, California based company ViaCyte Inc. has successfully differentiated human embryonic stem cells (hESCs) into pancreatic endoderm cells (PEC). The PECs displayed positive C-peptide, pro-insulin as well as key transcription factors that led to regulated insulin production post-transplantation and in-vivo differentiation [16, 96-97, 127]. Two clinical trials of Viacyte's VC-01(NCT02239354) and VC-02 (NCT03163511) utilize these hESC-derived PECs encased in a macroencapsulation device and implanted subcutaneously. In the first clinical trial, the encapsulation device has an intact membrane preventing direct immune cell-to-cell contact, whereas in the second trial, the device has microperforations designed to improve neovascularization, but necessitating requisite immunosuppression. Ongoing data are eagerly awaited to validate the safety and preliminary efficacy of these promising approaches.

\subsection{Islet Transplantation in Extrahepatic Sites}

The current site of transplantation in the liver is not ideal, due to several factors. These include amongst others, significant liver inflammation following islet infusion; potential complications such as massive bleeding and thrombosis, portal hypertension and fatal hepatic necrosis; islet toxicity due to high levels of immunosuppressants and gastrointestinal toxins; inability to retrieve islets post-transplantation; and development of graft dysfunction in a number of intrahepatic allogeneic and autologous islet graft recipients [12, 14, 77, 128-131]. Furthermore, islets in the liver, are subjected to variable glucose concentrations than they would be exposed to in the pancreas which could be toxic $[12,131]$. Also compared to the native tissue oxygen tension and parenchymal oxygen tension of 40 and $30 \mathrm{mmHg}$ that islets are exposed to in the pancreas, the liver has significantly lower tensions of $<10 \mathrm{mmHg}$ for both [12, 130,132]. Free fatty acids are also thought to potentially contribute to islet dysfunction in the liver [133]. Additionally, insulin secretion results in triglyceride deposition into the surrounding hepatic tissue further exacerbating this problem.

Other extrahepatic sites that have been explored include amongst others bone marrow, the gastric submucosa, genitourinary tract, the omentum, anterior eye chamber, testis, thymus, striated muscle, kidney capsule and the peritoneum $[5,12,16,131]$. Of these, sites favored have been the omental pouch due to its high level of angiogenic factors, the brachioradialis muscle where there has been some success, under the kidney capsule, within a venous sac, immune privileged sites which would allow for the avoidance of rejection, and also the pancreas itself although there is insufficient evidence for this location [12].

Several clinical trials are currently recruiting or active, are studying alternative site of transplantation. For instance, Clinical trial \# NCT02213003, NCT02821026 and NCT02803905 study islet allotransplantation in the omentum; Clinical trial \# NCT03977662 studies cotransplantation of allogeneic parathyroid glands (PTG) with adult pancreatic islets in the intramuscular site; Clinical trial \# NCT02916680 studies islet transplantation in the anterior chamber of the eye; Clinical trial \# 
NCT01722682 studies islet transplantation in the bone-marrow; and Clinical trial \# NCT01571817 and NCT02402439 study islet transplantation in the gastric submucosa.

\section{Islet Transplantation: Way Past an Experimental Procedure}

In Australia, Canada and many Asian and European countries including United Kindgdom, Sweden, Switzerland, France and Italy, islet allotransplantation is approved and covered by national healthcare systems [14]. However in the US, islet allotransplantation is still considered an experimental procedure. Two multicentre phase III Biological Licensure Application (BLA)-enabling islet allotransplantation clinical trials have been conducted that were funded by NIH and coordinated by the CIT Consortium [79, 134]. These Phase III trials represent a pivotal milestone since these and similar studies will help pave the way towards reimbursement for islet allotransplantation through Medicare and Medicaid, which will have major impact on its future as a therapeutic strategy for T1D in the USA. Currently patients with brittle T1D associated recurrent hypoglycemic episodes or marked glycemic lability as well as cardiovascular disease form the basis of consideration for coverage as pancreas transplantation is not feasible because of the risk of major surgery [21, 81]. Also improved outcomes that have been observed in long-term insulin independence with near normalization of $\mathrm{HbA1C}$ in the absence of severe hypoglycemic episodes in select trials, coupled with advances in technical approaches and immunosuppressive therapy as well as the increase in number of clinical islet allotransplantations performed further bolster the chances of BLA approval $[45,50]$. Costs incurred by this technology such as the costs that are charged by the Organ Procurement Organization for a donor pancreas or costs that are incurred for establishing an Federal Drug Administration (FDA) approved GMP islet isolation facility and maintaining a trained islet isolation team, have also proven to be a major deterrent to its wide spread application. Based on the improvement that has been observed in the quality of life and disease management as well as the reduced risk of diabetes associated complications in patients who have had either an autologous islet transplantation following total pancreatectomy or have had islet allotransplantation for treatment of brittle T1D associated with severe hypoglycemic episodes and unawareness and glycemic lability, the high cost associated with this technology should not play a primary role in the decision-making process to consider third party reimbursement, especially since similar costs are incurred by the already accepted pancreas transplantation [135].

\section{Conclusions}

Over the last 16 years, incremental advances have been made in several aspects of islet transplantation including amongst others, optimized donor selection, better preservation of donor pancreas, improvements in islet isolation technique and experience of the centers and personnel, novel beneficial islet culture techniques prior to transplantation and potent immunosuppressive therapy that promote longitudinal islet transplant outcomes. Improved islet graft durability at five years post transplantation now parallels that of whole pancreas grafts in select centers, with the added advantage of islet transplantation being a less invasive procedure that is accompanied with an improvement in the quality of life due to prevention of severe hypoglycemic episodes and unawareness and risk of complications. The main hurdles that currently remain relate to procedural availability, the cost of the technology and most importantly sustainable 
reimbursement. Islet transplantation is still considered an experimental procedure in the USA and recognition by the FDA would lead to third party reimbursement which would help pave the way to make islet transplantation a clinically therapeutic option with wide-spread application.

\section{Author Contributions}

Both authors contributed equally to this work. Dr. Preeti Chhabra contributed to literature survey, writing, editing and proof-reading this article. Dr. Kenneth L. Brayman contributed to writing and editing this article.

\section{Funding}

American Diabetes Association \#1-17-IBS-244.

\section{Competing Interests}

The authors have declared that no competing interests exist.

\section{References}

1. Dean PG, Kukla A, Stegall MD, Kudva YC. Pancreas transplantation. BMJ. 2017; 357: j1321.

2. Chhabra P, Brayman KL. Overcoming barriers in clinical islet transplantation: Current limitations and future prospects. Curr Probl Surg. 2014; 51: 49-86.

3. JDRF type 1 diabetes facts. Available from: https://www.jdrf.org/t1d-resources/about/facts/

4. ADA American Diabetes Association, Statistics about Diabetes. Available from: https://www.diabetes.org/resources/statistics/statistics-about-diabetes

5. Gamble A, Pepper AR, Bruni A, Shapiro AM. The journey of islet cell transplantation and future development. Islets. 2018; 10: 80-94.

6. Seckold R, Fisher E, de Bock M, King BR, Smart CE. The ups and downs of low-carbohydrate diets in the management of Type 1 diabetes: A review of clinical outcomes. Diabet Med. 2019; 36: 326-334.

7. Yeh HC, Brown TT, Maruthur N, Ranasinghe P, Berger Z, Suh YD, et al. Comparative effectiveness and safety of methods of insulin delivery and glucose monitoring for diabetes mellitus: A systematic review and meta-analysis. Ann Intern Med. 2012; 157: 336-347.

8. Stone JY, Haviland N, Bailey TS. Review of a commercially available hybrid closed-loop insulindelivery system in the treatment of Type 1 diabetes. Ther Deliv. 2018; 9: 77-87.

9. Allen N, Gupta A. Current diabetes technology: Striving for the artificial pancreas. Diagnostics. 2019; 9: 31.

10. Saunders A, Messer LH, Forlenza GP. MiniMed 670G hybrid closed loop artificial pancreas system for the treatment of type 1 diabetes mellitus: Overview of its safety and efficacy. Expert Rev Med Devices. 2019; 16: 845-853.

11. Diabetes Control and Complications Trial Research Group. The effect of intensive treatment of diabetes on the development and progression of long-term complications in insulindependent diabetes mellitus. N Engl J Med. 1993; 329: 977-986.

12. Ramesh A, Chhabra P, Brayman KL. Pancreatic islet transplantation in type 1 diabetes mellitus: An update on recent developments. Curr Diabetes Rev. 2013; 9: 294-311. 
13. Chhabra P, Brayman KL. Current status of immunomodulatory and cellular therapies in preclinical and clinical islet transplantation. J Transplant. 2011; 2011: 637692.

14. Shapiro AM, Pokrywczynska M, Ricordi C. Clinical pancreatic islet transplantation. Nat Rev Endocrinol. 2017; 13: 268-277.

15. Shapiro AM, Lakey JR, Ryan EA, Korbutt GS, Toth E, Warnock GL, et al. Islet transplantation in seven patients with type 1 diabetes mellitus using a glucocorticoid-free immunosuppressive regimen. N Engl J Med. 2000; 343: 230-238.

16. Pepper AR, Bruni A, Shapiro AM. Clinical islet transplantation: Is the future finally now? Curr Opin Organ Transplant. 2018; 23: 428-439.

17. Jin SM, Kim KW. Is islet transplantation a realistic approach to curing diabetes? Korean J Intern Med. 2017; 32: 62-66.

18. Schuetz C, Markmann JF. Islet cell transplant: Update on current clinical trials. Curr Transplant Rep. 2016; 3: 254-263.

19. Shapiro AM, Ricordi C, Kirk AD, Knechtle SJ, Larsen CP, Madsen JC, et al. Textbook of organ transplantation. Islet cell transplantation procedure \& surgical technique. New Jersey: WileyBlackwell; 2014. p.1314-p.1333.

20. Bellin MD, Barton FB, Heitman A, Harmon JV, Kandaswamy R, Balamurugan AN, et al. Potent induction immunotherapy promotes long-term insulin independence after islet transplantation in type 1 diabetes. Am J Transplant. 2012; 12: 1576-1583.

21. McCall M, Shapiro AM. Update on islet transplantation. Cold Spring Harb Perspect Med. 2012; 2: a007823.

22. Shapiro AM. State of the art of clinical islet transplantation and novel protocols of immunosuppression. Curr Diab Rep. 2011; 11: 345-354.

23. Banting FG, Best $\mathrm{CH}$, Collip JB, Campbell WR, Fletcher AA. Pancreatic extracts in the treatment of diabetes mellitus. Can Med Assoc J. 1922; 12: 141-146.

24. Minkowski O. Weitere mittheilungen über den diabetes mellitus nach exstirpation des pankreas. Berl Klin Wochenschr. 1892; 29: 90-94.

25. Williams $\mathrm{P}$. Notes on diabetes treated with extract and by grafts of sheep's pancreas. Br Med J. 1894; 2: 1303-1304.

26. Pybus F. Notes on supra renal and pancreatic grafting. Lancet. $1924 ; 204: 550-551$.

27. Ssobolew LW. Zur normalen und pathologischen morphologie der inneren secretion der bauchspeicheldrüse. Die eseutung der Langerhans schen inseln. Virchows Arch. 1902; 168: $91-$ 128.

28. Moskalewski S. Isolation and culture of the islets of langerhans of the guinea pig. Gen Comp Endocrinol. 1965; 5: 342-353.

29. Lacy PE, Kostianovsky M. Method for the Isolation of intact islets of Langerhans from the rat pancreas. Diabetes. 1967; 16: 35-39.

30. Ballinger WF, Lacy PE. Transplantation of intact pancreatic islets in rats. Surgery. 1972; 72: 175-186.

31. Kemp CB, Knight MJ, Scharp DW, Lacy PE, Ballinger WF. Transplantation of isolated pancreatic islets into the portal vein of diabetic rats. Nature. 1973; 244: 447.

32. Payne WD, Sutherland DE, Matas AJ, Najarian JS. Amelioration of diabetes in rats by transplantation of islet tissue from a single donor to multiple recipients. Surg Forum. 1977; 28: 301-304. 
33. Najarian JS, Sutherland DE, Matas AJ, Goetz FC. Human islet autotransplantation following pancreatectomy. Transplant Proc. 1979; 11: 336-340.

34. Najarian JS, Sutherland DE, Baumgartner D, Burke B, Rynasiewicz JJ, Matas AJ, et al. Total or near total pancreatectomy and islet autotransplantation for treatment of chronic pancreatitis. Ann Surg. 1980; 192: 526-542.

35. Ricordi C, Lacy PE, Finke EH, Olack BJ, Scharp DW. Automated method for isolation of human pancreatic islets. Diabetes. 1988; 37: 413-420.

36. Piemonti L, Pileggi A. 25 years of the ricordi automated method for islet isolation. CellR4 Repair Replace Regen Reprogram. 2013; 1: e128.

37. Tzakis AG, Zeng Y, Fung JJ, Todo S, Demetris AJ, Starzl TE, et al. Pancreatic islet transplantation after upper abdominal exenteration and liver replacement. Lancet. 1990; 336: 402-405.

38. Ricordi C, Tzakis AG, Carroll PB, Zeng YJ, Rilo HL, Alejandro R, et al. Human islet isolation and allotransplantation in 22 consecutive cases. Transplantation. 1992; 53: 407-414.

39. Hering BJ, Bretzel RG, Hopt UT, Brandhorst H, Brandhorst D, Bollen CC, et al. New protocol toward prevention of early human islet allograft failure. Transplant Proc. 1994; 26: 570-571.

40. Bretzel RG, Brandhorst D, Brandhorst H, Eckhard M, Ernst W, Friemann S, et al. Improved survival of intraportal pancreatic islet cell allografts in patients with type 1 diabetes mellitus by refined peritransplant management. J Mol Med. 1999; 77: 140-143.

41. Alejandro R, Angelico MC, Ricordi C, Burke G, Nery J, Miller J, et al. Long-term function of islet allograft in type I diabetes mellitus. Transplant Proc. 1995; 27: 3158.

42. Merani S, Shapiro AM. Current status of pancreatic islet transplantation. Clin Sci. 2006; 110: 611-625.

43. Ryan EA, Paty BW, Senior PA, Bigam D, Alfadhli E, Kneteman NM, et al. Five-year follow-up after clinical islet transplantation. Diabetes. 2005; 54: 2060-2069.

44. Shapiro AM, Ricordi C, Hering BJ, Auchincloss H, Lindblad R, Robertson RP, et al. International trial of the Edmonton protocol for islet transplantation. New Engl J Med. 2006; 355: 13181330.

45. Bellin MD, Barton FB, Heitman A, Harmon JV, Kandaswamy R, Balamurugan AN, et al. Potent induction immunotherapy promotes long-term insulin independence after islet transplantation in type 1 diabetes. Am J Transplant. 2012; 12: 1576-1583.

46. Vantyghem MC, Kerr-Conte J, Arnalsteen L, Sergent G, Defrance F, Gmyr V, et al. Primary graft function, metabolic control, and graft survival after islet transplantation. Diabetes Care. 2009; 32: 1473-1478.

47. Bellin MD, Kandaswamy R, Parkey J, Zhang HJ, Liu B, Ihm SH, et al. Prolonged insulin independence after islet allotransplants in recipients with type 1 diabetes. Am J Transplant. 2008; 8: 2463-2470.

48. Koh A, Senior $P$, Salam A, Kin T, Imes S, Dinyari $P$, et al. Insulin-heparin infusions peritransplant substantially improve single-donor clinical islet transplant success. Transplantation. 2010; 89: 465-471.

49. Leitão $C B$, Tharavanij $T$, Cure $P$, Pileggi A, Baidal DA, Ricordi $C$, et al. Restoration of hypoglycemia awareness after islet transplantation. Diabetes Care. 2008; 31: 2113-2115.

50. Berney T, Ferrari-Lacraz S, Bühler L, Oberholzer J, Marangon N, Philippe J, et al. Long-term insulin-independence after allogeneic islet transplantation for type 1 diabetes: Over the10year mark. Am J Transplant. 2009; 9: 419-423. 
51. Shapiro AM. Strategies toward single-donor islets of Langerhans transplantation. Curr Opin OrganTransplant. 2011; 16: 627-631.

52. Mineo D, Pileggi A, Alejandro R, Ricordi C. Point: Steady progress and current challenges in clinical islet transplantation. Diabetes Care. 2009; 32: 1563-1569.

53. Barton FB, Rickels MR, Alejandro R, Hering BJ, Wease S, Naziruddin B, et al. Improvement in outcomes of clinical islet transplantation:1999-2010. Diabetes Care. 2012; 35: 1436-1445.

54. Jamiolkowski RM, Guo LY, Li YR, Shaffer SM, Naji A. Islet transplantation in type I diabetes mellitus. Yale J Biol Med. 2012; 85: 37-43.

55. Collaborative Islet Transplant Registry. CITR 10th annual report. Avaliable from: https://www.citregistry.org/content/citr-10th-annual-report

56. Othonos N, Choudhary P. Who should be considered for islet transplantation alone? Curr Diab Rep. 2017; 17: 23.

57. Tatum JA, Meneveau MO, Brayman KL. Single-donor islet transplantation in type 1 diabetes: Patient selection and special considerations. Diabetes Metab Syndr Obes. 2017; 10: 73-78.

58. Manrique A, Jiménez $C$, Herrero ML, Meneu JC, Abradelo $M$, Moreno A, et al. Pancreas preservation with the University of Wisconsin versus Celsior solutions. Transplant Proc. 2006; 38: 2582-2584.

59. Iwanaga Y, Sutherland DE, Harmon JV, Papas KK. Pancreas preservation for pancreas and islet transplantation. Curr Opin Organ Transplant. 2008; 13: 135-141.

60. Hubert T, Gmyr V, Arnalsteen L, Jany T, Triponez F, Caiazzo R, et al. Influence of preservation solution on human islet isolation outcome. Transplantation. 2007; 83: 270-276.

61. Giraud S, Claire B, Eugene M, Debre P, Richard F, Barrou B. A new preservation solution increases islet yield and reduces graft immunogenicity in pancreatic islet transplantation. Transplantation. 2007; 83: 1397-1400.

62. Sthle $M$, Foss $A$, Gustafsson $B$, Lempinen $M$, Lundgren $T$, Rafael $E$, et al. Evaluation of perfluorohexyloctane/polydimethylsiloxane for pancreas preservation for clinical islet isolation and transplantation. Cell Transplant. 2016; 25: 2269-2276.

63. Hering BJ, Matsumoto I, Sawada T, Nakano M, Sakai T, Kandaswamy R, et al. Impact of twolayer pancreas preservation on islet isolation and transplantation. Transplantation. 2002; 74: 1813-1816.

64. Fraker CA, Alejandro R, Ricordi C. Use of oxygenated perfluorocarbon toward making every pancreas count. Transplantation. 2002; 74: 1811-1812.

65. Tsujimura T, Kuroda Y, Kin T, Avila JG, Rajotte RV, Korbutt GS, et al. Human islet transplantation from pancreases with prolonged cold ischemia using additional preservation by the two-layer (UW solution/perfluorochemical) cold-storage method. Transplantation. 2002; 74: 1687-1691.

66. Lakey JR, Tsujimura T, Shapiro AM, Kuroda Y. Preservation of the human pancreas before islet isolation using a two-layer (UW solution-perfluorochemical) cold storage method. Transplantation. 2002; 74: 1809-1811.

67. Kin T, Mirbolooki M, Salehi P, Tsukada M, O'Gorman D, Imes S, et al. Islet isolation and transplantation outcomes of pancreas preserved with University of Wisconsin solution versus two-layer method using preoxygenated perfluorocarbon. Transplantation. 2006; 82: 12861290. 
68. Caballero-Corbalán J, Eich T, Lundgren T, Foss A, Felldin M, Källen R, et al. No beneficial effect of two-layer storage compared with UW-storage on human islet isolation and transplantation. Transplantation. 2007; 84: 864-869.

69. Collaborative Islet Transplant Registry (CITR) Annual Report. Rockville, MD: The EMMES Corporation; 2007.

70. Brandhorst H, Friberg A, Nilsson B, Andersson HH, Felldin M, Foss A, et al. Large-scale comparison of liberase $\mathrm{HI}$ and collagenase NB1 utilized for human islet isolation. Cell Transplant. 2010; 19: 3-8.

71. Misawa R, Ricordi C, Miki A, Barker S, Molano RD, Khan A, et al. Evaluation of viable beta-cell mass is useful for selecting collagenase for human islet isolation: Comparison of collagenase NB1 and liberase HI. Cell Transplant. 2012; 21: 39-47.

72. Balamurugan AN, Breite AG, Anazawa T, Loganathan G, Wilhelm JJ, Papas KK, et al. Successful human islet isolation and transplantation indicating the importance of class 1 collagenase and collagen degradation activity assay. Transplantation. 2010; 89: 954-961.

73. Qi M, Valiente L, McFadden B, Omori K, Bilbao S, Juan J, et al. The choice of enzyme for human pancreas digestion is a critical factor for increasing the success of islet isolation. Transplant Direct. 2015; 1: e14.

74. Ionescu-Tirgoviste C, Gagniuc PA, Gubceac E, Mardare L, Popescu I, Dima S, et al. A 3D map of the islet routes throughout the healthy human pancreas. Sci Rep. 2015; 5: 14634.

75. Nano R, Clissi B, Melzi R, Calori G, Maffi P, Antonioli B, et al. Islet isolation for allotransplantation: Variables associated with successful islet yield and graft function. Diabetologia. 2005; 48: 906-912.

76. Piemonti L. Islet Transplantation. 2019 Jul 21. Endotext [Internet]. South Dartmouth, MA: MDText.com, Inc.; 2000-. Available from: https://www.ncbi.nlm.nih.gov/books/NBK278966/

77. Anazawa T, Okajima H, Masui T, Uemoto S. Current state and future evolution of pancreatic islet transplantation. Ann Gastroenterol Surg. 2018; 3: 34-42.

78. Witkowski P, Solomina J, Michael Millis J. Pancreas, biliary tract, liver and spleen. Shackelford's surgery of the alimentary tract, 2 Volume Set. 8th ed. Amsterdam: Elsevier; 2019; 1226-1238.

79. Sever CE, Demetris AJ, Zeng J, Carroll P, Tzakis A, Fung JJ, et al. Composition of human islet cell preparations for transplantation. Acta Diabetol. 1992; 28: 233-238.

80. Agarwal A, Brayman KL. Update on islet cell transplantation for type 1 diabetes. Semin Intervent Radiol. 2012; 29: 90-98.

81. Hering BJ, Clarke WR, Bridges ND, Eggerman TL, Alejandro R, Bellin MD, et al. Phase 3 trial of transplantation of human islets in type 1 diabetes complicated by severe hypoglycemia. Diabetes Care. 2016; 39: 1230-1240.

82. Owen RJ, Ryan EA, O'Kelly K, Lakey JR, McCarthy MC, Paty BW, et al. Percutaneous transhepatic pancreatic islet cell transplantation in type 1 diabetes mellitus: Radiologic aspects. Radiology. 2003; 229: 165-170.

83. Kikawa K, Sakano D, Shiraki N, Tsuyama T, Kume K, Endo F, et al. Beneficial effect of insulin treatment on islet transplantation outcomes in Akita mice. PLoS One. 2014; 9: e95451.

84. Senior PA, Kin T, Shapiro J, Koh A. Islet transplantation at the University of Alberta: Status update and review of progress over the last decade. Can J Diabetes. 2012; 36: 32-37. 
85. Villiger P, Ryan EA, Owen R, O'Kelly K, Oberholzer J, Al Saif F, et al. Prevention of bleeding after islet transplantation: Lessons learned from a multivariate analysis of 132 cases at a single institution. Am J Transplant. 2005; 5: 2992-2998.

86. Kawahara T, Kin T, Kashkoush S, Gala-Lopez B, Bigam DL, Kneteman NM, Koh A, et al. Portal vein thrombosis is a potentially preventable complication in clinical islet transplantation. Am J Transplant. 2011; 11: 2700-2707.

87. Rickels MR, Kearns J, Markmann E, Palanjian M, Markmann JF, Naji A, et al. HLA sensitization in islet transplantation. Clin Transpl. 2006; 413-420.

88. Cardani R, Pileggi A, Ricordi C, Gomez C, Baidal DA, Ponte GG, et al. Allosensitization of islet allograft recipients. Transplantation. 2007; 84: 1413-1427.

89. Campbell PM, Senior PA, Salam A, Labranche K, Bigam DL, Kneteman NM, et al. High risk of sensitization after failed islet transplantation. Am J Transplant. 2007; 7: 2311-2317.

90. Koh A, Imes S, Kin T, Dinyari P, Malcolm A, Toso C, et al. Supplemental islet infusions restore insulin independence after graft dysfunction in islet transplant recipients. Transplantation. 2010; 89: 361-365.

91. Naziruddin B, Wease S, Stablein D, Barton FB, Berney T, Rickels MR, et al. HLA class I sensitization in islet transplant recipients: Report from the Collaborative Islet Transplant Registry. Cell Transplant. 2012; 21: 901-908.

92. Eriksson O, Selvaraju R, Eich T, Willny M, Brismar TB, Carlbom L, et al. Positron emission tomography to assess the outcome of intraportal islet transplantation. Diabetes. 2016; 65: 2482-2489.

93. Hering BJ, Kandaswamy R, Ansite JD, Eckman PM, Nakano M, Sawada $T$, et al. Single-donor, marginal-dose islet transplantation in patients with type 1 diabetes. JAMA. 2005; 293: 830835.

94. Chhabra P, Brayman KL. Stem cell therapy to cure type 1 diabetes: From hype to hope. Stem Cells Transl Med. 2013; 2: 328-336.

95. Chhabra P, Brayman KL. Stem cell strategies to promote islet transplantation outcomes. OBM Transplant. 2018; 2: 10.

96. Chhabra P, Brayman KL. Contemporary assessment of stem cell therapies for type 1 diabetes mellitus-time for optimism. Encyclopedia of tissue engineering and regenerative medicine. Ocford: Academic Press; 2019. p.189-p.195.

97. Franz C, Görtz M, Wührl M, Kulu Y, Hoffmann K, Hackert T, et al. The role of pre-procurement pancreas suitability score (P-PASS) and pancreas donor risk index (PDRI) in the outcome of simultaneous pancreas and kidney or pancreas after kidney transplantation. Ann Transplant. 2019; 24: 439-445.

98. Wang LJ, Kin T, O'Gorman D, Shapiro AM, Naziruddin B, Takita M, et al. A multicenter study: North American islet donor score in donor pancreas selection for human islet isolation for transplantation. Cell Transplant. 2016; 25: 1515-1523.

99. Fridell JA, Rogers J, Stratta RJ. The pancreas allograft donor: Current status, controversies, and challenges for the future. Clin Transplant. 2010; 24: 433-449.

100.Fridell JA, Stratta RJ. Expanding the pancreas donor pool. Curr Transpl Rep. 2014; 1: 100-112.

101.Lakey JR, Warnock GL, Rajotte RV, Suarez-Alamazor ME, Ao Z, Shapiro AM, et al. Variables in organ donors that affect the recovery of human islets of Langerhans. Transplantation. 1996; 61: 1047-1053. 
102.Chang CA, Lawrence MC, Naziruddin B. Current issues in allogeneic islet transplantation. Curr Opin Organ Transplant. 2017; 22: 437-443.

103.Berney T, Johnson PR. Donor pancreata: Evolving approaches to organ allocation for whole pancreas versus islet transplantation. Transplantation. 2010; 90: 238-243.

104.Fishman JA. Infection in organ transplantation. Am J Transplant. 2017; 17: 856-879.

105.Kuschal C, Thoms KM, Schubert S, Schäfer A, Boeckmann L, Schön MP, et al. Skin cancer in organ transplant recipients: Effects of immunosuppressive medications on DNA repair. Exp Dermatol. 2012; 21: 2-6.

106.Ojo AO, Held PJ, Port FK, Wolfe RA, Leichtman AB, Young EW, et al. Chronic renal failure after transplantation of a nonrenal organ. N Engl J Med. 2003; 349: 931-940.

107.Azzi JR, Sayegh MH, Mallat SG. Calcineurin inhibitors: 40 years later, can't live without.... J Immunol. 2013; 191: 5785-5791.

108. Bechstein WO. Neurotoxicity of calcineurin inhibitors: Impact and clinical management. Transpl Int. 2000; 13: 313-326.

109. Randhawa PS, Starzl TE, Demetris AJ. Tacrolimus (FK506)-associated renal pathology. Adv Anat Pathol. 1997; 4: 265-276.

110.Rangel EB. Tacrolimus in pancreas transplant: A focus on toxicity, diabetogenic effect and drug-drug interactions. Expert Opin Drug Metab Toxicol. 2014; 10: 1585-1605.

111.Ekberg H, Bernasconi C, Tedesco-Silva H, Vitko S, Hugo C, Demirbas A, et al. Calcineurin inhibitor minimization in the Symphony study: Observational results 3 years after transplantation. Am J Transplant. 2009; 9: 1876-1885.

112. Webber $A B$, Vincenti $F$. An update on calcineurin inhibitor-free regimens: The need persists, but the landscape has changed. Transplantation. 2016; 100: 836-843.

113.Yoshihara E, O'Connor C, Gasser E, Wei Z, Oh TG, Tseng TW, et al. Immune-evasive human islet-like organoids ameliorate diabetes. Nature. 2020; 586: 606-611.

114.Rickels MR, Fuller C, Dalton-Baker C, Markmann E, Palanjian M, Cullison K, et al. Restoration of glucose counterregulation by islet transplantation in long-standing type I diabetes. Diabetes. 2015; 64: 1713-1718.

115.Vantyghem MC, Defrance F, Quintin D, Leroy C, Raverdi V, Prévost G, et al. Treating diabetes with islet transplantation: Lessons from the past decade in Lille. Diabetes Metab. 2014; 40: 108-119.

116. Hering BJ. Achieving and maintaining insulin independence in human islet transplant recipients. Transplantation. 2005; 79: 1296-1297.

117.Gibly RF, Graham JG, Luo X, Lowe Jr WL, Hering BJ, Shea LD. Advancing islet transplantation: From engraftment to the immune response. Diabetologia. 2011; 54: 2494-2505.

118.Senior PA, Kin T, Shapiro J, Koh A. Islet transplantation at the University of Alberta: Status update and review of progress over the last decade. Canad J Diabetes. 2012; 36: 32-37.

119.Posselt AM, Szot GL, Frassetto LA, Masharani U, Tavakol M, Amin R, et al. Islet transplantation in type 1 diabetic patients using calcineurin inhibitor-free immunosuppressive protocols based on T-cell adhesion or costimulation blockade. Transplantation. 2010; 90: 1595-1601.

120.Gangemi A, Salehi P, Hatipoglu B, Martellotto J, Barbaro B, Kuechle JB, et al. Islet transplantation for brittle type 1 diabetes: The UIC protocol. Am J Transplant. 2008; 8: 12501261. 
121.Maffi P, Scavini M, Socci C, Piemonti L, Caldara R, Gremizzi C, et al. Risks and benefits of transplantation in the cure of type 1 diabetes: Whole pancreas versus islet transplantation. $A$ single center study. Rev Diabet Stud. 2011; 8: 44-50.

122.Elliott RB, Escobar L, Tan PLJ, Muzina M, Zwain S, Buchanan C. Live encapsulated porcine islets from a type 1 diabetic patient 9.5 years after xenotransplantation. Xenotransplantation. 2007; 14: 157-161.

123.Wynyard S, Nathu D, Garkavenko O, Denner J, Elliott R. Microbiological safety of the first clinical pig islet xenotransplantation trial in New Zealand. Xenotransplantation. 2014; 21: 309323.

124.Morozov VA, Wynyard S, Matsumoto S, Abalovich A, Denner J, Elliott R. No PERV transmission during a clinical trial of pig islet cell transplantation. Virus Res. 2017; 227: 34-40.

125. Matsumoto S, Abalovich A, Wechsler C, Wynyard S, Elliott RB. Clinical benefit of islet xenotrans-plantation for the treatment of type 1 diabetes. EBioMedicine. 2016; 12: 255-262.

126. Matsumoto S, Tan P, Baker J, Durbin K, Tomiya M, Azuma K, et al. Clinical porcine islet xenotransplantation under comprehensive regulation. Transplant Proc. 2014; 46: 1992-1995.

127.Lilly MA, Davis MF, Fabie JE, Terhune EB, Gallicano Gl. Current stem cell based therapies in diabetes. Am J Stem Cells. 2016; 5: 87-98.

128.Chhabra P, Kensinger CD, Moore DJ, Brayman KL. Present accomplishments and future prospects of cell-based therapies for type 1 diabetes mellitus. Type 1 diabetes-pathogenesis, genetics and immunotherapy. London: IntechOpen; 2019. p.295-p.336.

129.Delaune V, Berney T, Lacotte S, Toso C. Intraportal islet transplantation: The impact of the liver microenvironment. Transpl Int. 2017; 30: 227-238.

130.Addison P, Fatakhova K, Rodriguez Rilo HL. Considerations for an alternative site of islet cell transplantation. J Diabetes Sci Technol. 2019; 14: 338-344.

131.Cantarelli E, Piemonti L. Alternative transplantation sites for pancreatic islet grafts. Curr Diab Rep. 2011; 11: 364-374.

132.Piemonti L, Guidotti LG, Battaglia M. Modulation of early inflammatory reactions to promote engraftment and function of transplanted pancreatic islets in autoimmune diabetes. Adv Exp Med Biol. 2010; 654: 725-747.

133. Leitao CB, Bernetti K, Tharavanij T, Cure P, Lauriola V, Berggren PO, et al. Lipotoxicity and decreased islet graft survival. Diabetes Care. 2010; 33: 658-660.

134.US National Library of Medicine, ClinicalTrials. gov. Efficacy of islet after kidney transplantation. Available from: https://clinicaltrials.gov/ct2/show/NCT00468117

135. Bottino R, Knoll MF, Knoll CA, Bertera S, Trucco MM. The future of islet transplantation is now. Front Med. 2018; 5: 202. 


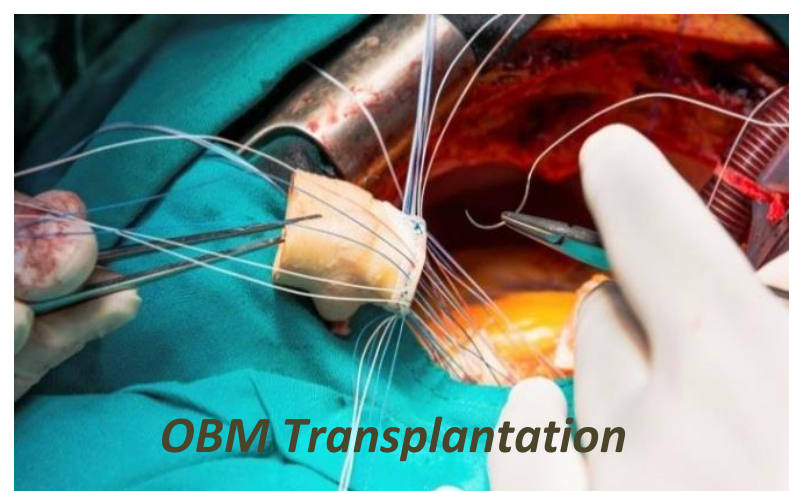

Enjoy OBM Transplantation by:

1. Submitting a manuscript

2. Joining in volunteer reviewer bank

3. Joining Editorial Board

4. Guest editing a special issue

For more details, please visit:

http://www.lidsen.com/journals/transplantation 
Review

\title{
Mauss and Organ Transplants: Ideas of Connectivity between Recipients and Donors and the "Spirit of the Gift"
}

Malcolm Voyce ${ }^{*}$

Macquarie Law School, Macquarie University, Sydney, Australia; E-mail: Malcolm.voyce@gmail.com

* Correspondence: Malcolm Voyce; E-Mail: Malcolm.voyce@gmail.com

Academic Editor: Yasuhiko Sugawara

Special Issue: Ethical and Legal Issues in Organ Transplantation

OBM Transplantation

2020, volume 4, issue 4

doi:10.21926/obm.transplant.2004124
Received: July 22, 2020

Accepted: October 29, 2020

Published: November 16, 2020

\begin{abstract}
This article aims to describe the relationship between donors and their recipients in the context of organ transplants. This analysis is made in the light of Marcel Mauss's work, offering an expansion on an analysis of his discussion on the "spirit of the gift" and his idea that gifts require reciprocation. It is argued that some recipients of donated organs receive a personal element from the donor in that there is a transfer or sharing of the donors' personality and spiritual qualities. The article examines the nature of this form of "interconnectedness". The article considers the qualities of this form of interconnectedness between donors and recipients by examining two specific cases of gift giving. One such case concerns the accounts of the reception of organs by recipients and how they may feel connected with a donated entity. The second case of gifting is the case of Tibetan lamas concerning their funeral ceremonies, where, following cremation, their relics are donated to disciples. This "donation" does not take place by dissecting useable parts of a body for use in another person, but rather by ingestion of the remains of the corpse following cremation. This example shows how such "donations" are seen as incorporating the spiritual qualities and attributes of the donor [1]. The article concludes that while scholars have employed different forms of metaphors to understand the cultural context of organ donations this
\end{abstract}

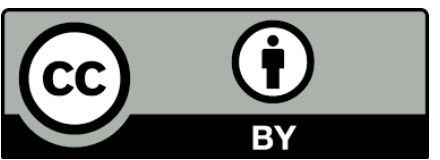

(C) 2020 by the author. This is an open access article distributed under the conditions of the Creative Commons by Attribution License, which permits unrestricted use, distribution, and reproduction in any medium or format, provided the original work is correctly cited. 
article analyzes the elements of the "spirit of the gift." This form of analysis may best be understood in terms of Mauss's notions of the return of the gift and the creation of a "communal bond".

\section{Keywords}

Mauss; reciprocity; gifts; organ transplants; Buddhism

\section{Organ Donations as Gifts}

This article was inspired by the novel of Javier Marius called Tomorrow in the Battle Think of Me (1997) [2]. In this work, Marius examines the connectivity that two men may have between each other through having sex with the same woman.

Marius relates how the sleeping with the same woman "establishes a relationship that our languages no longer reflect, but that certain dead languages do." He contends that there is in existence an ancient Anglo-Saxon verb, no longer in use, that has not survived, that describes the relationship or kinship acquired by two or more men who have slept with the same women, even though such intercourse happened at different times. This verb he conjects originally meant "comradeship", or "conjunction" or "travelling companion" [2].

While this story may be a literary device it represents the concern of this article which is; how do we describe the form of connectivity between donor and donee in organ transplants? It is admitted that not all people feel any connection with the donor and get on with their life regarding the new part merely as one would with a new engine in car.

To establish the shape and form of connectivity in organ transplants two examples are deplyed. The first example describes the experience of a few recipients who receive organs in the usual course of events and who notice the qualities of the donor in the organ.

One story in this context delineates the issue of connectivity (or dis-connectivity). This story narrates how a man who had a hand transplanted and his belief that the new hand did not give him a sense of wellbeing or integrity; eventually he had the hand amputated [3]. The case highlights how people who receive transplants may well have to deal with the incorporation of other bodies.

The second example utilised is from Tibetan culture where the "donors" who are the recipients of funeral relics, have commented how ingestion of these relics establishes a sense of interconnectedness [1]. This example from Tibetan culture is used as an imaginative mental framework to throw light on the cultural context of organ transplants. A discussion is therefor made from Tibetan Buddhist accounts to throw light on organ donations in order to examine a form of connectivity between organ donors and recipients.

\section{The Scholarship on Organ Transplants and Mauss}

As regards organ transplants, scholars have deployed several frameworks of analysis, such as viewing transplants as commodities, sacrifices or gifts. In this article, the idea of transplants as gifts, is developed mainly because this frame indicates a possible response to a donation such as gratitude or thankfulness or what I prefer to call "connectivity". 
Organ donations were first described as "gifts" in the early 1970s, by Titmuss, Fox and Swazey. These authors utilised the work of French sociologist and anthropologist Marcel Mauss, whose Essai sur le Don was published in English as The Gift. This work became paradigmatic for scholars analysing organ transplants [4].

Mauss's aim was to provide an alternative account of capitalist social relations, which he regarded as based on the idea of market relations and self-interest [5]. For Mauss the idea of a gift outlined a "general theory of obligation" to provide an account of the human foundations on which our society was built [6].

A common summary of Mauss's work was that recipients of gifts feel obliged to return gifts in kind, as part of the donor's soul becomes entangled in the gift, wishing to return home and thus compelling the recipient to make a return [5]. It is argued that it is important to add to this standard reading an examination of the connectivity of such gifts by examining the idea of the "spirit of the gift" as explained by Mauss.

While organ transplants have been analysed by different forms of metaphors such as commodification, cannibalism or altruism this article deploys Mauss's notion of the "spirit of the gift" to comprehend the nature of the exchange and importantly the kind of connectivity that may exist between donors and recipients.

To assist my reading of Mauss, the work of Bateman is noted who has commented on the connection between Mauss and Émile Durkheim: Mauss was the latter's nephew and both men shared a common interest in ideas of social solidarity. Bateman also notes how the original French title of the work deploys the word don: this is significant because the term becomes "gift" in English, indicating that the title of the book could be translated into English as An Essay on Giving [4]. Moreover, this emphasis on gifts may have obscured the fact that Mauss, while he frequently did refer to "gifts" (cadeaux), also referred to "services" and "benefits (presentations). In his conclusion, Mauss characterises these sorts of practices as "total social facts" (faits sociaux totaux).

These factors indicate how Mauss's work reflects broader ideas of social solidarity and that something may be lost, should we not adopt a broader concept of giving than that which conceptualises the return of the gift, and therefore the possibility of participating in a wider view of social solidarity [4]. I now expand on this approach to examine the nature of this connecting substance.

Mauss work utilised comparative ethnography and although he realised his generalisations could be criticised, it has been acknowledged that Mauss ultimately produced a "kind of myth, he did capture something essential" [5]. Mauss described what he saw as a common pattern of gifts and sacrifices in "archaic societies." He wrote that while "in theory [gifts] are voluntary, in reality given and returned obligatory; apparently free and disinterested [they are] nevertheless constrained and self-interested" [6].

However, Mauss's concept of a "gift" and the requirement of reciprocity has not been found to exist in deceased donations as practiced in most Western countries. Indeed as Shimazono notes deceased organ donation may be seen as a "modern" gift as such gifts are made possible by modern technology [7]. For instance, in the United States, donations are "voluntary, altruistic, and anonymous." It is noted that in some countries connections between the donor families and recipients are encouraged [8]. This situation is at "odds with Mauss's paradigm" as a wall of separation has been placed between donor and recipient that would seem to prevent any type of personal relationship, which was a key part of Mauss's concept of gift exchange [9]. 
Despite this, the suggestion in Mauss's as regards the idea of reciprocity should not be rejected entirely as regards donations. Should we take time to examine the concept of the "spirit of the gift" and the notion of hau (binding force of the gift) in Mauss's work, it is possible to develop a reading of Mauss that helps one understand the idea of reciprocity in a fashion that has implications for an understanding of organ transplants.

Mauss indicated that a gift had a personality of its own which was distinct from the personality of the donor [6]. Such gifts create a spiritual bond (hau) between the donor and the recipient, which should be returned [10]. Of greater interest here is the nature of hau, which may be seen to be linked to forms of natural forces, which by their very nature are inalienable and cannot be possessed, in the sense that one aspect of the gift still belongs or resides in the giver, even after it has been "given away." In this context the term "inalienable" indicates the essential power of spiritual forces across land, water and forest [11].

Mauss drew much of his inspiration from the New Zealand Maori: in Maori philosophy, the body is considered to be a vessel of wairua (spirit) and mauri (life-force), and all parts of the body exemplify hau (vital spirit). This ontology has resonance for organ donations because, as Mauss pointed out, to make a gift of something to someone is to make a present of some part of oneself. In Maori belief the body is not an inanimate object but instead part of a broader ancestry that provides a link between the physical and spiritual worlds, connecting the individual to their extended family and tribes $[12,13]$.

\section{An Example from Tibetan culture of Intercorporality}

It has been indicated that the possibility of reciprocity has generally been discounted as regards donations. However, some recent scholarship has indicated that anonymity might not necessarily mean there is a "form of alienation and passivity" but rather that this situation may, on the contrary, provide an "imaged canvas for novel ideational manoeuvres" [14].

It will be argued therefore that while feelings of debt or gratitude may exit in the mind of recipients what concerns me is the nature of mutuality between donor and recipient: this may be called a "communal bond" that may exist between donor and recipient. By the term "communal bond" I mean the way donors and recipients share, on both a conceptual and a bodily level, the experience of "natural forces".

This approach may be illustrated from the Tibetan Buddhist world as an aspect of the trikāya (the enlightened body) that is not limited by time or space [15]. A later explanation will be made of this interpretation of the trikāya includes the idea of a bodily and spiritual commonality between people and natural forces.

Here reference is made to the notion of trikāya as a means to develop ideas of intersubjectivity, namely the way bodies may be interconnected or linked with each other, rather than conceived of as discrete [15].

This approach to organ transplants as gifts has been developed from the ethnographical work of Tanya Zivkovic on Tibetan lamas. She studied the death and rebirth ceremonies of Tibetan Buddhists in the Darjeeling region. She has shown that the willing ingestion of bodily relics of a deceased lama imaginatively recreates the presence of the lama in the recipient. Relics taken from cremation grounds in the form of ashes or bones has also been seen as representing the former presence of the deceased [16]. 
This ingestion facilitated forms of inter-subjectivity from one body to another through the "transmission or intensity of force." This form of exchange allows recipients to be "affected in a way that leads to an intimate awareness of the body of another" [1]. Thus through these transfers of relics there was created what may be called a "communal spiritual body" between lamas and their disciples $[1,17,18]$.

Zivkovicz has shown how, through a shared belief in the trikāya disciples may a experience a sense of shared intersubjectivty. This intersubjectivity represents not only a sense of interconnectedness between different individuals but also of intercorporality [15, 17]. Through "intercorporality" aspects of a lama's body may be remade in the lives of disciples [15].

The social and spiritual worlds in Tibetan Buddhism constitute a dynamic of intersubjective engagements between lamas and monks within a spiritual universe involving gods, elemental nature spirits, hell beings, ghosts and enlightened beings [1]. The Tibetan practitioner may cross between these human and divine worlds as subjectivity is "neither independent or unified" and does not have "singularity" as a "bonded entity" [1]. In this understanding, the body does not "entail a notion of the subject or of self-hood as some skin encapsulated, seamless monad possessed of conceptual unity and continuity" [19].

Reference is made to the notion of trikāya in later Mahayana Buddhism. In ascending order of abstraction they are: the nirmāna-kāya, seen as the apparitional or physical body of the Buddha, namely Siddhartha Gautama; the sambhhoga-kāya, seen as the body of bliss, the reward body or the exalted and splendid manifestation of the Enlightened personality, which is only visible to those with advanced spiritual capacities; lastly, and by contrast, the dharma-kāya is the absolute body of the Buddha that is formless and imperishable. This third form of body indicates to practitioners that different levels of attainment are made possible through specific mediative practices. The notion of multiple bodies also promulgates the idea that the body is not a singular discrete object but instead represents a plurality of interconnected bodies [15].

While the cultural context of Tibetan Buddhism may be seen to be far removed from the medical operations involved in transplants it is suggested the above ideas provide a motif for notions of connectivity that exist between donors and recipients.

\section{Illustrations of Intercorporality and Intersubjectivity as regards Recipients of Organ Donations}

Several scholars have analysed organ donations, utilising notions of "intercorporality" and "intersubjectivity" to argue that, even in a situation where the donor does not know the recipient, the donation is not impersonal or neutral as the recipient may receive and retain the qualities of the donor. As Waldby concludes, "circuits of tissue exchange are relational and social" [20]. The issue this article has been developing is therefore as follows: what is the relation between donors and recipients when they are not known to each other? Furthermore, what are the social or religious connections established between donors and recipients?

To develop the argument that there is indeed a form of connectivity at play here, the article deploys the work of Zivkovic to show how, in certain circumstances, the transference of relics enables recipients to dwell in the spiritual body of the trikāya. This explanation of the giving of relics as an example of the way "spiritual forces" can be transferred from one person to another through the transfer of body parts. Implicit in my argument is that reciprocity is evident through an understanding of the hau concept developed by Mauss. I argue that reciprocity may be 
envisaged in different forms, as already shown by empirical work done with patients as regards their attitudes towards receiving an organ.

As has been noted Mauss conceptualised that a gift must have reciprocity to be construed as such. I have also stressed that, as regards donations, it is usually thought that there can be no reciprocity. The standard argument runs that, as the donor is dead, the donor would not have been able to visualise the person who might receive their organs and therefore be unable to develop any sense of reciprocation towards a donor.

However, if we invoke the notion of the "spirit of the gift," we may envisage that the recipient may experience along with the delivery of a gift a particular nature or spirit of the donor that creates a bond between the donor and the recipient. We may also note Mauss's postulation that the "spirit of the gift possessed an inner force that was invested with life and carried the individuality of the donor" [21, 22].

My interest in Mauss is in the nature of spiritual force inherent in the gift that "pushes for recognition" [23]. As Mauss himself asks, "what power resides in the object given that causes its recipient to pay it back?" [6]. Mauss goes on to say:

This is because the taonga ["everything that may properly be termed possessions, everything that makes one rich, powerful, and influential, and everything that can be exchanged ... precious articles... sometimes even the traditions, cults, and magic rituals"] is animated by hau [the spirit of things] of its forest, its native health and the soil ... in reality, it is the hau that "wishes to return to its birth place (lieu desa naissance) to the sanctuary of its forest and the clan, and to the owner" [6].

Three points may be made concerning this quotation. Firstly, the nature of taonga is linked to the person, the clan and the earth; as such, a gift functions as a vehicle for mana, which embodies a magical and spiritual force $[6,24]$. Secondly, this spiritual force is linked to ancestors and practices that establish clan solidarity. Thirdly, it is connected to the natural world: earth, seas, and forest.

In these ways, the hau exists as a spirit that co-constitutes both donor and recipient [24]. It cannot be transferred like a form of commodity because it is not capable of possession; it comes from the donor's clan and cultural tradition, as well as from its native soil and natural elements. Moreover, the hau also has a "vital essence," as "the assumption behind any material form is an invisible, dynamic power that makes it what it is. It is at once the source of appearance and potential for action ... and has an "expression of an inner nature. If interfered with, contaminated, or "lost," the object or being that is its emanation - in this case, a human, will lose its integrity and decay and die" $[5,25,26]$.

It is a premise of this article that this generative force reflects the natural processes that approximate an aspect of the trikāya idea of bodily substances, in that an organ transplant also transfers the experience of connectivity. This happens at different levels: firstly, at the level of clan or lineage; secondly, at the level of bodily experience in the sense of the interconnectivity of a common body; and thirdly, the realisation of a spiritual essence as the element of all natural manifestations. 


\section{The Incorporation or Disconnect of "Other" Body Parts}

As has been noted a body of empirical research on organ donations that has shown the effect of the incorporation of bodily parts into another person, specifically how that has altered the recipient's sense of integrity and wellbeing. In this regard several studies have reported that recipients expressed disruption to identity and bodily integrity, as well as interconnectedness with the donor, even when the recipient perceives the organ donor as a stranger [3, 18-20, 27].

In this regard, Karl-Leo Schwering has demonstrated from his interviews with people who received body parts how such recipients re-established a form of bond with the donor through "the intermediary of his or her imaginary speculations." Thus recipients, through what Schwering calls the "myth of the gift" create "imaginary scenarios" as a response "to the unknown to the anonymous." He reports how recipients restored on the "plane of the imaginary" the specific relationships of the "primary sociality in which the relation of the giving generally thrives" [28, 29].

Monica Konrad found similar results in her work on gamete and egg donations. She inquired how gift relationships can be established when reciprocity is impossible [30, 31]. In an attempt to reconstruct a form a kinship, she demonstrates that "anonymity is not necessarily a form of alienation." She shows how ova donors and recipients consistently imagine their relationships to a "somebody" at the other end of the transaction, even though they do not know that person's identity. It is in this imaginary extension of relations into the unknown that Konrad finds "the lurking gift" [32]. Konrad develops this argument through the importation of a concept from geology, transilience, which indicates how a leap is made from one stratum or substance to another. The concept of transilience, in Konrad's view, explains not the physiological outcome of ova donation itself, but the relationships envisioned by donors and recipients as a consequence of substances "gifted" between anonymous others.

\section{Conclusion}

This article has attempted to understand organ transplants by deploying an aspect of Mauss's work to give a background explanation to those who wish to help the psychological coping of recipients and assist in the positive rehabilitation after a transplant operation.

In this sense, the article explains the "absence of investigation" that exists to comprehend "such personality changes and the scepticism regarding whether such changes are possible" [22].

The article therefore describes the relationship between donors and recipients of organ transplants by analysing two examples that deal with the form of connection established between the two parties involved. The article therefore build on that line of scholarship that has noted how recipients receiving transplants have experience changes in their processes of self-formation and the establishment of a new identity.

As an imagined framework to understand this process reference was made to how relic donations were perceived in Tibetan Buddhism as constituting a form of linkage with one's teacher and their inherent religious qualities emanating from a universal spiritual essence. In this, this instance there was a harking back to the qualities of the donor and the religious qualities that linked the donor to natural and spiritual forces. This linkage may be seen as more than an instance of reciprocity because there was the establishment of a particular kind of a communal bond.

To support this approach a formulation was made of Mauss's insight on the nature of hau that enables a linkage or connection to the spiritual aspect of the donor's body and its celestial 
connections. The significance of this finding opens the door for future research on the nature of the communal bond and the importance of this connection for the psychology of organ recipients. It is arguable therefore, that organ transplants as gifts are more than simply a form of "sociality": a gift affects the social and spiritual fabric where both donors and recipients share an imagined bond.

\section{Author Contributions}

Malcolm Voyce did all the research work of this study.

\section{Competing Interests}

The author has declared that no competing interests exist.

\section{References}

1. Zivkovic TM. Death and reincarnation in Tibetan Buddhism: In-between bodies. London: Routledge; 2014.

2. Marías J. Tomorrow in the battle think of me. New York: Harcourt Brace; 1997.

3. Slatman J, Widdershoven G. Hand transplants and bodily integrity. Body Soc. 2010; 16: 69-92.

4. Bateman S. When Marcel Mauss's Essai sur le Don becomes the gift: Variations on the theme of solidarity. Theor Med Bioeth. 2016; 37: 447-461.

5. Graeber D. Towards An anthropological theory of valve: The false coin of our own dreams. New York: Palgrave Macmillan; 2001.

6. Mauss $M$. The gift: The form and reason for exchange in archaic societies. 2 nd ed. London: Routledge; 2002.

7. Shimazono Y. Repaying and cherishing the gift of life: Gift exchange and living-related kidney transplantation in the Philippines. Anthropol Action. 2008; 15: 34-46.

8. Voyce M. Organ transplants and the medicalisation of death: Dilemmas for Tibetan Buddhists. Contemp Buddhism. 2020; 9: 1-11.

9. Martin AE. The gift of life: Understanding organ donation and gift exchange through literature. Durham: Duke University; 2017.

10. MacCormack G. Mauss and the 'spirit' of the gift. Oceania. 1982; 52: 286-293.

11. Weiner A. Inalienable possession: The paradox of keeping while giving. Berkeley: University of California Press; 1992.

12. Shaw R, Webb R. Multiple meanings of "Gift" and its value for organ donation. Qual Health Res. 2015; 25: 600-611.

13. Penehira M, Smith LT, Green A, Aspin C. Mouri matters: Contextualizing mouri in Maori health discourse. AlterNative. 2011; 7: 177-187.

14. Copeman J. Veins of devotion: Blood donation and religious experience in North India. New Brunswick, NJ: Rutgers University Press; 2009.

15. Lee RL. Bodies, religion and relationality: The paradox of the Buddhist trikāya. Cult Relig. 2014; 15: 436-451.

16. Ruppert B. Jewel in the ashes: Buddha relics and power in early medieval Japan. Cambridge: Harvard University Press; 2000. 
17. Zivkovic TM. Tibetan Buddhist embodiment: The religious bodies of a deceased lama. Body Soc. 2010; 16: 119-142.

18. Zivkovic TM. The biographical process of a Tibetan lama. Ethnos. 2010; 75: 171-189.

19. Jackson M. Minima ethnographica: Intersubjectivity and the anthropological project. Chicago, IL: University of Chicago Press; 1998.

20. Waldby C. Biomedicine, tissue transfer and intercorporality. Fem Theory. 2002; 3: 239-254.

21. Sque MR. Organ and tissue donation: An evidence base for practice. Maidenhead: Open University Press; 2007. p.41-p.58.

22. Liester M. Personality changes following heart transplantation: The role of cellular memory. Med Hypotheses. 2020; 135: 109468.

23. Madalai Muthu AR. The ambiance of gift-giving. Int Rev Soc Sci Humanit. 2016; 11: 52-72.

24. Fritsch M. The gift of nature in Mauss and Derrida. Oxf Lit Rev. 2015; 37: 1-23.

25. Firth R. Economics of the New Zealand Maori. Owen: Wellington; 1959.

26. Prytz-Johansen J. The Maori and his religion in its non-ritualistic aspects. Copenhagen: I Kommission Hos Ejnar Munksgaard; 1954.

27. Shaw R. Organ donation in Aotearoa/New Zealand: Cultural phenomenology and moral humility. Body Soc. 2010; 16: 127-147.

28. Schwering KL. The spiralling gift in organ transplantation. Res Psychoanal. 2014; 1: 8-16.

29. Schwering KL, Aujoulat I. Gift dynamics and identity construction within the family. Ethical, legal and psychosocial aspects of organ transplantation. Lengerich: Pabst Science Publishers; 2014. p.189-p.195.

30. Konrad M. Nameless Relations: Anonymity, Melanesia and reproductive gift exchange between British ova donors and recipients. New York and Oxford: Berghahn Books; 2005.

31. Konrad M. Ova donation and symbols of substance: Some variations on the theme of sex, gender and the partible person. J R Anthropol Inst. 1998; 4: 643-667.

32. Demian M. Nameless relations: Anonymity, melanesia and reproductive gift exchange between British ova donors and recipients by Monica Konrad. Polit Leg Anth Rev. 2008; 31:171-174.

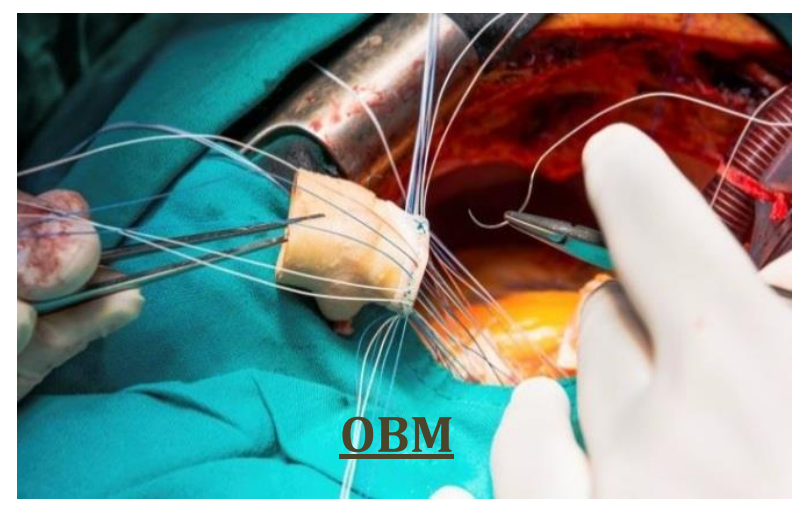

Enjoy OBM Transplantation by:

1. Submitting a manuscript

2. Joining in volunteer reviewer bank

3. Joining Editorial Board

4. Guest editing a special issue

For more details, please visit:

http://www.lidsen.com/journals/transplantation 
Case report

\title{
Liver Transplantation as a Cure for Neurologically Advanced Wilson's disease. Learning More from Experience
}

Marina Moguilevitch*, Tracey Straker

Montefiore Medical Center, 111 East 210th street, Bronx, NY, USA; E-Mails: mmoguile@montefiore.org; tstraker@montefiore.org

* Correspondence: Marina Moguilevitch; E-Mail: mmoguile@montefiore.org

Academic Editor: Yasuhiko Sugawara

Special Issue: Pediatric Liver Transplantation

OBM Transplantation

2020 , volume 4 , issue 4

doi:10.21926/obm.transplant.2004123
Received: July 05, 2020

Accepted: November 02, 2020

Published: November 11, 2020

\begin{abstract}
Clinical presentation and progression of Wilson's disease can be diverse in different groups of patients. While young children most likely to present with acute or chronic liver failure, older children and adults may exhibit extrahepatic manifestation like neuropsychiatric, cardiac, renal, pancreatic and several others. Diagnosis of Wilson's disease is based on the combination of specific clinical findings, laboratory and genetic testing. There are different modalities of treatment available for this condition. Liver transplantation has become a acceptable treatment option for acute and chronic liver failure related to Wilson's disease. It allows for resolution of metabolic disorder and hepatic disease progression. There are no definitive criteria and established outcomes in transplantation of the patients with Wilson's disease who have different degree of neuropsychiatric presentation. Therefore, it is very important to create specific criteria for selecting of these patients before transplantation and to have short-and long-term follow up system to improve their outcome and survival.
\end{abstract}

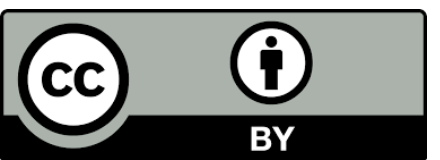

(C) 2020 by the author. This is an open access article distributed under the conditions of the Creative Commons by Attribution License, which permits unrestricted use, distribution, and reproduction in any medium or format, provided the original work is correctly cited. 


\section{Keywords}

Pediatric liver transplant; Wilson's disease; indications for liver transplant in Wilson's disease; selection criteria for liver transplant in Wilson's disease; outcomes after liver transplant for Wilson's disease

\section{Introduction}

Liver transplantation remains the primary treatment option for patients with acute liver failure secondary to Wilson's disease. Without transplantation, mortality is very high. However, the indications and time frame for liver transplantation in patients with Wilson's disease which progresses to cirrhosis are still not clearly identified in the literature. There are multiple reasons for the disease progression: some patients with advanced Wilson's disease were not started on copper chelating agents in a timely manner, other did not respond to treatment or demonstrated poor adherence. The rate of progression of liver disease with development of cirrhosis and neuropsychiatric complications is usually multifactorial and the decision of transplanting these patients is very complex. Compiling the indications for liver transplantation in this patient population is extremely important and it is the focus of this discussion. We would like to share our unique experience and outcome after liver transplantation of a patient who suffered significant neurologic damage from the advanced Wilson's disease.

\section{Case}

A 15 year-old, $28 \mathrm{~kg}$ male, without any medical conditions developed signs of liver disease at the age of 9 when he was first diagnosed with elevated bilirubin. His disease rapidly progressed with development of drooling, headaches, and speech disturbance. He failed Penicillamine and Zinc therapies, and presented to our center with tremors, stiffness, developmental and cognitive delays, dysarthria, dysphagia, and inability to ambulate. According to the family, the child was compliant with the treatment. At the time of admission he was dependent on G-tube feedings for nutrition and was wheelchair-bound. His Magnetic Resonance Imaging (MRI) scan of the brain showed significant volume loss, atrophy, and mineralization of the basal ganglia and substantia nigra (Figure 1). Ophthalmologic examination demonstrated Kayser-Fleischer rings. Liver biopsy performed shortly after admission, revealed signs of cirrhosis, mild portal inflammation, bile duct proliferation, and focally increased stainable copper on Rhodanine stain. Treatment with Trientine and Zinc failed to halt the progression of neurologic symptoms. 


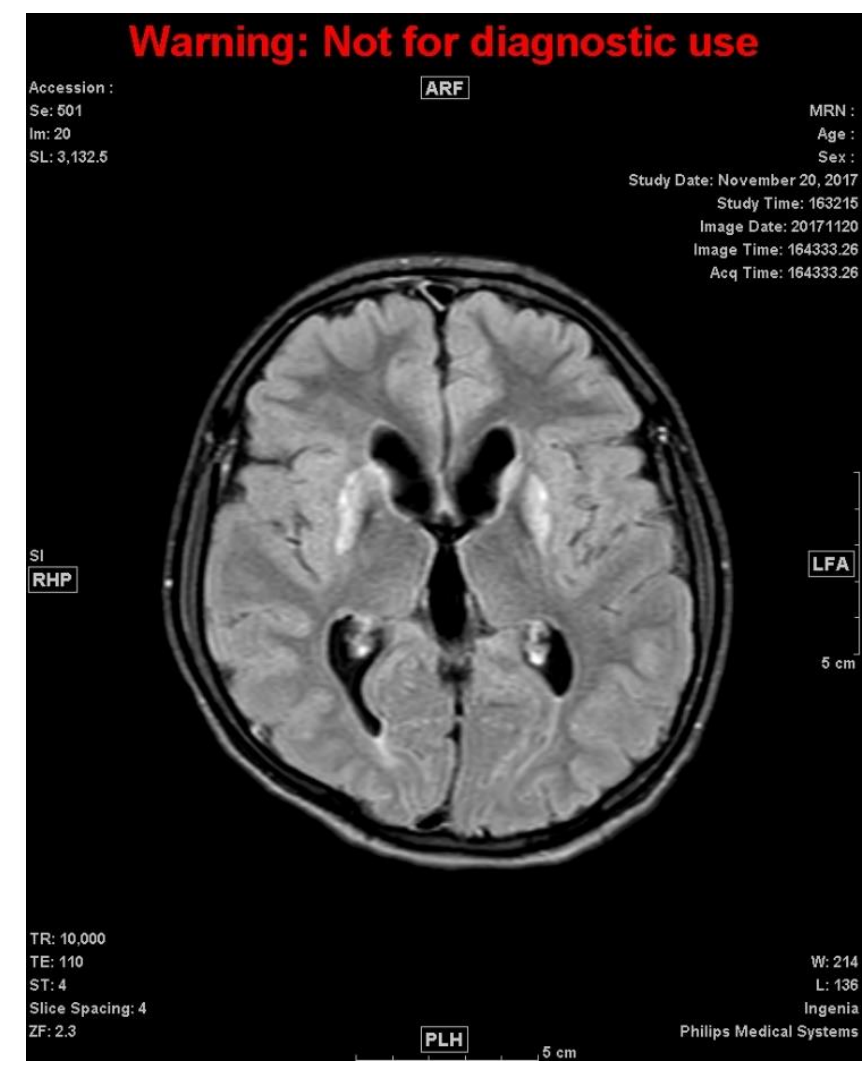

Figure 1

His laboratory findings were significant for alkaline phosphatase $230 \mathrm{IU} / \mathrm{L}$, hematocrit 28 percent, albumin $3.2 \mathrm{~g} / \mathrm{dl}$, total bilirubin $2.3 \mathrm{mg} / \mathrm{dl}$, and direct bilirubin $0.6 \mathrm{mg} / \mathrm{dl}$, ceruloplasmin 6 $\mathrm{mg} / \mathrm{dL}, 24$ hours urine copper $240 \mathrm{mcg} / \mathrm{dL}$. The rest of the laboratory findings were within normal limits.

After thorough multidisciplinary evaluation and bioethical committee approval, the patient was listed for liver transplant with Pediatric End Stage Liver Disease (PELD) score of 40. Additional points were given for the failure to thrive and devastating neurologic comlications of the disease. The transplant team and the patient's family were aware that neurological symptoms may not be reversible after the surgery. There was no living donor liver offer available for this patient. Shortly after listing the patient received deceased donor $A B O$ compatible whole liver graft. The liver transplant was uneventful, and required no blood or blood product transfusion. No signs of significant portal hypertension were noticed during the surgery. Eight months after transplantation, the patient became verbal with normal swallowing, gained wait, and demonstrated ability to ambulate. His tremors and stiffness were completely gone. We were able to observe complete resolution of his neurologic deficits in twelve months after transplantation.

\section{Discussion}

Wilson's disease (WD) is an inherited autosomal recessive disorder of copper metabolism that affects approximately 1 in 30,000 people. The carrier rate of this disease is 1 in 90 [1]. The disease results from dysfunction of the copper-transport adenosine triphosphatase mechanism in the ATP7B gene in the liver. This gene is responsible for excreting copper into the bile $[2,3]$. Failure to incorporate copper into the ceruloplasmin is also a consequence of the dysfunctional ATP7B 
protein. The hepatic production and secretion of the abnormal protein apoceruloplasmin results in decreased levels of ceruloplasmin, which is found in most WD patients [4]. The abundance of disease-specific mutations and their location at multiple sites across the genome have made molecular genetic diagnosis difficult. The subsequent copper accumulation, primarily in liver and brain, leads to hepatic and neurological manifestations [5].

Wilson's disease has a highly variable onset and clinical course [6-8]. In many cases, symptoms of the disease are nonspecific. Children and young adults are more likely to present with progression of liver disease. The presentation can vary from fulminant hepatic failure to a slow progression of decompensated cirrhosis. Late onset WD presents with neuropsychiatric symptoms, such as tremor, dysarthria, ataxia, rigidity, dyskinesia, cognitive impairment, and mood disturbances. Many patients with psychiatric or neurologic manifestations may have asymptomatic cirrhosis. Extra-hepatic manifestations include renal symptomatology such as aminoaciduria, nephrolithiasis, arthritis, premature osteoporosis, cardiomyopathy, hyperparathyroidism, pancreatitis, and infertility [9-14].

According to the latest guidelines published by the European Society for Pediatric Gastroenterology, Hepatology and Nutrition (ESPGHAN), European Association for Study of the Liver Disease (EASL), and Indian National Association for Study of the Liver (INASL)the diagnosis of WD is based on the combination of biochemical laboratory tests assessing copper metabolism, a broad spectrum of clinical features, and molecular analysis of the mutations in the ATP7B gene [15-17]. Corneal copper deposition called the Kayser- Fleisher ring, hemolytic anemia due to deficiency of ceruloplasmin, and neurologic symptoms are considered to be the most common clinical symptoms. Twenty-four hours urine copper, hepatic copper concentration, ceruloplasmin, and the presence of the ATP7B gene mutation are laboratory tests used to confirm the final diagnosis of WD.

In 2001, at the 8th International conference on Wilson's and Menkes disease in Leipzig the scoring system for the diagnosis of WD was discussed. A combination of clinical and biochemical tests with the score ranging from 0 to 4 for each test were developed. The aim of this system was to provide objective criteria with high sensitivity and specificity for the diagnosis of Wilson's disease. The patients with the total score of at least 4 are diagnosed with WD. Approximately five percent of all WD patients present with new onset acute liver failure, and require emergency liver transplantation that is life saving [18]. According to the studies by McCullough et al and Schilisky et al, the diagnosis of Wilson's disease in the acute liver failure setting is more challenging because traditional copper metabolism parameters are less reliable, and specific $[19,20]$. Korman et el demonstrated that the ratio of alkaline phosphatase to total serum bilirubin with a value of less than 2, in combination with the ratio of aspartate aminotransferase (AST) to alanine aminotransferase (ALT) with a value of greater than 2.2 , has $100 \%$ sensitivity and specificity [21]. These tests are proven to be reliable for the adult patient population with a relatively low Model for End Stage Liver Disease (MELD) score. In pediatric patients, bone-derived alkaline phosphatase can play a role in making the ratio of AST to ALT of 2.2 less reliable. Koppikar et al [22] proposed the Wilson's scoring index, which is composed of the international normalized ratio (INR), AST, white blood cells, albumin, and bilirubin for pediatric patients.

Until transplantation can be performed, temporizing measures like plasmapheresis [23], exchange transfusion [24], fractionated plasma separation and absorption (FPSA) [25], and molecular adsorbent recycling system (MARS) [26] can be helpful. 
Liver transplantation for chronic Wilson's disease is the definitive treatment for the metabolic disorder, and resolution of the hepatic failure associated with WD. Liver transplantation reverses biochemical and clinical futures of Wilson's disease, but its effect on neurologic symptoms is not very well established. The first successful resolution of neurological disorders after liver transplantation for chronic Wilson's disease was reported in mid 90's [27-29]. The decision to perform liver transplantation in these cases was based on deteriorating neurologic status with relatively stable liver function.

Likewise, Kassman et al [30] reported the case of a 22 year-old male with advanced neurological impairment and significant psychiatric manifestations secondary to Wilson's disease. The patient demonstrated normalization of liver metabolic function after liver transplantation. Unfortunately, neurological recovery was slow and incomplete, while the psychiatric manifestations never improved. He committed suicide 43 months after transplantation.

There are many studies that retrospectively analyzed liver transplant patients with Wilson's disease and varying degrees of neurological and psychiatric deterioration [31-34]. All patients showed an improvement, or complete disappearance of the neurological symptoms. The notion that better results can be achieved in transplanting patients with mild to moderate neurological deterioration has not been proven yet [35]. Wang et al demonstrated that results are favorable in patients with advanced neurological deficits after living-related liver transplants [32]. However, several studies have reported death as an outcome of liver transplantation for patients with neurological manifestations [27-33]. Despite the death of several of their patients, the authors have advocated liver transplantation for neurologically challenged patients.

There is minimal data available on the predictors of outcome on transplanted patients with varying degrees of neuropsychiatric symptoms of Wilson's disease, and their long-term survival. Medici et al presented a retrospective multicenter analysis of the outcome of 37 patients transplanted for Wilson's disease [36]. More than a third of the patients had multiple presentations of neuropsychiatric compromise. The authors used a scoring system to retrospectively assess the patient's pre-and post-operative neurological status. Reported patient and graft survival at 3 months, 12 months, 3 years, 5 years, and 10 years after transplantation were, respectively, $91.8 \%, 89.1 \%, 82.9 \%, 75.6 \%, 58.8 \%$, and $85.3 \%, 83 \%, 77.1 \%, 70.3 \%, 47.2 \%$.

According to the authors, neurologic symptoms significantly improved or completely resolved in $70 \%$ of the patients after transplantation, but survival in this cohort was lower than in patients with liver disease alone $(P=0.04)$. Wang et al demonstrated similar results in his retrospective study of eighteen living related liver transplants for Wilson's disease [37]. Among these eighteen patients, seven had mild to moderate neurological involvement. All showed improvement of their symptoms after surgery, but also demonstrated a slightly lower survival rate. The follow up time in this study ranged from 2 to 32 months.

Guillaud et al studied the biggest cohort of the Wilson's disease patients presented in the literature who underwent liver transplantation [38]. They analyzed retrospectively medical records of 121 French patients transplanted for WD, seventy-five were adults (median age 29 years, (1866)) and 46 were children (median age 14 years, (7-17)). The indications for liver transplantation were fulminant hepatic failure, decompensated cirrhosis, and severe neurological disease. Multivariate analysis of different groups of patients with different indications for transplantation concluded that liver transplantation allowed to achieve good long-term outcome, including improvement of renal function. 
Two latest papers by Poujois et al [39] and Ferrarese et al [40] specifically looked at the outcomes of Wilson's disease patients transplanted for neurological indications. Both articles recommended very careful approach to patients selection for the liver transplant surgery and indicated limited benefit of this procedure to improve neuropsychiatric symptoms or signs of the disease.

\section{Conclusions}

Liver transplantation remains the treatment of choice for acute liver failure related to Wilson's disease. Transplantation is indicated when patients develop cirrhosis, become unresponsive, or have never been on cooper chelating agents. Liver transplantation is a good option for symptom improvement or sometimes complete cure in patients that develop neurological deficits related to Wilson's disease. Nonetheless, there is not enough data available to draw a conclusion about the clear beneficial effect of liver transplantation in all cases of neurologically affected Wilson's disease patients. It is more research needed to look at larger cohorts in order to provide better stratification for postoperative survival and long term follow up of these patients. Our case can contribute to the ongoing effort to identify indications, predicting factors of cure, and survival after liver transplantation for the patients with chronic Wilson's disease.

\section{Acknowledgments}

The authors would like to thank the patient's family for supporting us in sharing this case report.

\section{Author Contributions}

All authors participated in manuscript creation, review process, and revisions.

\section{Competing Interests}

The authors have declared that no competing interests exist.

\section{References}

1. Loundianos G, Gitlin JD. Wilson's disease. Semin Liver Dis. 2000; 20: 353-364.

2. Bull PC, Thomas GR, Romments JM, Forbes JR, Cox DW. The Wilson disease gene is a putative copper transporting P-type ATPase similar to the Menkers gene. Nat Gen. 1993; 5: 327-337.

3. Yamaguchi $Y$, Heiney ME, Gitlin JD. Isolation and characterization of human liver cDNA as a candidate gene for Wilson disease. Biochem Biophys Res Commun. 1993; 197: 271-277.

4. Holzman NA, Gaumnitz BM. Studies on the rate of release and turnover of ceruloplasmin and apoceruloplasmin in rat plasma. J Biol Chem. 1970; 245: 2354-2358.

5. Roberts EA, Schilsky ML. A practice guideline on Wilson disease. Hepatology. 2003; 37: 14751492.

6. Ferenci P, Czionkowska A, Merle U, Ferenc S, Gromadzka G, Yurdadin C, et al. Late onset Wilson's disease. Gastroenterology. 2007; 132: 1294-1298.

7. Merle U, Schafer M, Ferenci P, Stremmel W. Clinical presentation, diagnosis and long-term outcome of Wilson's disease: A cohort study. Gut. 2007; 56: 115-120. 
8. Stremmel W, Meyerrose KW, Niederau C, Hefter H, Kreuzpainter G, Strohmeyer G. Wilson disease: Clinical presentation, treatment, and survival. Ann Intern Med. 1991; 115: 720-726.

9. Nakada SY, Brown MR, Rabinowittz R. Wilson's disease presenting as symptomatic urolithiasis: A case report and review of the literature. J Urol. 1994; 152: 978-979.

10. Goldin DN, Walshe JM. Arthropathy of Wilson's disease. Study of clinical and radiological features in 32 patients. Ann Rheum Dis. 1997; 36: 99-111.

11. Hlubocka Z, Maracek Z, Linhart A, Kejrova E, Pospisilova L, Martazek P, et al. Cardiac involvement in Wilson disease. J Inherit Metab Dis. 2002; 25: 269-277.

12. Carpenter TO, Carnes Jr DL, Anast CS. Hypoparathyroidism in Wilsosn's disease. N Engl J Med. 1983; 309: 873-877.

13. Weizman Z, Picard E, Barki Y, Moses S. Wilson's disease associated with pancreatitis. J Pediatr Gastroenterol Nutr. 1988; 7: 931-933.

14. Tarnacka B, Rodo M, Cichy S, Czlonkowska A. Procreation ability in Wilson's disease. Acta Neurol Scand. 2000; 101: 395-398.

15. Socha P, Janczyk W, Dhawan A, Baumann U, D'Antiga L, Tanner S, et al. Wilson's disease in children: A position paper by the hepatology committee of the european society for paediatric gastroenterology, hepatology and nutrition. J Pediatr Gastroenterol Nutr. 2018; 66: 334-344.

16. European Association for Study of the Liver. EASL clinical practice guidelines: Wilson's disease. J Hepatol. 2012; 56: 671-685.

17. Nagral A, Sarma SM, Matthai JK, Kukkle LP, Devarbhavi H, Sinha S, et al. Wilson's disease: Clinical practice guidelines of the indian national association for study of the liver, the Indian society of pediatric gastroenterology, hepatology and nutrition, and the movement disorder society of India. J Clin Exp Hepatol. 2019; 9: 74-98.

18. Ostapowicz G, Fontana RJ, Schiodt FV, Larson A, Davern TJ, Han SH, et al. Results of prospective study of acute liver failure at 17 tertiary care centers in the United States. Ann Intern Med. 2002; 137: 947-954.

19. McCullough AJ, Fleming CR, Thistle JL, Baldus WP, Ludwig J, McCall JT, et al. Diagnosis of Wilson's disease presenting as fulminant hepatic failure. Gastroenterology. 1983; 84:161-167.

20. Schilsky ML. Overcoming obstacles to the diagnosis of Wilson's disease. Gastroenterology. 1997; 113: 350-353.

21. Korman JD, Volenberg I, Balko J, Webster J, Schiodt FV, Squires Jr RH, et al. Screening for Wilson disease in acute liver failure: A comparison of currently available diagnostic tests. Hepatology. 2008; 48: 1167-1174.

22. Dhawan A. Evaluation of the scoring system for the diagnosis of Wilson's disease in children. Liver Int. 2005; 25: 680-681.

23. Asfaha S, Almansori M, Qarni U, Gutfreund KS. Plasmapheresis for hemolytic crisis and impending acute liver failure in Wilson disease. J Clin Apher. 2007; 22: 10-14.

24. Kiss JE, Berman D, Van Thiel D. Effective removal of cupper by plasma exchange in fulminant Wilson disease. Transfusion. 1998; 38: 327-331.

25. Skwarek A, Grodzicki M, Nyckowski P, Kotulski M, Zieniewick K, Michalowicz B, et al. The use prometus FPSA system in the treatment of acute liver failure: Preliminary results. Transplant Proc. 2006; 38: 209-211. 
26. Sen S, Felldin M, Steiner C, Larsson B, Gillett GT, Olausson M, et al. Albumin dialysis and Molecular Adsorbents Recirculating System (MARS) for acute Wilson's disease. Liver Transpl. 2002; 8: 962-967.

27. Mason AL, Marsh W, Alpers DH. Intractable neurological Wilson's disease treated with orthopnic liver transplantation. Dig Dis Sci. 1993; 38: 1746-1750.

28. Schumacher G, Platz KP, Mueller AR, Neuhaus R, Steinmüller T, Bechstein WO, et al. Liver transplantation treatment of choice for hepatic and neurological manifestations of Wilson's disease. Clin Transplant. 1997; 11: 217-224.

29. Bax RT, Hassler A, Luck W, Hefter H, Krägeloh-Mann I, Neuhaus P, et al. Cerebral manifestations of Wilson's disease successfully treated with liver transplantation. Neurology. 1998; 51: 863-865.

30. Kassman N, Witt N, Kneteman N, Bain VG. Liver transplantation for neuropsychiatric Wilson disease. Can J Gastroenterol. 1998; 12: 65-68.

31. Eghtesad B, Nezakatgoo N, Geraci LC, Jabbour N, Irish WD. Liver transplantation for Wilson's disease: A single-center experience. Liver Traspl Surg. 1995; 5: 467-474.

32. Wang $X H$, Cheng $F$, Zhang $F$, Li XC, Kong $L B$, Li GQ, et al. Living-related liver transplantation for Wilson's disease. Transpl Int. 2005; 18: 651-656.

33. Marin C, Robles R, Parilla G, Ramirez P, Bueno FS, Parilla P. Liver transplantation in Wilson's disease are its indications established? Transplant Proc. 2007; 39: 2300-2301.

34. Geissler I, Heinemann K, Rohm S, Hauss J, Lamesch P. Liver transplantation for hepatic and neurological Wilson's disease. Transplant Proc. 2003; 35: 1445-1446.

35. Stracciari A, Tempestini A, Borghi A, Guarino M. Effect of liver transplantation on neurological manifestation in Wilson disease. Arch Neurol. 2000; 57: 384-386.

36. Medici V, Mirante VG, Fassati LR, Pompili M, Forti D, Del Gaudio M, et al. Liver transplantation for Wilson's disease: The burden of neurological and psychiatric disorders. Liver Transpl. 2005; 11: 1056-1063.

37. Wang XH, Zhang F, Li XC, Cheng F, Li J, Li GQ, et al. Eighteen living related liver transplants for Wilson's disease: A single-center. Transplant Proc. 2004; 36: 2243-2245.

38. Guillaud O, Dumortier J, Sobesky R, Debray D, Wolf P, Valemmens C, et al. Long term results of liver transplantation for Wilson's disease: Experience in france. J Hepatol. 2014; 60: 579589.

39. Poujois A, Sobensk R, Meissner WG, Brunet AS, Broussolle E, Laurencin C, et al. Liver transplantation as a rescue therapy for severe neurologic forms of Wilson disease. Neurology. 2020; 94: 2189-2202.

40. Ferrarese A, Morelli MC, Carrai P, Milana M, Angelico M, Perricone G, et al. Outcomes of liver transplant for adults with Wilson's disease. Liver Transplant. 2020; 26: 507-516. 


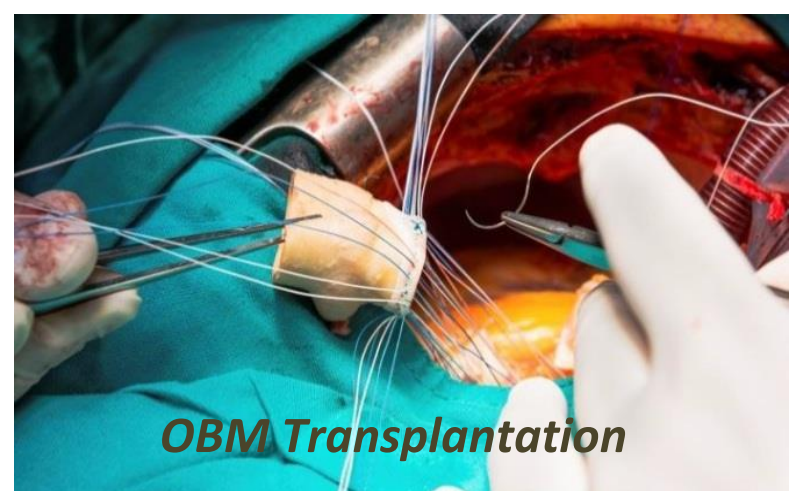

Enjoy OBM Transplantation by:

1. Submitting a manuscript

2. Joining in volunteer reviewer bank

3. Joining Editorial Board

4. Guest editing a special issue

For more details, please visit:

http://www.lidsen.com/journals/transplantation 
Communication

\title{
Appropriate Vancomycin Use and Incidence of Vancomycin-Resistant Enterococci in Liver Transplant Recipients
}

\author{
Jessica Ferguson ${ }^{1,}{ }^{*}$, Marisa Holubar ${ }^{1}$, Waldo Concepcion ${ }^{2}$, Dora Y. Ho ${ }^{1}$
}

1. Division of Infectious Diseases and Geographic Medicine, Department of Medicine, Stanford, CA, USA; E-Mails: jferg1@stanford.edu; mholubar@stanford.edu; jsbach@stanford.edu

2. Division of Abdominal Transplantation, Department of Surgery, Stanford University School of Medicine, Stanford, CA, USA; E-Mails: waldo1@stanford.edu

* Correspondence: Jessica Ferguson; E-Mail: jferg1@stanford.edu

Academic Editor: Haval Shirwan

OBM Transplantation

2020, volume 4, issue 4

doi:10.21926/obm.transplant.2004122
Received: July 26, 2020

Accepted: October 28, 2020

Published: November 09, 2020

\begin{abstract}
Liver transplant recipients (LTRs) are at risk for vancomycin-resistant Enterococcus (VRE) infections which can lead to significant morbidity or mortality. Antibiotic exposure, including vancomycin, is associated with greater risk of VRE infection. This study aimed to assess the appropriateness of vancomycin use and rates of VRE infection in this population. We performed a retrospective cohort study of 327 patients who underwent liver transplantation at our center from January 1, 2012 to June 30, 2017. Sixty (18.3\%) LTRs had at least one VREpositive culture between six-months pre-transplant and six-months post-transplant. LTRs with VRE had greater vancomycin exposure as compared to VRE-negative LTRs $(p<0.05)$ and were more likely to receive prolonged vancomycin courses ( 72 hours, $p<0.05$ ). Overall appropriateness of vancomycin use $>72$ hours among VRE-positive LTRs was only $26.8 \%$. Inappropriate vancomycin use most commonly occurred in patients with presumed sepsis without an identifiable source or pneumonia with negative respiratory cultures. Our findings illustrate an opportunity to improve antibiotic stewardship and reduce vancomycin use in the transplant population.
\end{abstract}

\section{Keywords}

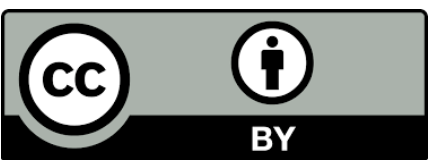

(C) 2020 by the author. This is an open access article distributed under the conditions of the Creative Commons by Attribution License, which permits unrestricted use, distribution, and reproduction in any medium or format, provided the original work is correctly cited. 
Vancomycin-resistant enterococcus; liver transplant; antimicrobial stewardship; vancomycin

\section{Introduction}

Bacterial infections are associated with significant morbidity and mortality in patients with endstage liver disease (ESLD) [1]. In particular, ESLD patients are at greater risk for infections with multidrug resistant bacteria due to their underlying illness and comorbidities, frequent hospitalizations, prior exposure to antibiotics and disruption of normal gastrointestinal flora [2, 3]. Among the multidrug resistant bacteria, vancomycin-resistant Enterococcus (VRE) infections have been associated with increased overall mortality in liver transplant recipients (LTRs) [4]. Risk factors that lead to greater rates of VRE infections in LTRs include prolonged hospital or ICU courses, biliary tract complications, duration of organ ischemia and prior antibiotic exposure $[5,6]$. Previous studies have identified exposure to vancomycin, cephalosporins, carbapenems and antianaerobic antibiotics as risk factors for the development of VRE colonization and infections $[7,8]$.

Given overall rising rates of antimicrobial resistance, there is an increasing focus worldwide on antibiotic stewardship. Robust antibiotic stewardship, in particular, appropriate de-escalation of antibiotic therapy, will likely have significant positive impacts on the transplant populations [9]. No studies to date have specifically investigated vancomycin exposure in association with VRE infection in LTRs. We chose to focus on VRE infections given high incidence rates at our institution. This study aimed to evaluate the association between total vancomycin exposure and subsequent rates of VRE infection in LTRs, as well as the appropriateness of vancomycin use in this patient population.

\section{Methods}

This is a retrospective cohort study of 327 LTRs transplanted at a single tertiary center (Stanford Hospital) between January 1, 2012 and June 30, 2017. This study was approved by the Institutional Review Board at Stanford University. Inclusion criteria were defined as all adult (age $\geq 18$ years) LTRs who received a liver transplant at Stanford Hospital during the study period, including 30 with multi-organ transplants. LTRs transplanted at outside institutions were excluded.

Chart review was performed to identify positive VRE cultures (including blood, urine, intraabdominal fluid or other sources) among the LTRs from six-months pre-transplant until six-months post-transplant. Any cultures collected with the purpose of screening for VRE colonization were excluded. Culture data were collected from microbiology results for source, date, organisms and susceptibilities. Microbiology results from outside institutions were excluded due to incomplete accessibility to comprehensive results. Data collected also included age, gender, mortality at oneyear post transplant, etiology of liver disease, MELD (Model for End-stage Liver Disease) score at time of transplant and days of vancomycin exposure. The VRE-positive (VRE-pos) group included all LTRs with at least one VRE-positive culture between six-months pre-transplant and six-months post-transplant. Those without any positive cultures for VRE during this period were included in the VRE-negative (VRE-neg) group. 
Vancomycin exposure was defined as any administration of intravenous vancomycin at Stanford Hospital from two years prior to transplant until six-months post-transplant. Total vancomycin exposure was calculated as the cumulative number of days in which one or more doses of vancomycin were administered during the defined time period. For patients on hemodialysis, vancomycin exposure represented the cumulative number of days vancomycin was ordered per the electronic medical record to account for non-daily dosing schedules. Outpatient dosing of vancomycin was not included.

Vancomycin use $>72$ hours was classified as appropriate only if its use met one of the following criteria: treatment of methicillin-resistant Staphylococcus aureus (MRSA), coagulase-negative staphylococci (with Mec A PCR positivity), bacterial infections for which vancomycin is the drug of choice, skin and soft tissue infections or other deep-seated infections (e.g. osteomyelitis), for which MRSA infection cannot be ruled out by cultures. Seventy-two hours was chosen as adequate time for culture results to be made available and providers to de-escalate antibiotics based on these results [10]. Mortality rate was defined as death occurring within the first year following liver transplant.

For statistical analysis, continuous variables are reported as means, median and range. Fisher exact test was used to compare characteristics between the two groups. All tests were two-tailed and $P<0.05$ used to determine significance. All analyses were performed using Microsoft Excel and SPSS 24.

\section{Results}

A total of 327 LTRs were identified during the study period. Of these, 60 LTRs had at least one VRE-positive culture (VRE-pos group). The remaining 267 LTRs were included in the VRE-neg group. The demographics of the two groups are shown in Table 1. The VRE-pos group was transplanted at a younger mean age $(54.3$ vs. $57.2, p<0.05)$ and with a significantly higher MELD score (34.5 vs. $22.2, p<0.05)$. The VRE-pos group also included a higher proportion of multi-organ transplant recipients, including 10 LTRs who also received kidney transplants and one liver and heart transplant. Mortality at one-year post-transplant was also greater in the VRE-pos group compared to VRE-neg group $(23.3 \%$ vs $6.7 \%, p<0.05)$. In the VRE-pos group, the most common reason for transplantation was due to alcoholic cirrhosis and hepatitis C (Table 2). The VRE-neg group had a larger proportion transplanted due to hepatocellular carcinoma $(46.1 \%)$, followed by alcoholic cirrhosis and hepatitis $\mathrm{C}$.

Table 1 Demographics of liver transplant recipients (LTRs).

\begin{tabular}{llll}
\hline & VRE-pos $(n=60)$ & VRE-neg $(n=267)$ & P-value \\
\hline Female, no. (\%) & $31(51.7 \%)$ & $78(29.2 \%)$ & $<0.05$ \\
Age at transplant & & & \\
Mean & 54.3 & 57.2 & \\
Median & 57 & 59 & $<0.05$ \\
IQR & $51-60$ & $52-64$ &
\end{tabular}


MELD at transplant

Mean

Median

IQR

Multi-organ transplant

One-year mortality, no. (\%)

\section{5}

37

$33-40$

$11(18.0 \%)$

$14(23.3 \%)$
22.2

19

$<0.05$

11-35

$19(7.0 \%) \quad<0.05$

$18(6.7 \%) \quad<0.05$

Abbreviations: VRE-pos, LTRs with at least one VRE-positive culture; VRE-neg, LTRs without any VRE-positive cultures.

Table 2 Underlying liver disease(s) of the liver transplant recipients (LTRs).

\begin{tabular}{llll}
\hline \multirow{2}{*}{ Underlying Liver Disease } & VRE-Pos $(\mathrm{N}=60)$ & VRE-Neg $(\mathrm{N}=267)$ & P-valve \\
\hline $\mathrm{HCC}$ & $\mathrm{N}(\%)$ & $\mathrm{N}(\%)$ & 0.05 \\
$\mathrm{HCC}+$ additional etiology** & $7(11.7)$ & $17(6.4)$ & $<0.05$ \\
$\mathrm{HCV}$ & $11(18.3)$ & $106(39.7)$ & 0.07 \\
$\mathrm{HCV}+\mathrm{EtOH}$ & $4(6.7)$ & $26(9.8)$ & 0.49 \\
$\mathrm{HBV}$ & $2(3.3)$ & $11(4.1)$ & 1.00 \\
$\mathrm{HBV}+\mathrm{EtOH}$ & 0 & $11(4.1)$ & 1.00 \\
EtOH & $18(30.0)$ & $2(0.8)$ & $<0.05$ \\
Autoimmune & $8(13.3)$ & $42(15.7)$ & $<0.05$ \\
Cryptogenic & $1(1.7)$ & $15(5.6)$ & 1.00 \\
NASH & $3(5.0)$ & $7(2.6)$ & 0.43 \\
Other*** & $6(10.0)$ & $8(3.0)$ & 0.62 \\
\hline
\end{tabular}

** Includes HCV, HBV, alcoholic cirrhosis, autoimmune, cryptogenic, NASH and other

*** Other includes drug and toxin induced liver failure, biliary etiologies and unknown cause of liver failure

There was a total of 67 positive VRE cultures in the VRE-pos group, including 33 urine (49.2\%), 15 blood (22.4\%), 6 peritoneal (9.0\%), 11 with > 1 sites (blood with either urine or peritoneal, $16.4 \%$ ) and 2 others (wound or sputum) (3.0\%). The VRE isolates were identified to the species level in 24 cases, including Enterococcus faecium $(n=22)$, Enterococcus faecalis $(n=1)$ and Enterococcus casseliflavus ( $n=1)$. Of these 67 positive VRE culture results, $53(79.1 \%)$ resulted in treatment, most commonly with linezolid $(35,66.0 \%)$ or daptomycin $(11,20.8 \%)$. The untreated VRE cultures were all from urine samples $(14,20.9 \%)$. The median time to first VRE-positive culture was within 1 month of transplant.

The VRE-pos LTRs had greater total days of vancomycin exposure (8.32 vs 5.30 days, < 0.05$)$. Extended vancomycin exposure $>72$ hours was also higher in VRE-pos LTRs (9.50 vs 6.71 days, $p<$ 0.05) as compared to VRE-neg LTRs (Table 3). A total of 71 events of vancomycin use $>72$ hours occurred in the VRE-pos group. Of these events, the most common indications cited for vancomycin use included bacteremia/sepsis or systemic inflammatory response syndrome (SIRS) (57.7\%), pneumonia (21.1\%) and intra-abdominal infection (5.6\%) (Table 4). Overall 
appropriateness of vancomycin use $>72$ hours was only $26.8 \%$. Cultures obtained the start of vancomycin led to an identified organism in 38 cases ( $n=67,56.7 \%)$. Inappropriate vancomycin use most commonly occurred in "septic" patients without an identifiable infectious source and in patients with pneumonia with negative sputum cultures.

Table 3 Comparison vancomycin use in VRE-pos vs VRE-neg liver transplant recipients (LTRs).

\begin{tabular}{llll}
\hline & VRE-Pos $(\mathrm{N}=60)$ & VRE-Neg $(\mathrm{N}=267)$ & P-value \\
\hline $\begin{array}{l}\text { Cumulative vancomycin use } \\
\text { per LTR, days }\end{array}$ & & \\
Mean & 8.32 & 5.30 & $<0.05$ \\
Median & 3 & 3 & \\
IQR & $0-15$ & $0-8$ & \\
Vancomycin use & & & $<0.05$ \\
$>72$ hours, days & & & \\
Mean & 9.50 & 6.71 & \\
Median & 7 & 5 & \\
IQR & $5-11$ & $4-8$ & \\
\hline
\end{tabular}

Abbreviations: VRE-pos, LTRs with at least one VRE-positive culture; VRE-neg, LTRs without any VRE-positive cultures.

Table 4 Appropriateness of prolonged (> 72 hours) vancomycin use in VRE-pos liver transplant recipients (LTRs).

\begin{tabular}{lll}
\hline $\begin{array}{l}\text { Suspected infectious source } \\
\text { (per documentation) }\end{array}$ & Number of events $(\mathrm{n}=71)$ & $\begin{array}{l}\text { Events with appropriate } \\
\text { vancomycin use, no. (\%) }\end{array}$ \\
\hline Bacteremia, Sepsis/SIRS & 41 & $10(25.6)$ \\
Intra-abdominal & 4 & $2(50.0)$ \\
Respiratory tract & 15 & $2(13.3)$ \\
Genitourinary & 3 & $2(66.7)$ \\
Skin/Soft Tissue & 3 & $2(66.7)$ \\
Other* & 5 & $1(20.0)$ \\
Total & 71 & $19(26.8)$ \\
\hline
\end{tabular}

Abbreviations: SIRS, systemic inflammatory response syndrome; *Includes: chest tube prophylaxis, surgical prophylaxis, central nervous system (CNS)

\section{Discussion}

The prevalence of VRE-positive cultures among our LTRs was approximately $20 \%$. There were both greater number of cumulative days of vancomycin use and greater incidence of vancomycin use $>72$ hours in VRE-positive LTRs. Based on the higher MELD scores and mortality rate in the 
VRE-pos group, increases in vancomycin use and VRE positivity likely correlate with increased illness severity and healthcare exposure.

When vancomycin was used for $>72$ hours in the VRE-pos group, we found only $26.8 \%$ to have a clinically appropriate reason for its use. Nearly three-quarters of all vancomycin use was not substantiated by microbiologic data. The categories with greatest inappropriate vancomycin use were sepsis with negative culture data and empirical pneumonia coverage with negative respiratory cultures. This highlights a significant opportunity for antibiotic de-escalation based on culture results which has become a prominent strategy for antimicrobial stewardship programs [9]. Additional strategies may be beneficial in cases with negative microbiologic workups [11, 12].

Our study has several limitations. While we focus only on vancomycin exposure, additional antibiotics including fluoroquinolones, beta-lactams and carbapenems have also been associated with the development of VRE infections [7, 8]. Furthermore, we did not assess rates of VRE colonization and all positive VRE-cultures were assumed to represent VRE infections. This assumption may overestimate the true number of VRE infections in this cohort. This study only evaluates overall vancomycin exposure and VRE infections among these patients, but cannot prove direct causality between a particular course of vancomycin and an incidence of VRE infection. Lastly, this study relied on clinician documentation which may not accurately reflect the clinical context leading to antibiotic use and lead to an overestimation of inappropriate vancomycin use.

Future studies are needed to investigate additional variables affecting vancomycin use, including length of hospitalization, number of hospital admissions and illness severity. These factors impact overall antibiotic utilization and the development of resistant organisms independent of vancomycin exposure. Further examination of the practice of antimicrobial use and development of resistant organisms would help develop antibiotic stewardship guidelines, particularly in the transplant populations.

In summary, we found that LTRs with VRE had significantly greater exposure to vancomycin as compared to VRE-negative LTRs. Additionally, up to $73 \%$ of prolonged ( $>72$ hours) vancomycin use was inappropriate, highlighting the need for ongoing improvement in antibiotic stewardship.

\section{Author Contributions}

JF Study concept/design, data collection, analysis of data, drafting of the manuscript; MH Study concept/design, critical revision of the manuscript; WC Critical revision of the manuscript; $\mathrm{DH}$ Study concept/design, interpretation of data, drafting and critical revision of the manuscript.

\section{Competing Interests}

The authors have declared that no competing interests exist.

\section{References}

1. Piano S, Brocca A, Mareso S, Angeli P. Infections complicating cirrhosis. Liver Int. 2018; 38: 126-133.

2. Patel G, Snydman DR, AST Infectious Diseases Community of Practice. Vancomycin-resistant enterococcus infections in solid organ transplantation. Am J Transplant. 2013; 13: 59-67. 
3. Papanicolaou GA, Meyers BR, Meyers J, Mendelson MH, Lou W, Emre S, et al. Nosocomial infections with vancomycin-resistant enterococcus faecium in liver transplant recipients: Risk factors for acquisition and mortality. Clin Infect Dis Off Publ Infect Dis Soc Am. 1996; 23: 760766.

4. Orloff SL, Busch AM, Olyaei AJ, Corless CL, Benner KG, Flora KD, et al. Vancomycin-resistant enterococcus in liver transplant patients. Am J Surg. 1999; 177: 418-422.

5. McNeil SA, Malani PN, Chenoweth CE, Fontana RJ, Magee JC, Punch JD, et al. Vancomycinresistant enterococcal colonization and infection in liver transplant candidates and recipients: A prospective surveillance study. Clin Infect Dis. 2006; 42: 195-203.

6. Santoro-Lopes G, de Gouvêa EF. Multidrug-resistant bacterial infections after liver transplantation: An ever-growing challenge. World J Gastroenterol. 2014; 20: 6201-6210.

7. Chavers LS, Moser SA, Funkhouser E, Benjamin Jr WH, Chavers P, Stamm AM, et al. Association between antecedent intravenous antimicrobial exposure and isolation of vancomycin-resistant enterococci. Microb Drug Resist. 2003; 9: 69-77.

8. Fridkin SK, Edwards JR, Courval JM, Hill H, Tenover FC, Lawton R, et al. The effect of vancomycin and third-generation cephalosporins on prevalence of vancomycin-resistant enterococci in 126 U.S. adult intensive care units. Ann Intern Med. 2001; 135: 175-183.

9. Zuccaro V, Columpsi $P$, Sacchi $P$, Lucà MG, Fagiuoli S, Bruno R. Antibiotic stewardship and empirical antibiotic treatment: How can they get along? Dig Liver Dis. 2017; 49: 579-584.

10. Olson G, Davis AM. Diagnosis and treatment of adults with community-acquired pneumonia. JAMA. 2020; 323: 885-886.

11. Sager R, Kutz A, Mueller B, Schuetz P. Procalcitonin-guided diagnosis and antibiotic stewardship revisited. BMC Med. 2017; 15: 15.

12. Sandkovsky U, Kalil AC, Florescu DF. The use and value of procalcitonin in solid organ transplantation. Clin Transplant. 2015; 29: 689-696.

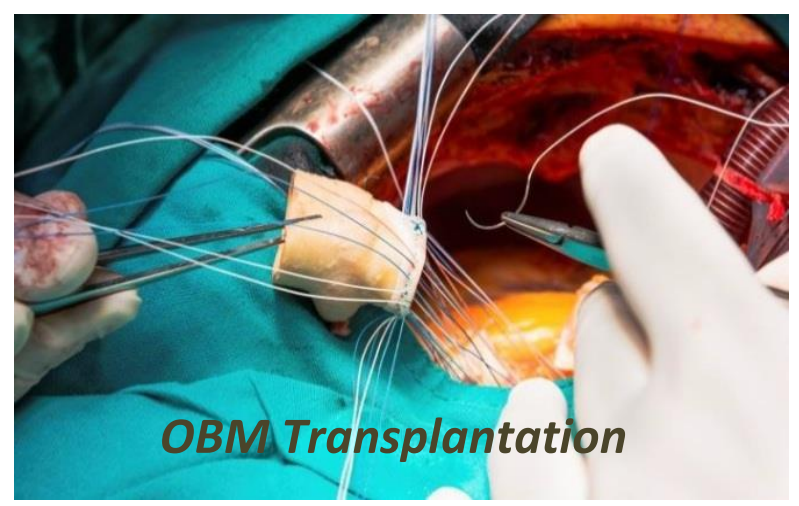

Enjoy OBM Transplantation by:

1. Submitting a manuscript

2. Joining in volunteer reviewer bank

3. Joining Editorial Board

4. Guest editing a special issue

For more details, please visit:

http://www.lidsen.com/journals/transplantation 
Original Research

\title{
"Real World" Australian Experience of Allogeneic Hematopoietic Stem Cell Transplantation (HSCT) in Adults with Severe Aplastic Anaemia.
}

\author{
Courtney Tate ${ }^{1,2,3}$, Jason P Butler ${ }^{1}$, Cameron Curley ${ }^{1}$, Siok-Keen Tey ${ }^{1,2,4}$, Glen A Kennedy ${ }^{1,2}$, \\ Ashleigh P Scott ${ }^{1,2, *}$
}

1. Royal Brisbane and Women's Hospital, Herston, QLD, Australia; E-mails: courtney.tate@health.qld.gov.au; Cameron.curley@health.qld.gov.au; jason.butler@health.qld.gov.au; glen.kennedy@health.qld.gov.au; Ashleigh.scott@health.qld.gov.au

2. The University of Queensland, St Lucia, QLD, Australia

3. Gold Coast University Hospital, Southport, QLD, Australia

4. QIMR Berghofer Medical Research Institute, Herston, QLD, Australia

* Correspondence: Ashleigh P Scott; E-Mail: Ashleigh.scott@health.qld.gov.au

Academic Editor: Martin Guimond

Special Issue: Allogeneic Stem Cell Transplantation

\section{OBM Transplantation}

2020 , volume 4 , issue 4

doi:10.21926/obm.transplant.2004121
Received: June 23, 2020

Accepted: October 14, 2020

Published: October 23, 2020

\begin{abstract}
Acquired Severe Aplastic Anaemia (SAA) is a rare bone marrow failure syndrome, for which allogeneic haematopoietic stem cell transplant (HSCT) is a proven curative therapy. Despite excellent outcomes for matched sibling SAA recipients in terms of engraftment and survival, HSCT remains highly challenging in older matched-unrelated-donor (MUD) recipients, due to increased non-relapse mortality (NRM) from causes such as graft versus host disease (GVHD), organ failure and infection. We sought to evaluate our local HSCT outcomes for SAA, determine factors that predict for inferior outcomes, and benchmark local outcomes against international cohorts. To define outcomes for sibling and MUD HSCT in adults $\geq 17$ years of age with SAA at a single Australian institution between 2002 and 2018 and compare these outcomes to internationally published cohorts. The primary outcome was 1-year overall
\end{abstract}

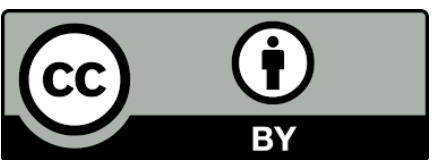

(C) 2020 by the author. This is an open access article distributed under the conditions of the Creative Commons by Attribution License, which permits unrestricted use, distribution, and reproduction in any medium or format, provided the original work is correctly cited. 
survival (OS). Secondary outcomes included the incidences of engraftment, response, secondary graft failure, GVHD, and moderate to severe organ dysfunction. All 21 patients comprising 10 sibling and 11 MUD HSCTs, with a median age of 30 (range 17-64), received bone marrow grafts. At a median follow up of 3.5 years, 17 (81\%) of 21 patients remained alive and in remission from SAA. 1-year OS, non-relapse mortality (NRM), and GVHD incidence were $85 \%, 15 \%$, and $48 \%$ respectively. Two patients died prior to engraftment at Day+27 and Day+33. When comparing sibling and MUD HSCT recipients, incidences of survival, engraftment and post-HSCT complications were similar; however, MUD HSCT survivors experienced a higher incidence of chronic GVHD (67\% vs. $11 \%$; $p=0.04$ ). Age $>40$ years, AKI by Day+28, infection by Day+100 and deviation from intended GVHD prophylaxis predicted for worse OS. Our outcomes following HSCT for SAA are comparable to international cohorts with age $>40$ years, early onset infection, AKI and deviation from intended GVHD prophylaxis protocol negatively impacting OS. Further research is warranted to optimise MUD HSCT conditioning and GVHD prophylaxis protocols for SAA, particularly in older patients.

\section{Keywords}

Aplastic anaemia; HSCT; GVHD

\section{Introduction}

Acquired Severe Aplastic Anaemia (SAA) is a rare, life-threatening, immune-mediated acquired bone marrow failure syndrome. Hematopoietic stem cell transplantation (HSCT) is the preferred treatment in patients $<40$ years old with a matched sibling donor, as well as in patients with a fully matched unrelated donor (MUD) who have failed or relapsed despite prior immunosuppressive therapy (IST) [1].

HSCT conditioning protocols for matched sibling SAA recipients report excellent outcomes in terms of engraftment and survival; standard conditioning is cyclophosphamide (CY) $200 \mathrm{mg} / \mathrm{kg}$ (total) and horse (equine) anti-thymocyte globulin (ATG) $90 \mathrm{mg} / \mathrm{kg}$ (total) (CY-ATG). However, the optimal conditioning for MUD HSCT is less well established. Typical MUD conditioning incorporates low dose total body irradiation (TBI, 2Gy) (CY-ATG-TBI), which improves engraftment and overall survival (OS) for younger MUD recipients [2-4]. However, HSCT for SAA remains highly challenging in older MUD recipients, due to increased non-relapse mortality (NRM) from causes such as graft versus host disease (GVHD), organ failure and infection [4].

Recently, researchers have sought to reduce MUD HSCT NRM by modifying conditioning protocols and GVHD prophylaxis. Examples include T-cell manipulation, co-transplantation with mesenchymal stem cells, and dose-reducing or omitting high-dose cyclophosphamide and introducing fludarabine as a "cyclophosphamide-sparing" agent [5-9]. For matched adult HSCT using bone marrow as donor stem cell source, the most promising novel conditioning regimen, published by Anderlini et al [9], evaluated intermediate dose CY $50-100 \mathrm{mg} / \mathrm{kg}$ with rabbit ATG, fludarabine and TBI 2Gy (rATG-Cy50-100-Flu-TBI). Despite only $19 \%$ of the cohort being aged $>40$ years, moderate to severe organ dysfunction remains common before Day+100 (14\%), and graft 
failure and mortality are not insignificant (14\% and $16 \%$ respectively at 1 -year). For clinicians, performing MUD HSCT in SAA remains a complex juggling act between selecting conditioning strength to facilitate sustainable engraftment, optimising pre-HSCT patient medical selection and fitness to withstand conditioning, and delivering adequate GVHD prophylaxis.

Our institution uses CY-ATG-TBI (2Gy) as HSCT conditioning for patients aged up to 65 years undergoing MUD HSCT for SAA. To inform the design of a prospective clinical trial of a novel MUD HSCT protocol, we sought to evaluate our local HSCT outcomes for SAA using CT-ATG-TBI, and to explore the incidence and potential impact of complications such as GVHD, infection or organ failure.

\section{Materials and Methods}

\subsection{Study Population}

We conducted a retrospective analysis of all adults $\geq 17$ years undergoing HSCT for SAA at our institution between August 2002 and May 2018. The study was conducted in accordance with the Declaration of Helsinki and received appropriate local institutional approvals.

\subsection{Recipient Selection}

All HSCT recipients required a confirmed bone marrow diagnosis of SAA, and normal pre-HSCT organ function including normal echocardiogram ejection fraction (EF $>50 \%$ ), normal creatinine clearance and glomerular filtration rate $($ GFR $>60)$, normal bilirubin and liver function tests (LFTs) and normal corrected pulmonary diffusion capacity (cDLCO $>65 \%$ ). No recipients were allowed to proceed to HSCT with an unresolved infection, and individualised transplant protocols including antibiotic prophylaxis and empiric antibiotic choice after accounting for prior infections were developed.

\subsection{Donor Selection}

All sibling donors were $8 / 8$ matched for HLA-A, -B, -C and DRB1 by serology typing for HLA class I antigens and allele typing using sequence specific oligonucleotide probes (SSOP) for HLA class II antigens. Serology typing was subsequently confirmed by SSOP. All unrelated donors were 10/10 high-resolution matches for HLA-A, -B, -C, DRB1 and DQ by allele typing using SSOP.

\subsection{HSCT Procedures}

All sibling HSCT recipients underwent CY-ATG conditioning, comprising cyclophosphamide $50 \mathrm{mg} / \mathrm{kg} /$ day on Day-5 to Day-2 (total $200 \mathrm{mg} / \mathrm{kg}$ ) and equine anti-thymocyte globulin (ATGAM, Pfizer Inc., New York, NY, USA) $30 \mathrm{mg} / \mathrm{kg} /$ day (total $90 \mathrm{mg} / \mathrm{kg}$ ) on Day-5 to Day-3 (equine ATG was available throughout the study period). MUD HSCT recipients received 2Gy TBI at Day-1 in addition to CY-ATG (CY-ATG-TBI). All patients received bone marrow grafts without in vitro T-cell depletion. Post-HSCT GVHD prophylaxis consisted of methotrexate with folinic acid rescue at $15 \mathrm{mg} / \mathrm{m}^{2}$ on Day +1 , and $10 \mathrm{mg} / \mathrm{m}^{2}$ on Days $+3,+6$ and +11 , as well as cyclosporin A (CsA) $5 \mathrm{mg} / \mathrm{kg}$ Day-1 to Day +1 , and then $3 \mathrm{mg} / \mathrm{kg}$ from Day+2. CsA trough level targets were 150-300ug/L. CsA weaning was 
commenced on Day+180 and occurred over 3-6 months depending on individual patient chimerism and GVHD incidence. Tacrolimus was substituted in the event of CsA intolerance.

\subsection{Data Collection}

Patients were identified from an existing departmental database, and data were collected by retrospective chart review. Patients were divided into sibling and MUD HSCT cohorts for subsequent comparison.

\subsubsection{Baseline Patient Characteristics Collected}

-Patient demographics;

-Pre-HSCT organ function and prior significant infections;

-SAA details: severity, presence of associated paroxysmal nocturnal haemoglobinuria (PNH) clone at diagnosis, use of prior IST, time from diagnosis to HSCT;

-HSCT details: donor source, CMV matching, ABO matching, conditioning regimen, and infused stem cell number (total nucleated cell count, TNC).

\subsubsection{Post-HSCT Details}

-Engraftment details: day of neutrophil and platelet engraftment, incidence of primary and secondary graft failure, best SAA response;

-GVHD details: GVHD prophylaxis received, incidence and severity of acute and chronic GVHD $[10,11]$;

-Incidence of moderate to severe organ dysfunction (grade 2 to 5 as per CTCAE v4.03) including but not limited to: acute kidney injury (AKI) prior to Day+28, hyperbilirubinaemia, hepatitis, thrombotic microangiopathy (TMA), pulmonary haemorrhage, veno-occlusive disease (VOD), and infection prior to Day+100.

-Survival.

The primary outcome was 1-year OS. Secondary outcomes included the incidences of engraftment, response, secondary graft failure, GVHD, and moderate to severe organ dysfunction (grade 2 to 5 as per CTCAE v4.03).

\subsection{Statistical Analysis}

Outcomes between the two cohorts were compared using Chi-square test for categorical variables and Mann-Whitney test for continuous variables. OS was measured from time of stem cell infusion to date of death, or last date patient follow up at time of censoring. Survival curves were obtained using the Kaplan-Meier method and comparison performed using log-rank test. Univariate Cox proportional hazard model was used to analyse factors potentially impacting on overall survival including recipient age ( $<40$ vs. $\geq 40$ years), prior IST, number of lines of IST ( $<2$ vs. $\geq$ 2 ), days from diagnosis to HSCT (<6 months vs. $\geq 6$ months), AKI, infection, and GVHD. Results are expressed as hazard ratios (HR) with $95 \%$ confidence intervals $(\mathrm{Cl})$. GraphPad version 8.0.0 was used for statistical analysis. 


\section{Results}

\subsection{Baseline Characteristics}

21 patients were identified and included for analysis, comprising 10 sibling and 11 MUD HSCT. Donor and recipient characteristics are outlined in Table 1. Five (24\%) patients underwent first-line sibling HSCT. As expected, when comparing the MUD HSCT cohort with sibling HSCTs, there was a significantly greater time to HSCT, and higher incidence of prior IST use and ABO mismatch in the MUD HSCT cohort. In the sibling HSCT cohort there were more female donors due to selection preference of male donors for MUD HSCT when available.

Table 1 Donor, recipient and transplant characteristics.

\begin{tabular}{|c|c|c|c|c|}
\hline & All HSCTs & Sibling HSCTs & MUD HSCTs & p-value \\
\hline Transplant type & 21 & 10 & 11 & \\
\hline Bone marrow derived stem cells & 21 & 10 & 11 & \\
\hline Recipient age, median (range) & $30(17-64)$ & $26(17-58)$ & $31(18-64)$ & 0.29 \\
\hline Donor age, median (range) & $35(14-58)$ & $26(14-58)$ & $42(22-49)$ & 0.13 \\
\hline Male gender (\%) & $15(71)$ & $6(60)$ & $9(82)$ & 0.36 \\
\hline $\mathrm{PNH}$ clone ${ }^{\dagger}$ & $9(43)$ & $2(20)$ & $7(64)$ & 0.81 \\
\hline Prior IST $\ddagger$, n (\%) & $16(76)$ & $5(50)$ & $11(100)$ & $0.01 *$ \\
\hline No. treated with $\geq 2$ lines of IST & 4 (19) & $0(0)$ & $4(36)$ & 0.09 \\
\hline \multicolumn{5}{|l|}{ Conditioning regimen§ } \\
\hline Cy/ATGAM/2Gy TBI, n (\%) & & & $11(100)$ & \\
\hline Cy/ATGAM, n (\%) & & $10(100)$ & & \\
\hline Days from diagnosis to HSCTף & $231(18-5185)$ & $86(18-436)$ & $310(124-5185)$ & $0.003^{*}$ \\
\hline $\begin{array}{l}\text { Donor female to male recipient, } \\
\mathrm{n}(\%)\end{array}$ & $4(19)$ & $4(40)$ & $0(0)$ & $0.04 *$ \\
\hline \multicolumn{5}{|l|}{$A B O, n(\%)$} \\
\hline match & $11(52)$ & $8(80)$ & $3(27)$ & $0.03 *$ \\
\hline minor mismatch & $5(24)$ & $1(10)$ & $4(36)$ & \\
\hline major mismatch & $2(10)$ & $0(0)$ & $2(18)$ & \\
\hline
\end{tabular}


minor and major mismatch

Median infused cell dose, (range)

TNC, $\times 10^{8} / \mathrm{kg} ¥$

$\begin{array}{lll}2.51 & 1.975 & 2.66 \\ (1.15-23.94) & (1.5-11.03) & (1.15-23.94)\end{array}$

0.32

†PNH indicates paroxysmal nocturnal haemoglobinuria: The PNH clone in all patients was $<5 \%$, except for one patient where the PNH clone comprised $50 \%$ of granulocytes, $64 \%$ of monocytes, with $2 \%$ type III red cells. No patients had evidence of haemolysis; \#IST immunosuppressive therapy; §Conditioning regimens explained in detail in methods section; ๆ HSCT haematopoietic stem cell transplant; $¥$ TNC total nucleated cell

\subsection{Post-HSCT Outcomes}

Post-HSCT outcomes are summarised in Table 2. The median follow-up is 3.5 years (range 0.116 years).

Table 2 Haematopoietic Stem Cell Transplantation Outcomes.

\begin{tabular}{|c|c|c|c|c|}
\hline & $\begin{array}{l}\text { All } \\
\text { HSCTs' } \\
(n=21)\end{array}$ & $\begin{array}{l}\text { Sibling } \\
(n=10)\end{array}$ & $\begin{array}{l}\text { MUD } \\
(n=11)\end{array}$ & p-value \\
\hline Neutrophil engraftment, n (\%) & $19(91)$ & $9(90)$ & $10(91)$ & 0.83 \\
\hline Platelet engraftment, $\mathrm{n}(\%)$ & $19(91)$ & $9(90)$ & $10(91)$ & 0.10 \\
\hline $\begin{array}{l}\text { Deviation from intended GVHD§ prophylaxis, } n \\
\text { (\%) }\end{array}$ & $9(43)$ & $5(50)$ & $4(36)$ & 0.67 \\
\hline AKI prior to $\mathrm{D}+28, \mathrm{n}(\%)$ & $7(33)$ & $3(30)$ & $4(36)$ & $>0.99$ \\
\hline Infection prior to $\mathrm{D}+100, \mathrm{n}(\%)$ & $10(48)$ & $4(40)$ & $6(55)$ & 0.67 \\
\hline Any GVHD, n (\%) & $10(48)$ & $2(20)$ & $8(73)$ & $0.03^{*}$ \\
\hline Acute GVHD, n (\%) & $6(29)$ & $1(10)$ & $5(46)$ & 0.08 \\
\hline Chronic GVHD, n (\%) & $7(33)$ & $1(10)$ & $6(66)$ & $0.04 *$ \\
\hline - $\quad$ Extensive stage, $\mathrm{n}(\%)$ & $3(14)$ & $0(0)$ & $3(33)$ & 0.10 \\
\hline Mortality, n (\%) & $4(19)$ & $1(10)$ & $3(27)$ & 0.49 \\
\hline
\end{tabular}

†HSCT indicates haematopoietic stem cell transplant; ¥MUD matched unrelated donor; §GVHD graft versus host disease; AKI acute kidney injury 


\subsubsection{Engraftment and Response}

Two (10\%) patients, comprising one sibling and one MUD HSCT recipient, died at Day+27 and Day+33 respectively, prior to neutrophil engraftment. In those who did engraft, sibling and MUD cohorts showed similar median time to engraftment for neutrophils (18 [range 16-23] vs. 20 [range 12-46] days respectively; $p=0.83$ ) and platelets (32 [range 24-312] vs. 25 [range 21-56] days respectively; $p=0.10$ ).

All those who engrafted achieved a complete response (CR) from their SAA. There were no cases of secondary graft failure. One patient had mixed chimerism and refractory thrombocytopenia at Day+180 despite full morphological megakaryocyte engraftment on bone marrow aspirate, indicating a degree of peripheral platelet consumption. He underwent second HSC infusion from the same sibling donor, which was unsuccessful, but ultimately achieved a normal platelet count after therapeutic splenectomy despite ongoing mixed chimerism; thus consistent with a diagnosis of post-HSCT immune thrombocytopenic purpura.

\subsubsection{Incidence of Moderate-Severe Organ Dysfunction}

13 patients (62\%) experienced at least one episode of moderate-severe organ dysfunction prior to Day+100 post HSCT, described in Table 3. These included infection (10), AKI (7), hepatic dysfunction (3), heart failure (1), pulmonary haemorrhage (1; secondary to infection), and thrombotic microangiopathy (TMA) (1). There were no cases of VOD. The incidence of any moderate-severe organ dysfunction did not differ between sibling and MUD recipients (60\% vs $64 \% ; p=1.0$ ), however, the incidence was non-significantly higher in those aged $>40$ years compared to $<40$ years ( $83 \%$ vs $53 \% ; p=0.33$ ).

9 of these patients ( $43 \%$ of the entire cohort) experienced their episode(s) of acute moderatesevere organ dysfunction within the first 14 days post HSCT, and consequently their intended GVHD prophylaxis was modified or temporarily omitted until resolution of the organ dysfunction (Table 3). Reasons for deviation included grade 2-3 AKI $(n=5)$, grade 3-4 hyperbilirubinaemia $(n=2)$ or transaminitis $(n=1)$, and grade 3 TMA $(n=1)$. Rates of deviation from intended GVHD prophylaxis were similar between sibling and MUD HSCT cohorts ( $50 \%$ vs. $36 \% ; p=0.67$ ), between patients $\geq 40$ and $<40$ years ( $50 \%$ vs. $67 \% ; p=0.98)$ and between patients who received upfront HSCT compared with prior IST ( $60 \%$ vs. $38 \%$; $p=0.61)$. 
OBM Transplantation 2020; 4(4), doi:10.21926/obm.transplant.2004121

Table 3 Modifications to graft versus host disease (GVHD) prophylaxis and patient outcomes.

\begin{tabular}{|c|c|c|c|c|c|c|c|c|}
\hline $\begin{array}{l}\text { Recipient } \\
\text { Age/sex }\end{array}$ & Sib/MUD & $\begin{array}{l}\text { Intended GVHD } \\
\text { prophylaxis }\end{array}$ & $\begin{array}{l}\text { Indication for altering } \\
\text { GVHD prophylaxis** }\end{array}$ & $\begin{array}{l}\text { Modification to } \\
\text { GVHD prophylaxis }\end{array}$ & $\begin{array}{l}\text { D100 } \\
\text { Infection }\end{array}$ & $\begin{array}{l}\text { Acute } \\
\text { GVHD } \\
\text { Grade } \\
\end{array}$ & $\begin{array}{l}\text { Chronic GVHD } \\
\text { Seattle stage }\end{array}$ & $\begin{array}{l}\text { Outcome/days post } \\
\text { HSCT at censoring }\end{array}$ \\
\hline $24 \mathrm{~F}$ & sib & $\mathrm{CsA}^{*}, \mathrm{MTX}$ & Grade 2 AKI D+5 & $\begin{array}{l}\text { Tacro from } D+5 \\
\text { instead of CsA }\end{array}$ & $\mathrm{N}$ & 0 & 0 & 4562 \\
\hline $23 \mathrm{M}$ & sib & $\mathrm{CsA}^{*}, \mathrm{MTX}$ & $\begin{array}{l}\text { Grade } 3 \\
\text { hyperbilirubinaemia } \\
D+13\end{array}$ & $\begin{array}{l}\text { MMF from } D+13 \\
\text { instead of CsA }\end{array}$ & Y & 0 & $\begin{array}{l}\text { Limited } \\
\text { (cutaneous) }\end{array}$ & 1249 \\
\hline $17 \mathrm{M}$ & sib & CsA, MTX & NA & NA & $\mathrm{N}$ & 0 & 0 & 1537 \\
\hline $19 M$ & sib & CsA, MTX & NA & NA & $\mathrm{N}$ & 0 & 0 & 1467 \\
\hline $58 \mathrm{~F}$ & sib & CsA, MTX & NA & NA & Y & II & 0 & 629 \\
\hline $28 \mathrm{~F}$ & sib & CsA, MTX & NA & NA & $\mathrm{N}$ & 0 & 0 & 553 \\
\hline $32 \mathrm{M}$ & sib & CsA, MTX & NA & NA & $\mathrm{N}$ & 1 & 0 & 379 \\
\hline $36 \mathrm{M}$ & sib & CsA, MTX* & Grade 2 AKI D+12 & $\begin{array}{l}\text { D+11 MTX } \\
\text { withheld, MP } 1 \\
\mathrm{mg} / \mathrm{kg} \text { until CsA } \\
\text { therapeutic, and } \\
\text { Basiliximab }\end{array}$ & Y & 0 & 0 & 188 \\
\hline $20 M$ & sib & CsA, MTX* & $\begin{array}{l}\text { Grade } 4 \text { transaminitis } \\
D+3\end{array}$ & $\begin{array}{l}\mathrm{D}+3,+6,+11 \mathrm{MTX} \\
\text { withheld }\end{array}$ & $\mathrm{N}$ & 0 & 0 & 116 \\
\hline
\end{tabular}




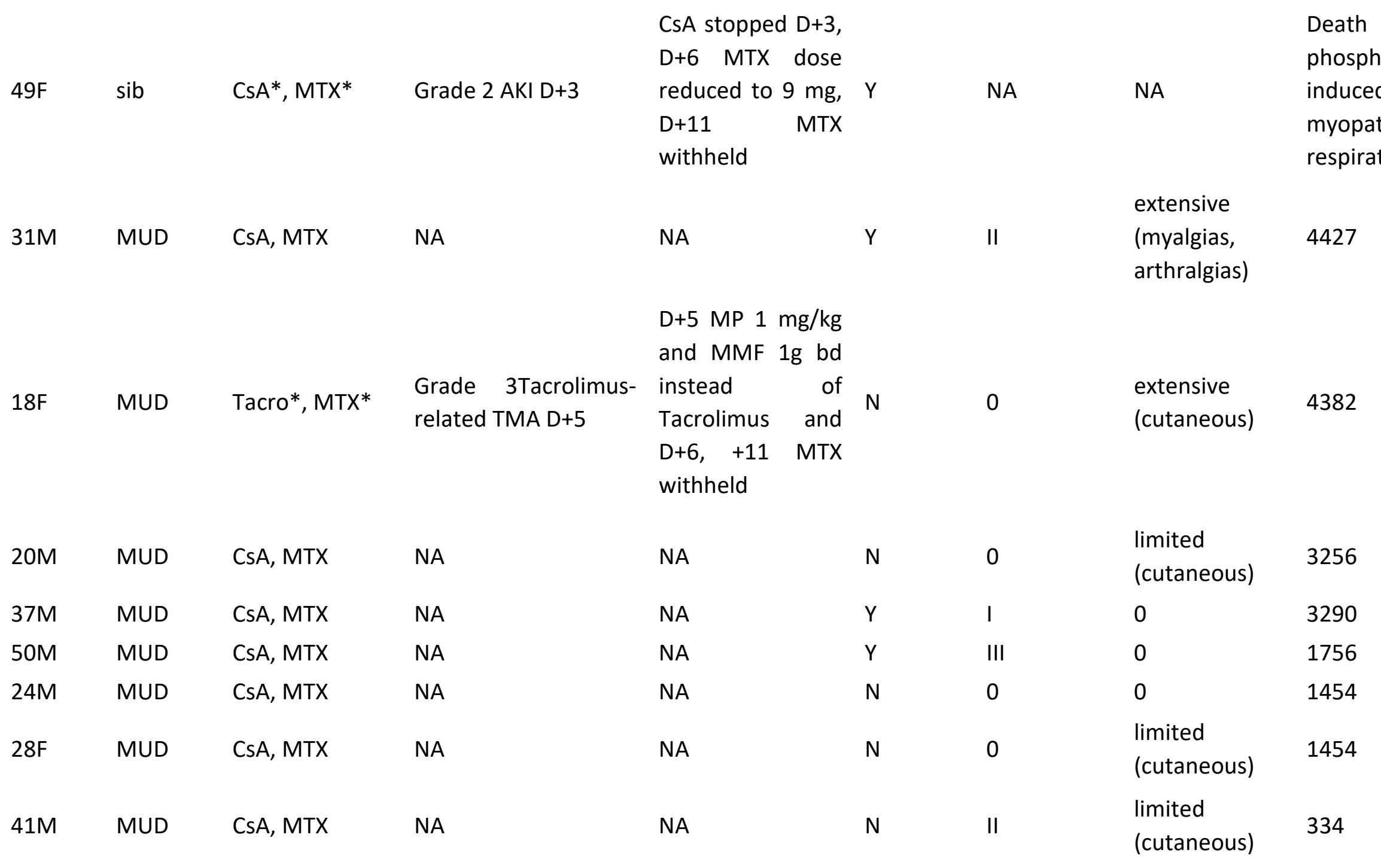




\begin{tabular}{|c|c|c|c|c|c|c|c|c|}
\hline $64 \mathrm{M}$ & MUD & CsA*, MTX* & Grade 2 AKI D+5 & $\begin{array}{l}\mathrm{D}+1,+3+6+11 \\
\mathrm{MTX} \text { withheld, } \\
\mathrm{MMF} 1 \text { bd and } \\
\text { prednisolone } 1 \\
\mathrm{mg} / \mathrm{kg} \text { from } \mathrm{D}+3\end{array}$ & $\mathrm{Y}$ & II & $\begin{array}{l}\text { extensive } \\
\text { (cutaneous) }\end{array}$ & $\begin{array}{l}\text { Death D+1350: RSV } \\
\text { pneumonitis with } \\
\text { respiratory failure }\end{array}$ \\
\hline $30 \mathrm{M}$ & MUD & CsA*, MTX* & Grade 2 AKI D+12 & $\begin{array}{lr}\mathrm{D}+11 & \mathrm{MTX} \\
\text { withheld, } & \mathrm{CsA} \\
\text { ceased } \mathrm{D}+13, \mathrm{MP} \\
1 \mathrm{mg} / \mathrm{kg}, 1 \mathrm{~g} \text { bd } \\
\mathrm{MMF} & \text { and } \\
\text { Basiliximab }\end{array}$ & Y & IV & NA & $\begin{array}{l}\text { Death D+102: acute } \\
\text { lower gastro- } \\
\text { intestinal GVHD }\end{array}$ \\
\hline $63 \mathrm{M}$ & MUD & Tacro, MTX* & $\begin{array}{l}\text { Grade } 3 \\
\text { hyperbilirubinaemia } \\
D+3\end{array}$ & $\begin{array}{l}D+11 \\
\text { withheld }\end{array}$ & Y & NA & NA & 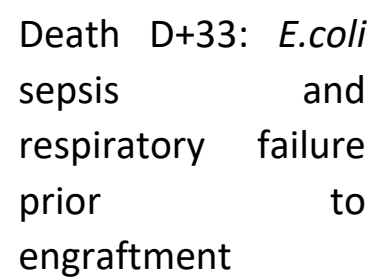 \\
\hline
\end{tabular}

*indicates modified GVHD prophylaxis; ${ }^{* *}$ Grading as per CTCAE v4.03 Sib: sibling; MUD: matched unrelated donor; CsA: Cyclosporin A; MTX: methotrexate; Tacro: Tacrolimus; D: Day; AKI: acute kidney injury; MMF: mycophenolate mofetil; MP: methylprednisone; TMA: thrombotic microangiopathic anaemia. 


\subsubsection{GVHD Details}

The incidences of acute and chronic GVHD are shown in Figure 1. In patients who engrafted $(n=19)$, there was a non-significant trend towards a higher incidence of moderate to severe (Grade II-IV) acute GVHD in MUD compared to sibling HSCT ( $50 \%$ vs. $11 \%, \mathrm{p}=0.08$ ). Severe (Grade III-IV) acute GVHD was seen in MUD HSCT only (20\%). In those surviving beyond Day+100 (18 patients, comprising nine sibling and nine MUD HSCT), chronic GVHD occurred in seven (39\%) patients. Chronic GVHD occurred significantly more frequently in MUD compared to sibling HSCT (67\% vs. $11 \%, p=0.04)$. Two of the three cases of extensive chronic GVHD occurred in MUD HSCT, and two of these patients had modifications to their GVHD prophylaxis (Table 3). The incidence of GVHD was similar between patients with unmodified compared to modified GVHD prophylaxis (60\% vs. $55 \% ; p=0.96)$.
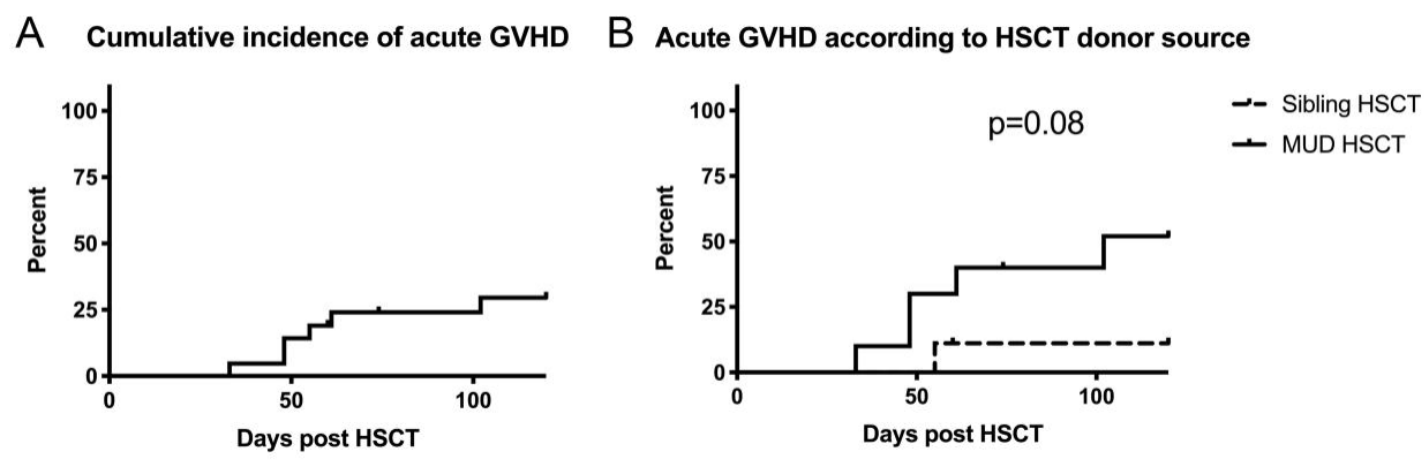

C Cumulative incidence of chronic GVHD
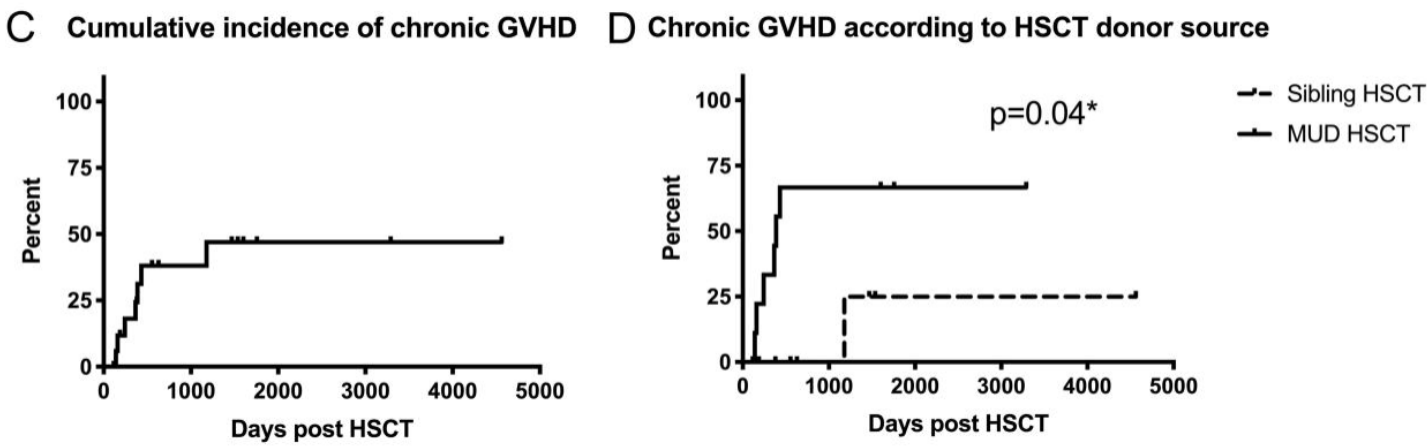

Figure 1 Incidence of graft versus host disease (GVHD) post allograft for severe aplastic anaemia (SAA). A. Cumulative incidence of acute GVHD. B. Acute GVHD according to hematopoietic stem cell transplant (HSCT) donor source. C. Cumulative incidence of chronic GVHD. D. Chronic GVHD according to HSCT donor source. MUD; matched unrelated donor.

\subsubsection{Survival}

At a median follow up of 3.5 years, 17 (81\%) HSCT recipients remain alive and in remission from SAA, with NRM $19 \%$ and death due to secondary graft failure $0 \%$. There was no significant difference in OS between sibling and MUD cohorts at 1 year (1-year OS 90\% vs. 82\% respectively; $\mathrm{p}=0.93$ ) (Figure 2 ) or at the time of censoring (OS $90 \%$ vs. $71 \%$ respectively; $p=0.48$ ). Notably, at the time of censoring, survival in the 6 patients aged $>40$ years is $50 \%$. Of those who had experienced early AKI but survived beyond $D+100$, none developed chronic kidney disease. 


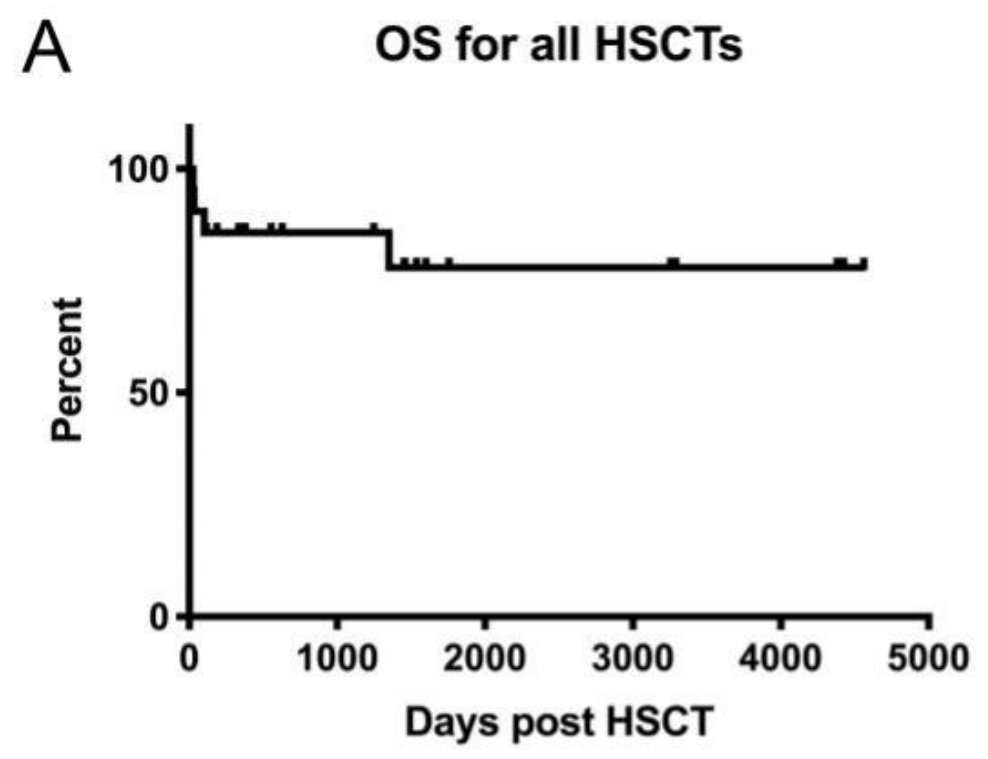

\section{B OS according to HSCT donor source}

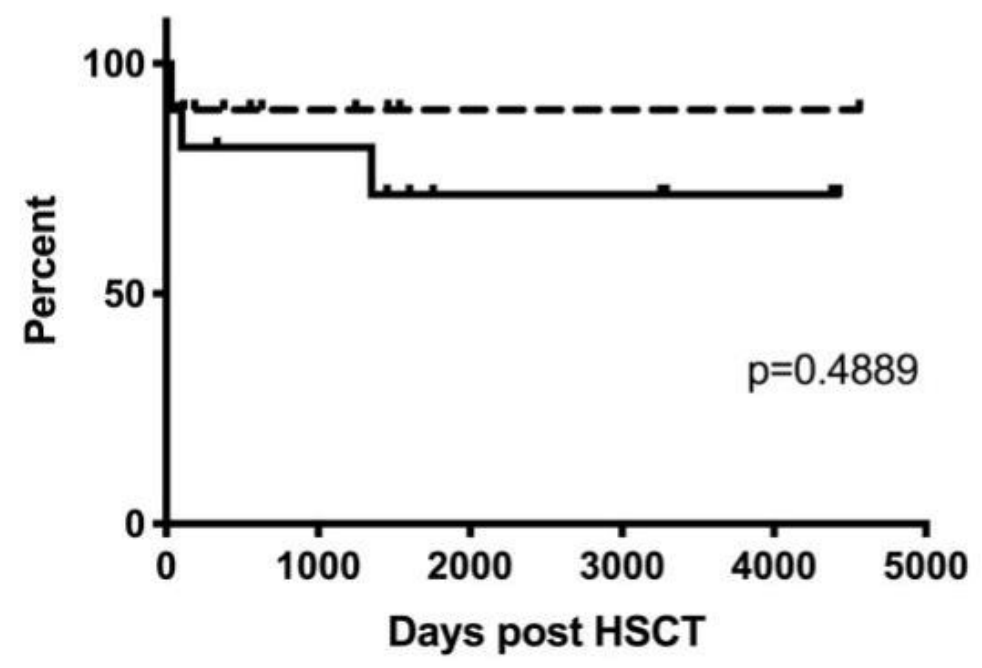

Figure 2 Overall survival (OS) post allograft for severe aplastic anaemia (SAA). A. OS for all allografts performed for SAA. B. OS according to hematopoietic stem cell transplant (HSCT) donor source. MUD; matched unrelated donor.

MUD mortality occurred secondary to refractory acute GVHD at Day+102 $(n=1)$, sepsis and secondary respiratory failure in the setting of primary graft failure at Day+33 $(n=1)$, and respiratory syncytial virus associated pneumonitis and respiratory failure in the setting of longterm immunosuppression for extensive cutaneous GVHD at 4 years $(n=1)$. One sibling HSCT recipient died at Day+27 due to cyclophosphamide induced cardiomyopathy and secondary respiratory failure prior to engraftment. All patients who died had required protocol deviations from planned GVHD prophylaxis due to early complications, compared with no deaths in patients who did not require protocol deviations ( $44 \%$ vs. $0 \%$ respectively; $p=0.09$ ). 


\subsection{Univariate Analysis}

Univariate analysis identified age $>40$ years (HR 15.4; 95\% Cl 1.6-151.1; $p=0.02$ ), AKI (HR 77.31; 95\% Cl 7.5-796.0; $p=0.0005$ ), infection (HR 9.137; 95\% Cl 1.2-65.7; $p=0.03$ ), and deviation from intended GVHD prophylaxis (HR 15.84; $95 \% \mathrm{Cl} 2.0-12.8 ; \mathrm{p}=0.008$ ) as predictors of adverse OS in the total cohort. There was a non-significant trend toward inferior OS if the time from initial SAA diagnosis to HSCT exceeded 6 months, compared with those transplanted within 6 months of initial diagnosis (OS $100 \%$ vs. $67 \%$; $p=0.08$ ). Multivariate analysis was not performed due to small study cohort size.

\section{Discussion}

This is the largest case series of adult allogeneic HSCT undertaken for SAA in Australia and complements our previous analyses of SAA outcomes including allograft and non-allograft patients $[12,13]$. Although these retrospective data are underpowered compared to those published by the EBMT and CIBMTR, they do provide valuable insight into HSCT for SAA practice in Australia.

Compared to post-HSCT survival for malignancies such as leukaemia, SAA HSCT survival outcomes typically reflect NRM rather than post-HSCT relapse or secondary graft failure. We have previously described 15 patients transplanted at this institution for SAA between 1989-1999 with $100 \% 6$-year OS [12]. Notably, this cohort was significantly younger (median age 22 years, range 346) than the current cohort (median age 30 years, range 18-64), reflecting changes in transplantation practice over decades.

In this current cohort (2002-2018), we report 81\% OS and 19\% NRM at median 3.5 years followup. Although 1-year OS was similar between sibling and MUD recipients ( $90 \%$ vs. $82 \%$; $p=0.1$ ), we note that 3 of 4 deaths occurred in MUD HSCT patients, and thus likely reflects the known association between MUD HSCT and increased NRM. Not unexpectedly, compared to sibling HSCT, MUD HSCT survivors experienced a significantly greater incidence of chronic GVHD and a nonsignificant trend toward an increased incidence of acute GVHD. Overall, local outcomes for survival, engraftment and acute GVHD for sibling and MUD HSCT appear similar to those reported in large international series [2, 3].

Interestingly, we report a higher incidence of chronic GVHD (67\%; predominantly cutaneous) in MUD recipients than that published elsewhere (14-44\%) [2, 3]. Potential contributors include: a) the overall older age of our MUD population (median 35 years), and b) a potential centre effect, as chronic GVHD incidence (particularly cutaneous) at our institution is typically high compared to other international centres across all disease groups, occurring in $>50 \%$ of HSCT survivors beyond 6 months of follow up. Any centre effect for chronic GVHD incidence may be magnified by the low incidence of relapse for SAA compared to other malignant indications for HSCT.

Most notably, our study highlights an apparently substantial incidence of unexpected moderate-severe organ dysfunction (43\% prior to $D+14,62 \%$ prior to $D+100$ ), occurring despite rigorous pre-HSCT evaluation of organ function and use of standard HSCT conditioning. When these complications occurred prior to $D+14$, the impact appeared substantial: all required dose reduction or omission of GVHD prophylaxis, with a possible negative impact upon survival. AKI was the major contributor in half of these cases prior to D+14 (24\% of the entire cohort); conversely, AKI occurring after engraftment but prior to $D+100(n=2)$ did not impact survival. We have 
previously reported in non-SAA HSCT that early AKI significantly increases post-HSCT NRM due to an increased incidence of acute and chronic GVHD [14]. Potentially, a significant proportion of NRM in SAA HSCT may be either attributable to direct toxicity from HSCT conditioning, or indirect toxicity due to subsequent GVHD prophylaxis modification resulting in fatal GVHD.

Our study reinforces a pertinent issue for SAA HSCT: that older MUD ( $>40$ years) recipients have relatively poor post-HSCT OS due to excess NRM $[6,15]$. In our series, OS for those aged $>40$ years at HSCT was $50 \%(n=6)$, including two who died of cardiac and pulmonary toxicities prior to engraftment, and one from complications of GVHD. All three remaining survivors $>40$ years experienced moderate to severe chronic GVHD. Furthermore, although our study is not powered to fully evaluate risk factors for organ dysfunction or any impact upon survival, the highest incidence was observed in MUD HSCT recipients aged $>40$ years.

Our study's results support research investigating novel MUD HSCT conditioning strategies that aim to minimise toxicity and therefore NRM. Although the studies reported to date are highly informative and valuable, patients aged $>40$ years appear relatively under-reported, likely reflecting a) the rarity of SAA overall, b) the relative infrequency of HSCT in this age group, and c) compared to younger SAA patients, the increased likelihood that older patients will have comorbidities that preclude their enrolment in HSCT trials. For MUD recipients aged $>40$ years, it is not yet clear which, if any, conditioning protocol is safest. Whilst we acknowledge the inherent limitations of comparing our small retrospective study with a prospective phase II trial, the incidence of grade 3-5 organ dysfunction following CY-ATG-TBI in our study appears similar to that reported following rATG-Cy50-100-Flu-TBI (27\% vs 22\%). This is apparently despite our MUD recipients being aged $>40$ years in $36 \%$ and $18-40$ years in $64 \%$, compared with $21 \%$ and $41 \%$ respectively [9]. Currently, for MUD HSCT recipients aged $>40$ years, alternative HSCT protocols lack convincing evidence for superior safety compared to existing regimens.

The authors acknowledge the major limitations of this study are its retrospective design and small numbers which limit analysis of prognostic factors that occur at a low incidence; however, this is not dissimilar to many other SAA HSCT publications due to the rarity of the disease.

\section{Conclusion}

Our single-centre outcomes following sibling or MUD HSCT for SAA appear comparable to those in the published literature, with the exception of higher rates of chronic cutaneous GVHD which may reflect the older age of our cohort. Despite acceptable OS, HSCT for SAA remains challenging due to a high incidence of early organ dysfunction, particularly AKI, which likely contribute to increased NRM by necessitating deviations from planned GVHD prophylaxis. Further research is warranted to optimise MUD HSCT conditioning and GVHD prophylaxis protocols for SAA, particularly in older patients.

\section{Acknowledgements}

The authors wish to thank Dr Andrea S Henden, Dr A James Morton, Dr Elango Subramoniapillai and Dr Kirk Morris for review of the manuscript. 


\section{Author Contributions}

All authors contributed to study concept and design, and contributed to the manuscript. CT and APS collected and analysed the data, and wrote the first and final drafts of the manuscript. CT, APS and JPB performed the statistical analyses.

\section{Competing Interests}

The authors have declared that no competing interests exist.

\section{Reference}

1. Bacigalupo A. How I treat acquired aplastic anemia. Blood. 2017; 129: 1428-1436.

2. Bacigalupo A, Socie G, Hamladji RM, Aljurf M, Maschan A, Kyrcz-Krzemien S, et al. Current outcome of HLA identical sibling versus unrelated donor transplants in severe aplastic anemia: An EBMT analysis. Haematologica. 2015; 100: 696-702.

3. Champlin RE, Perez WS, Passweg JR, Klein JP, Camitta BM, Gluckman E, et al. Bone marrow transplantation for severe aplastic anemia: A randomized controlled study of conditioning regimens. Blood. 2007; 109: 4582-4585.

4. Deeg HJ, O'Donnell M, Tolar J, Agarwal R, Harris RE, Feig SA, et al. Optimization of conditioning for marrow transplantation from unrelated donors for patients with aplastic anemia after failure of immunosuppressive therapy. Blood. 2006; 108: 1485-1491.

5. Bacigalupo A, Locatelli F, Lanino E, Marsh J, Socie G, Maury S, et al. Fludarabine, cyclophosphamide and anti-thymocyte globulin for alternative donor transplants in acquired severe aplastic anemia: A report from the EBMT-SAA working party. Bone Marrow Transplant. 2005; 36: 947-950.

6. Giammarco S, Peffault de Latour R, Sica S, Dufour C, Socie G, Passweg J, et al. Transplant outcome for patients with acquired aplastic anemia over the age of 40: Has the outcome improved? Blood. 2018; 131: 1989-1992.

7. Maury S, Bacigalupo A, Anderlini P, Aljurf M, Marsh J, Socie G, et al. Improved outcome of patients older than 30 years receiving HLA-identical sibling hematopoietic stem cell transplantation for severe acquired aplastic anemia using fludarabine-based conditioning: A comparison with conventional conditioning regimen. Haematologica. 2009; 94: 1312-1315.

8. Maury S, Balere-Appert ML, Pollichieni S, Oneto R, Yakoub-Agha I, Locatelli F, et al. Outcome of patients activating an unrelated donor search for severe acquired aplastic anemia. Am J Hematol. 2013; 88: 868-873.

9. Anderlini P, Wu J, Gersten I, Ewell M, Tolar J, Antin JH, et al. Cyclophosphamide conditioning in patients with severe aplastic anaemia given unrelated marrow transplantation: A phase 1-2 dose de-escalation study. Lancet Haematol. 2015; 2: e367-e375.

10. Filipovich AH, Weisdorf D, Pavletic S, Socie G, Wingard JR, Lee SJ, et al. National institutes of health consensus development project on criteria for clinical trials in chronic graft-versus-host disease: I. Diagnosis and staging working group report. Biol Blood Marrow Transplant. 2005; 11: 945-956.

11. Przepiorka D, Weisdorf D, Martin P, Klingemann HG, Beatty P, Hows J, et al. 1994 consensus conference on acute GVHD grading. Bone Marrow Transplant. 1995; 15: 825-828. 
12. Mollee P, Woodward N, Durrant S, Lockwood L, Gillett EA, Morton J, et al. Single institution outcomes of treatment of severe aplastic anaemia. Intern Med J. 2001; 31: 337-342.

13. Scott A, Morris K, Butler J, Mills AK, Kennedy GA. Treatment of aplastic anaemia with lowerdose anti-thymocyte globulin produces similar response rates and survival as per standard dose anti-thymocyte globulin schedules. Intern Med J. 2016; 46: 1198-1203.

14. Birchley A, Butler JP, Scott A, Curley C, Kennedy G. Early acute kidney injury post allogeneic hematopoetic progenitor cell transplant is associated with increased risk of GVHD, higher mortality and reduced survival. Blood. 2016; 128: 2227.

15. Gupta V, Eapen M, Brazauskas R, Carreras J, Aljurf M, Gale RP, et al. Impact of age on outcomes after bone marrow transplantation for acquired aplastic anemia using HLA-matched sibling donors. Haematologica. 2010; 95: 2119-2125.

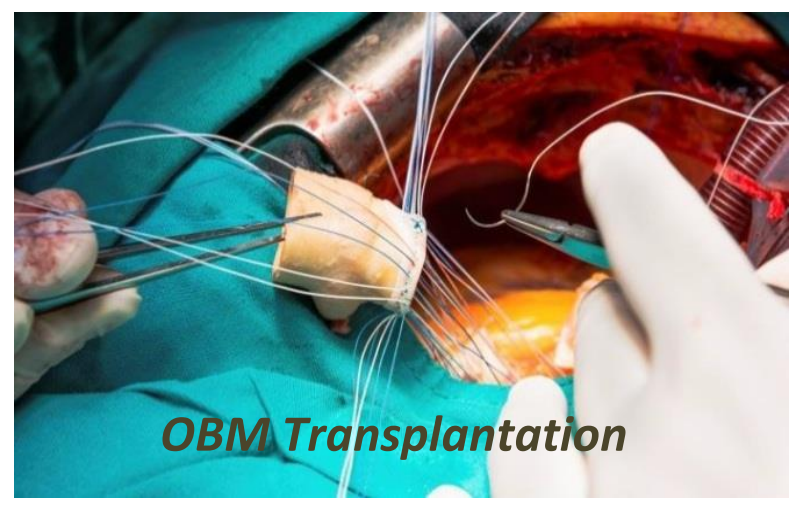

Enjoy OBM Transplantation by:

1. Submitting a manuscript

2. Joining in volunteer reviewer bank

3. Joining Editorial Board

4. Guest editing a special issue

For more details, please visit:

http://www.lidsen.com/journals/transplantation 
Case report

\title{
Donor Derived Strongyloidiasis in a Lung Transplant Recipient: From Life Cycle to Hyperinfection Syndrome
}

Shalika B. Katugaha * , Oksana Shlobin, Christopher King, Steven Nathan, Shambhu Aryal, Kareem Ahmad, Whitney Brown

Inova Advanced Lung Disease and Transplant, VA, USA; E-Mails: skb1078@gmail.com; Oksana.Shlobin@inova.org; Christopher.King@inova.org; Steven.Nathan@inova.org; Shambhu.Aryal@inova.org; Kareem.Ahmad@inova.org; Anne.Brown@inova.org

* Correspondence: Shalika Basnayake Katugaha; E-Mail: skb1078@gmail.com

Academic Editor: Yasuhiko Sugawara

Special Issue: Current Opinion in Organ Transplantation

OBM Transplantation

2020, volume 4, issue 4

doi:10.21926/obm.transplant.2004120
Received: September 04, 2020

Accepted: October 04, 2020

Published: October 13, 2020

\begin{abstract}
Strongyloides stercoralis infection derived from the donor in solid organ transplant (SOT) places recipients at risk for hyperinfection syndrome and death. We describe the case of a lung transplant recipient who developed strongyloidiasis presenting with GI symptoms and progressing to diffuse alveolar hemorrhage, bacteremia and multi-organ failure. The patient's clinical course illustrates the life cycle of Strongyloides. For treatment, the patient received ivermectin and albendazole. We advocate that early diagnosis and treatment, prior to hyperinfection, are essential in management in SOT. These rarer donor-derived infections need to remain in the differential, especially given the expanding landscape of the donor population.
\end{abstract}

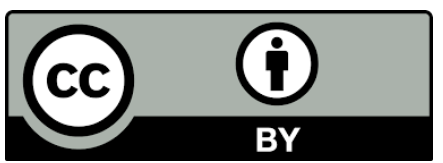

(C) 2020 by the author. This is an open access article distributed under the conditions of the Creative Commons by Attribution License, which permits unrestricted use, distribution, and reproduction in any medium or format, provided the original work is correctly cited. 


\section{Keywords}

Strongyloides stercoralis; strongyloidiasis; lung transplant; donor derived; hyperinfection syndrome

\section{Introduction}

Strongyloides stercoralis is a soil-transmitted nematode endemic to the tropics and subtropics with foci of infection occurring in temperate regions [1] where poor sanitation or other factors facilitate transmission. Immigrants and refugees comprise a significant population at risk for the helminthiasis in developed countries [2]. Acute infection commonly manifests with generalized abdominal pain, diarrhea, and emesis [3]. As these symptoms mimic other more common disease entities like viral gastroenteritis, Strongyloides infection can escape early diagnosis without a high index of suspicion [4]. In immunocompetent individuals, infection is typically self-limited and responsive to anthelmintic agents such as ivermectin. However, among immunosuppressed individuals, including the posttransplant population, lack of early detection can lead to disseminated infection and hyperinfection syndrome (HS). This may result in rapid multi-organ failure and death [5]. Despite use of anti-parasitic agents, mortality rate in disseminated disease is greater than fifty percent [6].

Cases of HS have been documented in the post-transplant population, and most have been attributed to reactivation of chronic infection in the recipient that escaped detection prior to transplant. Notably, there have been a rising number of cases of HS resulting from donor-derived (DD) infection not detected during pre-transplant screening $[7,8]$. A 2012 report by the Centers for Disease Control (CDC) described seven cases of donor-derived strongyloidiasis between 2009-2012 and underscored the need to reassess the screening policies for both donors and recipients from endemic regions [9]. Current guidelines from the American Society of Transplantation recommend screening for strongyloidiasis among recipients from highly endemic regions; however, there remains no policy provision for the screening of all donors, regardless of origin [10].

We report the case of a patient who received single lung transplant and developed donor derived (DD) strongyloidiasis and HS. Given that the infection was derived from the donor, we observed manifestations of the life cycle of the parasite in her clinical course.

\section{Donor Characteristics}

The donor was a 38-year-old man who emigrated to the U.S. several years prior from Central America. He met criteria as an "increased risk donor" (CDC criteria) due to lack of available medical history, but not because of country of origin or risk for endemic disease [9]. He was serologically positive for both cytomegalovirus (CMV) and Epstein-Barr virus (EBV) and had bronchoalveolar lavage cultures positive for Stenotrophomas maltophilia and Kluyvera ascorbata. No other information or pending test results was communicated at the time of transplant. 


\section{Case Presentation}

A 40-year-old African American female with interstitial lung disease due to mixed connective tissue disease (CMV negative, EBV negative) received a left single lung transplant. She had serology negative for Strongyloides on pre-transplant evaluation. She had never traveled outside of the US. She did not receive induction therapy. Her post transplantation immunosuppressive regimen consisted of tacrolimus, mycophenolate and corticosteroids. Antimicrobial prophylaxis included voriconazole, valganciclovir and atovaquone. She had a relatively uneventful post-operative clinical course and was discharged on post-operative day (POD)\# 12 to an acute rehabilitation hospital and then subsequently home.

She presented on POD\#47 with progressive nausea, vomiting, early satiety and diarrhea over the prior 24 hours. Physical exam was notable for diffuse abdominal tenderness. She had leukocytosis with a left shift and $3 \%$ peripheral eosinophilia (Table 1). Blood and stool cultures, $C$. difficile PCR and stool ova and parasites were all negative. Computed tomography (CT) of the chest, abdomen and pelvis demonstrated no focal pathology. The patient was admitted for probable gastroenteritis and started on empiric ciprofloxacin. She continued to have nausea and vomiting, and erythromycin was added for possible gastroparesis with some therapeutic benefit.

Table 1 Relevant laboratory data from date of discharge from index transplant admission to death.

\begin{tabular}{llllll}
\hline & $\begin{array}{l}\text { Discharge post- } \\
\text { transplant } \\
\text { admission, }\end{array}$ & $\begin{array}{l}\text { Presentation, } \\
\text { POD\#47 }\end{array}$ & $\begin{array}{l}\text { Intubation, anti- } \\
\text { helminthic } \\
\text { started POD\#56 }\end{array}$ & $\begin{array}{l}\text { Refractory } \\
\text { acidemia, } \\
\text { CRRT POD\#60 }\end{array}$ & $\begin{array}{l}\text { Death, } \\
\text { POD\#63 }\end{array}$ \\
\hline WBC & 8.92 & 11.83 & 5.94 & 8.91 & 3.35 \\
Neutrophils (\%) & 76 & 73 & Not done & 88 & Not done \\
Band neutrophils (\%) & 0 & 10 & Not done & 6 & Not done \\
Eosinophils (\%) & 1 & 3 & Not done & 0 & Not done \\
Platelet count & 313 & 295 & 201 & 157 & 50 \\
Creatinine $(\mathrm{mg} / \mathrm{dL})$ & 1.1 & 1.3 & 0.7 & 1.3 & 0.5 \\
\hline
\end{tabular}

By (hospital day) HD\#3/POD \#50, she developed acute respiratory failure with hypoxemia, with room air oxygen saturations in the low-80\%s while at rest. CT chest angiogram was negative for pulmonary embolism but revealed worsening left upper lobe ground glass opacities in a posterior distribution. On HD\#4/POD\#51, bronchoscopy was performed and the bronchoalveolar lavage was noted to be slightly sanguineous. By HD\#6/POD\#53, her respiratory status worsened. Antibiotics were broadened to include vancomycin and aztreonam (due to penicillin allergy), and pulsed-dose methylprednisolone was initiated for concern of graft rejection. Planned upper endoscopy for continued Gl symptoms was delayed due to clinical instability. She had progressive hypoxemic respiratory failure and on HD\#9/ 
POD\#56, required mechanical ventilation. Repeat CT chest revealed continued progression of the ground glass opacities. Bronchoscopy with lavage of the RUL was consistent with diffuse alveolar hemorrhage.

On HD\#9/POD\#56 the United Network for Organ Sharing (UNOS) communicated to us that the donor had positive Strongyloides IgG and there was concern for donor derived Strongyloides infection. The patient was immediately started on oral ivermectin $200 \mathrm{mcg} / \mathrm{kg}$ daily. The following day, she underwent upper endoscopy which showed markedly inflamed duodenal mucosa with biopsies positive for numerous parasites, morphologically consistent with invasive Strongyloides (Figure 1).

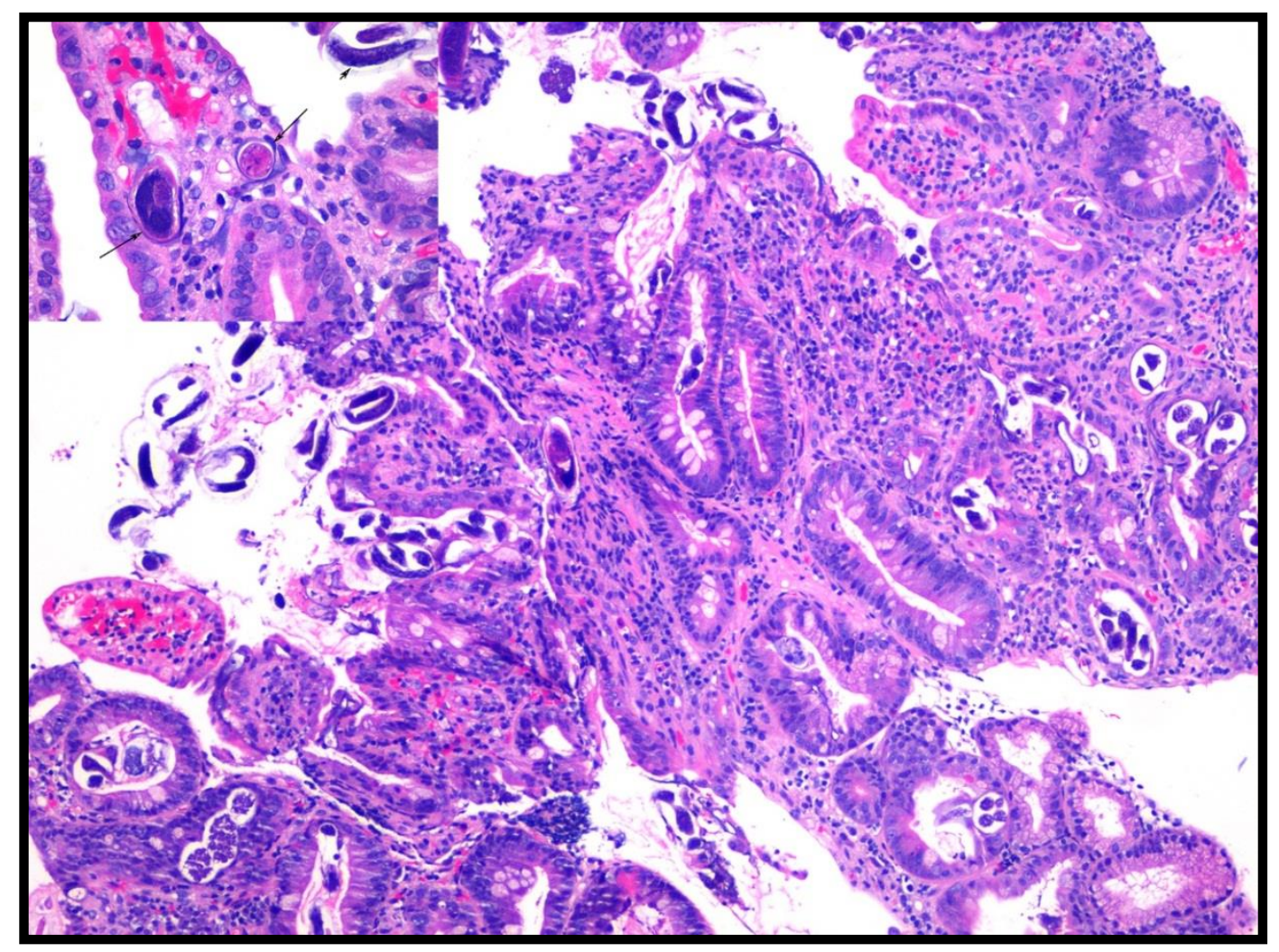

Figure 1 Duodenal biopsy revealed parasites morphologically consistent with Strongyloides both on the luminal aspect (inset, small arrow indicating adult parasite in lumen) as well as tissue invasive forms (inset, long arrows indicating larvae in lacteals) (H\&E, 100x; inset left upper corner 200x).

The recipient remained critically ill on mechanical ventilation and quickly developed multi-organ failure marked by adult respiratory distress syndrome (ARDS), acute kidney injury and shock. Blood cultures from HD\#9/POD\#56 revealed vancomycin resistant Enterococcus (VRE), consistent with a systemic sign of disseminated disease as larvae in the large intestine migrate to other organs pulling mucosal wall bacteria along with them. The patient's antibiotics were broadened to meropenem and linezolid to cover pneumonia and VRE bacteremia. On HD\#11/POD \#58, albendazole was added to the anti-parasitic regimen. On HD\#12/ POD \#59, rectal ivermectin was added, and she received intravenous 
immune globulin. Continuous renal replacement therapy (CRRT) for refractory acidemia was initiated on HD\#13/POD\#60.

Due to clinical deterioration and question of absorption of the ivermectin, we sought and received Food and Drug Administration and Institutional Review Board approval for the veterinary subcutaneous formulation of ivermectin, and she was administered subcutaneous ivermectin starting on HD\#14/POD\#61. Additionally, inhaled nitric oxide and systemic paralytics were employed for refractory hypoxemia. Despite the aggressive measures, the patient did not improve and ultimately died on HD\#16/POD\#63.

\section{Discussion}

We present a case of hyperinfection syndrome as a result of donor-derived strongyloidiasis. With transmission of the parasite to a recipient on immunosuppression, we see the life cycle of the parasite play out from the GI symptoms caused by larvae in the gastrointestinal tract to disseminated strongyloidiasis with VRE bacteremia following high dose intravenous steroids. The augmentation of immunosuppression likely hastened HS, although it is unclear if the avoidance of steroid bolus treatment or earlier initiation of anti-helminthic therapy would have afforded a different clinical outcome. Of note, the patient did not have significant eosinophilia following presentation. Corticosteroid therapy promotes eosinophil apoptosis reducing the value of this marker in the immunosuppressed host [11].

The case highlights the need for early identification of risk factors for and diagnosis of donor- derived parasitic infection, which can mimic more common complications of lung transplantation. The case underscores the importance of communication between transplant centers and organ procurement organizations (OPOs). Seamless and longitudinal communication between OPOs and transplant centers is critical, particularly as the increased demand for organs has prompted the routine use of organs from higher risk donors. This is particularly salient in the setting of increasing immigration from developing countries where parasitic infections are endemic. There is a common, imperceptible mind shift from donor-derived complications to recipient-centered issues that occurs in the first week post-transplant. Ongoing recognition of the potential for longer lasting donor-derived complications would enable a more comprehensive differential diagnosis to include infections such as Strongyloides infection.

Additionally, given the continued case reports of Strongyloides hyperinfection in the transplant community, we advocate for serologic screening of all donors and recipients who have ever lived or traveled to areas endemic for strongyloidiasis. We can consider the example of Norway in the United States. Following the cases of two transplant recipients who developed Stronglyoides HS after organ transplantation from the same deceased donor in Scandinavia - the first donor-derived strongyloidiasis cases in Scandinavia, all deceased donors in Norway are screened for strongyloidiasis (not just donors originating from endemic areas) [12]. While transmission of parasitic infection from donor to recipient is a rare event, it is preventable and has potentially devastating consequences without intervention. Treatment in the early post-transplant period is, however, simple and highly effective at preventing morbidity. With the knowledge of Stronglyoides infection or prior infection in either donor or recipient, 
clinical suspicion and early treatment for this parasitic infection could be instituted and catastrophic outcomes potentially avoided.

\section{Author Contributions}

The case report was initially written by Shalika Katugaha, Whitney Brown, Oksana Shlobin and Christopher King. The case was edited, and major revisions provided by Steven Nathan, Shambhu Aryal and Kareem Ahmad.

\section{Competing Interests}

None of the authors has any proprietary interests or conflicts of interest related to this submission.

\section{References}

1. Schar F, Trostdorf U, Giardina F, Khieu V, Muth S, Marti H, et al. Strongyloides stercoralis: Global distribution and risk factors. PLoS NegI Trop Dis. 2013; 7: e2288.

2. Nutman TB. Human infection with Strongyloides stercoralis and other related Strongyloides species. Parasitology. 2017; 144: 263-273.

3. Buonfrate D, Requena-Mendez A, Angheben A, Muñoz J, Gobbi F, Van Den Ende J, et al. Severe strongyloidiasis: A systematic review of case reports. BMC Infect Dis. 2013; 13: 78.

4. Agrawal V, Agarwal T, Ghoshal UC. Intestinal Strongyloidiasis: A diagnosis frequently missed in the tropics. Trans R Soc Trop Med Hyg. 2009; 103: 242-246.

5. Marcos LA, Terashima A, Dupont HL, Gotuzzo E. Strongyloides hyperinfection syndrome: An emerging global infectious disease. Trans R Soc Trop Med Hyg. 2008; 102: 314-318.

6. Roxby AC, Gottlieb GS, Limaye AP. Strongyloidiasis in transplant patients. Clin Infect Dis. 2009; 49: 1411-1423.

7. Hamilton KW, Abt PL, Rosenbach MA, Bleicher MB, Lavine MS, Mehta J, et al. Donor-derived Strongyloides stercoralis infections in renal transplant recipients. Transplantation. 2011; 91: 10191024.

8. Patel G, Arvelakis A, Sauter BV, Gondolesi GE, Caplivski D, Huprikar S. Strongyloides hyperinfection syndrome after intestinal transplantation. Transpl Infect Dis. 2008; 10: 137-141.

9. Hasan A, Le M, Pasko J, Ravin KA, Clauss H, Hasz R, et al. Transmission of Strongyloides stercoralis through transplantation of solid organs - Pennsylvania, 2012. MMWR Morb Mortal Wkly Rep. 2013; 62; 264-266.

10. Fischer SA, Avery RK, AST Infectious Disease Community of Practice. Screening of donor and recipient prior to solid organ transplantation. Am J Transplant. 2009; 9: S7-S18.

11. Camargo LF, Kamar N, Gotuzzo E, Wright AJ. Schistosomiasis and strongyloidiasis recommendations for solid-organ and transplant recipients and donors. Transplantation. 2018; 102: 27-34. 
12. Nordheim E, Olafsson Storr $\varnothing$ M, Natvik AK, Birkeland Kro G, Midtvedt K, Varberg Reisaeter A, et al. Donor-derived strongyloidiasis after organ transplantation in Norway. Transpl Infect Dis. 2019; 21 : e13008.

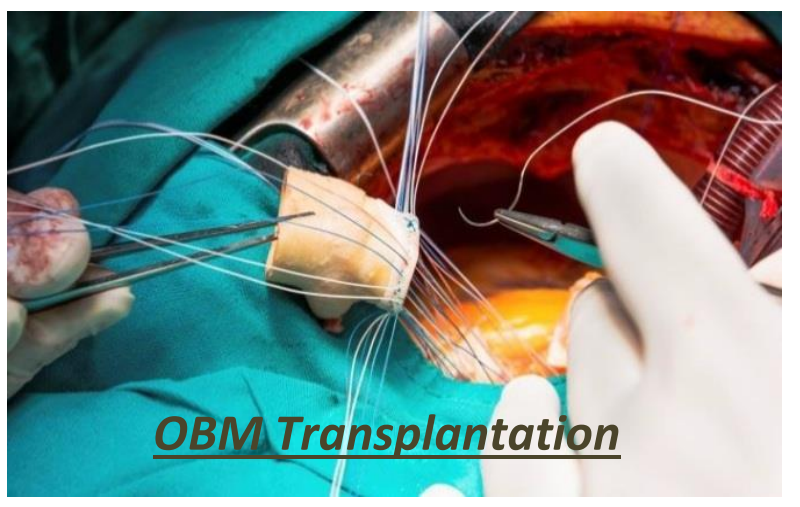

Enjoy OBM Transplantation by:

1. Submitting a manuscript

2. Joining in volunteer reviewer bank

3. Joining Editorial Board

4. Guest editing a special issue

For more details, please visit: http://www.lidsen.com/journals/transplantation 
OBM Transplantation Editorial Office 73 Hongkong Middle Road, Qingdao, China Tel./Fax: +86-532-8979-9572

E-Mail: E-Mail: transplantation@lidsen.com http://www.lidsen.com/journals/transplantation

LIDSEN Publishing Inc.

2000 Auburn Drive, One Chagrin Highlands, Suite 200

Beachwood, OH 44122, USA

Tel.: +1-216-370-7293

Fax: +1-216-378-7505

https://www.lidsen.com 
LIDSEN Publishing Inc.

2000 Auburn Drive, One Chagrin

Highlands, Suite 200 Beachwood

$\mathrm{OH} 44122$

USA

Tel.: +1-216-370-7293

Fax: +1-216-378-7505

https://www.lidsen.com 